Avaliação de desempenho para seleção de abordagens visando à composição automática de web services em arquiteturas orientadas a serviços e com QoS 



\section{Avaliação de desempenho para seleção de abordagens visando à composição automática de web services em arquiteturas orientadas a serviços e com QoS}

\section{Bruno Tardiole Kuehne}

Orientador: Prof. Dr. Marcos José Santana

Tese apresentada ao Instituto de Ciências Matemáticas e de Computação - ICMC-USP, como parte dos requisitos para obtenção do título de Doutor Programa de Ciências de Computação e Matemática Computacional. VERSÃO REVISADA 
Ficha catalográfica elaborada pela Biblioteca Prof. Achille Bassi e Seção Técnica de Informática, ICMC/USP, com os dados fornecidos pelo(a) autor(a)

Tardiole Kuehne, Bruno

T95a Avaliação de desempenho para seleção de abordagens visando à composição automática de web services em arquiteturas orientadas a serviços e com QoS / Bruno Tardiole Kuehne; orientador Marcos José Santana. -São Carlos, 2015. $82 \mathrm{p}$.

Tese (Doutorado - Programa de Pós-Graduação em Ciências de Computação e Matemática Computacional) -Instituto de Ciências Matemáticas e de Computação, Universidade de São Paulo, 2015.

1. Composição de Web Services. 2. Qualidade de Web Services. 3. Avaliação de Desempenho. 4. Arquitetura Orientada a Serviços. 5. Sistemas Distribuídos. I. José Santana, Marcos, orient. II. Título. 
Gradeço aos meus pais, Beno e Maria de Lourdes que além do apoio emocional ainda me supriram com apoio financeiro durante o tempo de desenvolvimento deste trabalho. Agradeço a minha esposa Marina por sempre ter me apoiado e suportado muitas vezes minha ausência para dedicação a esta Tese. Agradeço a toda minha família especialmente aos meus irmãos Aldo, Henrique, Douglas e Helga por sempre terem ficado ao meu lado em tudo que faço.

Agradeço também aos meus amigos e colegas tanto na ajuda técnica que foi imprescindível para o desenvolvimento do trabalho, quanto nos momentos de lazer que passamos juntos durante esse período de desenvolvimento do doutorado.

Agradeço pela contribuição para o desenvolvimento ao orientador Prof. Dr. Marcos José Santana que me ajudou em todas as etapas deste projeto, à Profa. Dra. Regina Helena Carlucci Santana e ao Prof. Dr. Júlio Cezar Estrella que colaboraram sempre de forma ativa no desenvolvimento da Tese. Agradeço também ao Prof. Dr. Stephan Reiff-Marganiec ao Prof. Dr. Volker Linnemann pelas colaborações. Gostaria também de agradecer a todos os membros do grupo de Sistemas Distribuídos e Programação Concorrente que sempre deram ótimas sugestões para o desenvolvimento do trabalho.

Agradeço à FAPESP (Fundação de Amparo à Pesquisa do Estado de São Paulo) pelo apoio financeiro que permitiu ao aluno dedicação exclusiva ao desenvolvimento do projeto

Agradeço também ao DAAD/CAPES/CNPq pela bolsa concedida para desenvolvimento do estágio de doutorado sanduíche na Universidade de Lübeck. 

Sta tese de doutorado tem como objetivo principal, a proposta de um sistema onde é possível avaliar abordagens diferentes para composição automática de Web services, baseando-se em parâmetros de QoS que dependem da execução para serem medidos. O objetivo foi atingido por meio da implementação de um sistema denominado AWSCS ( $\mathrm{Au}$ tomatic Web Service Composition System). O AWSCS é um sistema onde é possível implementar abordagens diferentes para composição automática de Web services e também executar os fluxos resultantes dessas abordagens. Com o objetivo de demonstrar os resultados desta tese de doutorado, foram elaborados cenários, onde fluxos empíricos foram construídos para fazer a demonstração do funcionamento do AWSCS, uma vez que algoritmos para composição automática não foram encontrados para download na literatura. Com os resultados foi possível fazer um estudo do comportamento da execução de fluxos de Web services compostos, quando fluxos com mesma funcionalidade, mas estratégias de solução do problema diferentes foram comparados. Além disso, foi possível observar a influência das cargas aplicadas no sistema em execução, uma vez que o tipo de carga submetida ao sistema é um fator importante para se definir qual abordagem para composição de Web services pode levar ao melhor desempenho, de acordo com o ambiente e tipos de cargas que ele vai receber, quando em produção. 

7 His PhD thesis has as main goal the propose of a system where it is possible to evaluate different approaches for automatic composition of Web services, based on QoS parameters that depend on the execution to be measured. The goal was reached by means of the implementation of a system named AWSCS (Automatic Web Service Composition System). The AWSCS is a system where it is possible to implement different approaches for automatic composition of Web services and also to execute the resulting flows from these approaches. Aiming at demonstrating the results of this $\mathrm{PhD}$ thesis different scenarios were developed, where empirical flows were built to demonstrate the operation of AWSCS, once algorithms for automatic composition were not found to download in the literature,. With the results it was possible to study the behavior of running composite Web services, when flows with the same functionality but different problem-solving strategies were compared. Furthermore it was possible to observe the influence of the load applied on the running system once the type of load submitted to the system is an important factor to define which approach for the Web service composition can take to the best performance according to the environment and types of load it will receive when in production. 

Resumo

$\begin{array}{lll}\text { Abstract } & \text { iii }\end{array}$

Lista de Siglas $\quad$ xi

1 Introdução 1

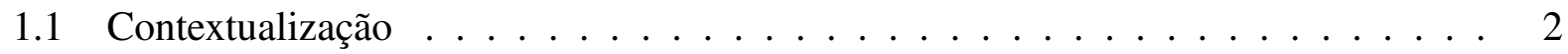

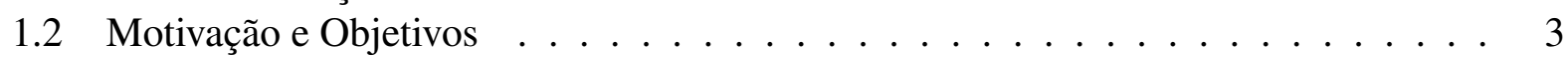

2 SOA - Service Oriented Architecture 5

2.1 Considerações Iniciais $\ldots \ldots \ldots \ldots \ldots \ldots$

2.2 Definições de SOA . . . . . . . . . . . . . . . . . . . 5

2.2 .1 Modelo SOA . . . . . . . . . . . . . . . . . 6

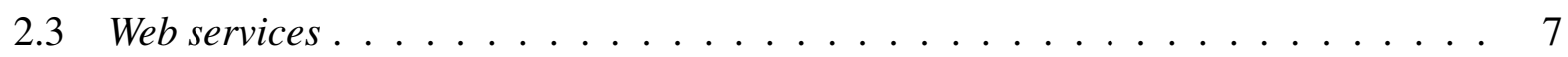

2.3.1 Modelo de Web services . . . . . . . . . . . . . . . . . . 7

2.3.2 Ciclo de vida de Web services . . . . . . . . . . . . . . . . . . . . . 8

2.3.3 Arquitetura de Web services . . . . . . . . . . . . . . . . . . . 9

2.4 Qualidade de Serviço em Web services . . . . . . . . . . . . . . . . . . . . 11

2.5 Considerações Finais . . . . . . . . . . . . . . . . . . . . 14

3 Composição de Web services $\quad 15$

3.1 Considerações Iniciais . . . . . . . . . . . . . . . . . . . . . . . . . . . . . . . . . . .

3.2 Composição de Web services . . . . . . . . . . . . . . . . . . . . . . . . . . . . . . . . . . . .

3.2 .1 Fases da composição . . . . . . . . . . . . . . . . . . . . 17

3.3 QoS em composição de Web services . . . . . . . . . . . . . . . . . . . 18

3.4 Algoritmos para composição dinâmica de Web services . . . . . . . . . . . . . . . . 21

3.5 Web semântica e Ontologia . . . . . . . . . . . . . . . . . . . . . . . . . . . . 22

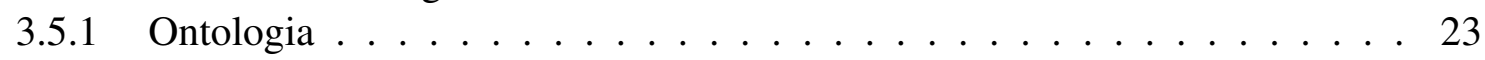

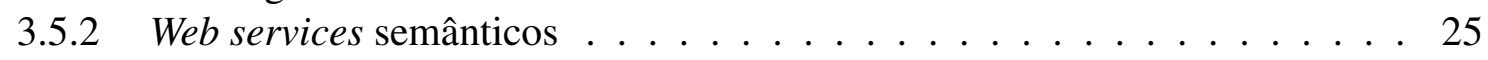

3.6 Composição de Web services automática . . . . . . . . . . . . . . . . . . 25

3.6.1 Algoritmos para composição Automática de Web services . . . . . . . . . 28

3.7 Considerações Finais . . . . . . . . . . . . . . . . . 30 
4 AWSCS(Automatic Web Service Composition System) 33

4.1 Considerações Iniciais . . . . . . . . . . . . . . . . . . . . . 33

4.2 Modelo arquitetural do AWSCS . . . . . . . . . . . . . . . . . . . . . . . . . . . . . . .

4.2.1 Diagrama de Sequência do AWSCS . . . . . . . . . . . . . . . . 36

4.3 Módulo AWSCE - Automatic Web Service Composition Execution . . . . . . . . . 38

4.4 WSARch . . . . . . . . . . . . . . . . . . . 40

4.5 Ferramentas utilizadas para desenvolvimento do

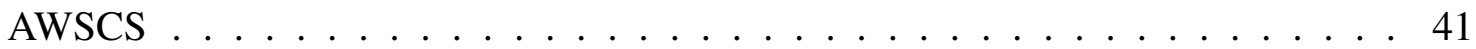

4.5.1 Apache Tomcat . . . . . . . . . . . . . . . . 42

4.5 .2 Apache Axis2 . . . . . . . . . . . . . . . 42

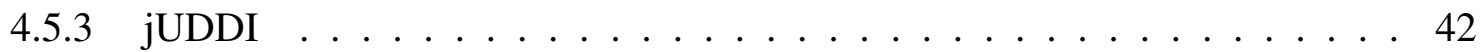

4.6 Considereções Finais . . . . . . . . . . . . . . . . . . . 43

5 Experimentos $\quad 45$

5.1 Considerações Iniciais . . . . . . . . . . . . . . . . . . . . . . . . . . . . . . . . . . . . . . . . .

5.2 Ambiente de Experimento . . . . . . . . . . . . . . . . . . 46

5.2.1 Algoritmo de Seleção . . . . . . . . . . . . . . . . . . . . . 47

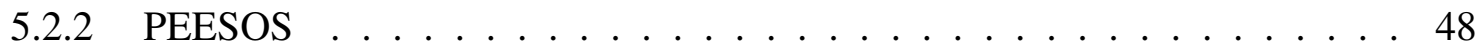

5.3 Cenário $1 \ldots \ldots \ldots \ldots \ldots \ldots \ldots$

5.3 .1 Experimento $1 \ldots \ldots \ldots \ldots \ldots$

5.3 .2 Experimento $2 \ldots \ldots \ldots \ldots \ldots$

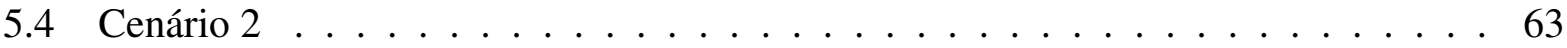

5.4 Experimento $3 \ldots \ldots \ldots \ldots \ldots$

5.5 Considerações Finais . . . . . . . . . . . . . . . . . . . . 68

6 Conclusões $\quad \mathbf{7 1}$

6.1 Considerações Iniciais . . . . . . . . . . . . . . . . . . . 71

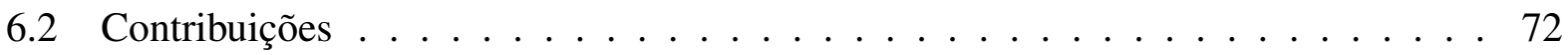

6.3 Dificuldades relacionadas ao projeto . . . . . . . . . . . 73

6.4 Trabalho Futuros . . . . . . . . . . . . . . . . . . . . . 74 


\section{Lista de Figuras}

2.1 Arquitetura Orientada a Serviço $($ Bih, 2006) . . . . . . . . . . . . . . . . . 6

2.2 Modelo de Web services (Kreger, 2003) _ . . . . . . . . . . . . . . . . 8

2.3 Pilha da estrutura de Web services(Kreger, 2003) . . . . . . . . . . . . . . . . 9

3.1 Grafo de Agregação - (Jaeger e Ladner, 2005) . . . . . . . . . . . . . . . . . . . 20

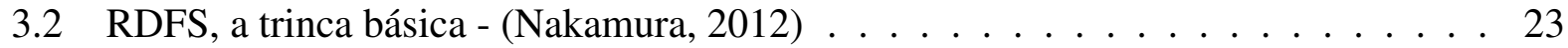

3.3 Ontologia de serviços em alto nível - (Martin et al., 2004) . . . . . . . . . . . . . 27

4.1 Modelo arquitetural AWSCS . . . . . . . . . . . . . . . . . 35

4.2 Diagrama de Atividades do AWSCS . . . . . . . . . . . . . . . . . 37

4.3 Fluxo de Execução - XML Schema . . . . . . . . . . . . . . . . . . . . . . . . 39

4.4 Diagrama de Classe Simplificado - AWSCE . . . . . . . . . . . . . . . . . . . . 40

4.5 Arquitetura WSArch . . . . . . . . . . . . . . . . . . 41

5.1 Ambiente de Experimento . . . . . . . . . . . . . . . . . . . . . . . . . . . 47

5.2 Componentes da PEESOS (Nunes et al., 2014) . . . . . . . . . . . . . . 48

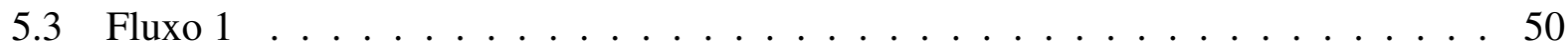

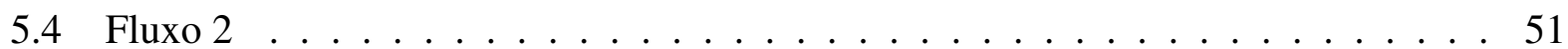

5.5 Fluxo 1 x Fluxo 2 - rajadas a cada $3000 \mathrm{~ms} \ldots \ldots \ldots$. . . . . . . . 52

5.6 Fluxo 1 x Fluxo 2 - rajadas a cada $9000 \mathrm{~ms} \ldots \ldots \ldots 3$

5.7 Fluxo 1 x Fluxo 2 - Influência dos Fatores . . . . . . . . . . . . . . . . . . 54

5.8 Tempo de resposta por Web service . . . . . . . . . . . . . . . . . . . . . 54

5.9 Custo por Web service . . . . . . . . . . . . . . . . . . . . . 55

5.10 Reputação por Web service . . . . . . . . . . . . . . . . . . 55

5.11 Tempo de resposta Fluxo 1 x Fluxo 2 - QoS Diferente para cada cliente . . . . . 57

5.12 Custo Fluxo 1 x Fluxo 2 - QoS diferente para cada cliente . . . . . . . . . . . 58

5.13 Reputação Fluxo 1 x Fluxo 2 - SLA diferente para cada cliente . . . . . . . . . . 58

5.14 Influência de Fatores $\mathrm{C} 1$ com C2 - Tempo de Resposta . . . . . . . . . . . . . 59

5.15 Influência de Fatores C1 com C3 - Tempo de Resposta . . . . . . . . . . . . 59

5.16 Influência de Fatores C2 com C3 - Tempo de Resposta . . . . . . . . . . . . . . 60

5.17 Influência de Fatores - Custo . . . . . . . . . . . . . . . . . . . . 61

5.18 Influência de Fatores - Reputação . . . . . . . . . . . . . . . . . . 62

5.19 Fluxo $3 \ldots \ldots \ldots \ldots \ldots \ldots$

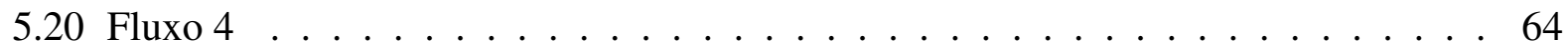

5.21 Fluxo 3 x Fluxo 4 - rajadas a cada 9000ms . . . . . . . . . . . . . . 66

5.22 Fluxo 3 x Fluxo 4 - rajadas a cada $3000 \mathrm{~ms} \ldots \ldots$. . . . . . . . . 67 
5.23 Fluxo 3 x Fluxo 4 - Influência dos Fatores . . . . . . . . . . . . . . . . 67

5.24 Tempo de resposta por Web service . . . . . . . . . . . . . . . . . . 68

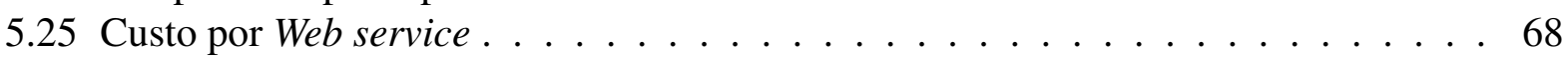

5.26 Reputação por Web service . . . . . . . . . . . . . . . . . . . . . . 69 


\section{Lista de Tabelas}

5.1 Configuração do cluster WSArch . . . . . . . . . . . . . . . . . . . . . . . . . . . . . . . 46

5.2 Configuração do cluster . . . . . . . . . . . . . . . . . . . 46

5.3 Acordos SLAs . . . . . . . . . . . . . . . . . . . 50

5.4 Planejamento Experimento $1 \ldots \ldots \ldots \ldots \ldots$

5.5 SLAs definidos . . . . . . . . . . . . . . . . . . . 51

5.6 Classes de QoS para cada Web service e cliente . . . . . . . . . . . . . . . . 56

5.7 SLAs definidos para cada cliente . . . . . . . . . . . . . . . 56

5.8 Planejamento Experimento $2 \ldots \ldots \ldots \ldots \ldots$

5.9 Acordos SLAs . . . . . . . . . . . . . . . . . . . . . . . . . . . . . . . . . . 63

5.10 Planejamento Experimento $3 \ldots \ldots \ldots \ldots$

5.11 SLAs definidos . . . . . . . . . . . . . . . . . 65 

ASF - Apache Software Foundation

ASP - Active Server Pages

AWSCE - Automatic Web Service Composition Execution

AWSCS - Automatic Web Service Composition System

Axis2 - Apache eXtensible Interaction System

CGI - Common Gateway Interface

FTP - File Transfer Protocol

HTTP - Hyper Text Transport Protocol

LaSDPC - Laboratório de Sistemas Distribuído e Programação Concorrente

OASIS - Organization for the Advancement of Structured Information Standards

OWL - Ontology Web Language

OWL-S - Ontology Web Language - Service

PDDL - Planning Domain Definition Language

PEESOS - Planejamento e Execução de Experimentos em Sistemas Orientados a Serviços

QoWS - Quality of Web services

RDF - Resource Description Framework

RDFS - Resource Description Framework Schema

SLA - Service Level Agreement

SMTP - Simple Mail Transfer Protocol

SNMP - Simple Network Management Protocol

SOA - Service Oriented Architecture

SOAP - Simple Object Access Protocol 


$\begin{array}{lll}\text { TI } & - & \text { Tecnologia da Informação } \\ \text { UDDI } & - & \text { Universal Description Discovery and Integration } \\ \text { URI } & - & \text { Uniform Resource Identifier } \\ \text { WAR } & - & \text { Web Archive } \\ \text { WS-BPEL } & - & \text { Web Services Business Process Execution Language } \\ \text { WS-CDL } & - & \text { Web Services Choreography Description Language } \\ \text { WSDL } & - & \text { Web Service Description Language } \\ \text { WSFL } & - & \text { Web Services Flow Language } \\ \text { WSLA } & - & \text { Web Service Level Agreement } \\ \text { WSOL } & - & \text { Web Service Offer Language } \\ \text { XML } & - & \text { eXtensible Markup Language } \\ \text { YAWL } & - & \text { Yet Another Language Workflows }\end{array}$


A Web é amplamente utilizada para a veiculação de aplicações que envolvem comércio eletrônico, jogos online, aplicações multimídia, vídeo sob demanda, etc. Com o surgimento dos Web services, tem sido possível que aplicações executando em diferentes plataformas e em diferentes linguagens de programação possam se comunicar pela Web por meio de uma interface denominada WSDL (Web Service Description Language), todag1 composta em XML (eXtensible Markup Language). XML é uma linguagem com suporte a interoperabilidade, independente de plataforma e de sistema operacional. Nas interfaces WSDLs ficam descritas todas as informações necessárias para que as aplicações possam se comunicar por meio de troca de mensagens XML. Os Web services oferecem uma característica valiosa, que é a implementação de sistemas distribuídos abertos, por meio da composição de sistemas autônomos.

Como os Web services estão sendo aplicados em ambientes B2B (Business to Business), a qualidade de serviço e a entrega contínua de serviços torna-se uma questão crítica para propiciar alta disponibilidade e confiabilidade, apesar da falha e indisponibilidade de serviços participantes ou também da rede de comunicação (Chen et al., 2014). Por isso, é importante caracterizar como vários Web services interagem entre si, com o objetivo de prover melhor qualidade de serviços para os usuários e para as aplicações.

A interação entre Web services é denominada composição de Web services e tem como finalidade permitir que Web services independentes interajam para formação de novos serviços, com novas funcionalidades, podendo assim fazer uso da reutilização de serviços implementados e em funcionamento. A composição de serviços permite a utilização de serviços com a mesma funcionalidade, implementados de forma diferente e com diferentes características de qualidade de 
serviços. Outra característica importante da composição de serviços é fazer a integração entre empresas que já possuam seus sistemas disponibilizados como Web services.

A integração entre Web services exige mais que simples interações entre os protocolos padrões dos serviços, por isso faz-se necessário um mecanismo para conseguir interações complexas entre serviços. Linguagens como YAWL (Yet Another Language Workflows), WSFL (Web Services Flow Language) e WS-BPEL (Web Services Business Process Execution Language) foram propostas para conseguir tal interação. WS-BPEL é o fruto da combinação de esforço das empresas Microsoft e IBM e é atualmente a linguagem mais utilizada para composição de Web services. Ela é atualmente padronizada pela organização OASIS (Organization for the Advancement of Structured Information Standards) (Jordan et al., 2007).

\subsection{Contextualização}

O surgimento dos Web services provocou uma mudança de paradigma na integração de aplicações, onde serviços podem ser compartilhados para permitir a otimização de processos de negócios numa ampla estrutura de TI (Tecnologia da Informação). A adoção efetiva dos Web services é atualmente uma realidade, uma vez que a indústria vem considerando duas frentes: padrões e produtos (Tan e Zhou, 2013). A IBM investiu tempo, talento e recursos financeiros em ambas as frentes, em projetos que envolvem arquiteturas orientadas a serviços, composição de Web services e computação em nuvem (cloud computing) (Zhang, 2009).

No estado atual de suporte, os Web services são capazes de integrar aplicações executando em diferentes plataformas, habilitar informações de uma base de dados de aplicações para serem disponibilizadas para outras, além de permitir que aplicações internas se tornem disponíveis na rede mundial de computadores. Os benefícios trazidos pela utilização dos Web services só têm se tornado possível em virtude da adoção de uma linguagem padrão da Web, como a XML e suas derivações, tal como a WSDL (Web Service Description Language), dentre outras.

Muito mais que a integração de aplicações, os Web services têm se tornado padrão no desenvolvimento de aplicações corporativas. Os Web services constituem uma realidade para a integração de aplicações Web, sendo um assunto amplamente pesquisado pela comunidade acadêmica, além de empresas de grande porte como IBM (Kreger et al., 2012).

A avaliação de QoS prestada pelos Web services é analisada para comparação entre as abordagens de composição automática. No entanto, o desenvolvimento de Web services compostos é uma tarefa complexa, pelo fato de ser difícil encontrar Web services desenvolvidos por terceiros, que se adequem a função desejada pelo desenvolvedor do serviço composto. No trabalho apresentado em (Lu et al., 2007), um estudo das dificuldades de se conseguir composição de Web services é apresentado. Entre as maiores dificuldades apontadas pelos autores estão a dificuldade de se encontrar os Web services e também conseguir fazer a invocação desses Web services, já que algumas vezes Web services listados nos repositórios não estavam disponíveis para serem acessados. 
Para fazer a busca dos Web services, a utilização de Web services semânticos é proposta. Com Web services semânticos é possível fazer toda a descrição das funcionalidades dos Web services, e além disso é possível encontrar as relações entre os Web services. Essas relações, denominadas links semânticos, são identificadas por meio da similaridade semântica das entradas e saídas dos Web services, possibilitando assim a composição automática desses serviços.

Na composição automática é possível gerar uma composição a partir de especificações semânticas de entradas e saídas desejadas de um serviço. Um algoritmo para composição automática irá então encontrar os Web services, cujos links semânticos com outros Web services possibilitarão que o objetivo esperado da composição seja atingido.

\subsection{Motivação e Objetivos}

$\mathrm{Na}$ literatura existem várias propostas de como se conseguir a composição automática de Web services, no capítulo 3 são apresentadas algumas dessas propostas. No entanto, devido à composição automática ser uma técnica que ainda habita apenas ambientes específicos, a avaliação do resultado desses algoritmos são muitas vezes restritos apenas a qualidade semântica (Lecue e Mehandjiev, 2011) da composição resultante e também baseada em parâmetros de QoS fixos que não variam de acordo com o comportamento da execução.

Neste trabalho de doutorado foi proposto um sistema chamado AWSCS (Automatic Web service Composition System). O AWSCS é um ambiente onde é possível a comparação entre as abordagens de composição automática disponíveis(Matchmaking e Algoritmo de Seleção para composição automática). A comparação é feita baseado no desempenho real da execução do Web service composto resultante.

O objetivo do AWSCS é auxiliar na tomada de decisão de qual abordagem para composição pode atingir o resultado mais próximo do desejado de acordo com o cenário onde a composição automática será utilizado. A comparação entre as abordagens é feita com base em parâmetros de QoS funcionais como tempo de resposta ou disponibilidade resultantes da execução dos fluxos obtidos pelos algoritmos de composição automática de Web services.

Nesta tese de doutorado é apresentado um estudo do comportamento da execução de Web services compostos, já que todo o ambiente foi projetado para fazer medições do comportamento da execução de cada serviço pertencente ao fluxo de execução. Permite ainda a comparação de algoritmos para composição de Web services, em termos de execução, já que é possível implementar mais de um algoritmo no mesmo ambiente e fazer uma comparação da execução dos mesmos tendo o mesmo repositório e implementações de serviços disponíveis para ambos.

Um protótipo AWSCS foi implementado, como nenhum algoritmo para composição automática foi encontrado para download e teste na literatura disponível, nesta tese, com o objetivo de teste do AWSCS, fluxos empíricos foram construídos. Dois cenários foram propostos e executados no AWSCS. 
Em um primeiro cenário dois fluxos foram desenvolvidos com o objetivo de resolver um problema de planejamento de viagem. No segundo cenário dois fluxos foram desenvolvidos com o objetivo de criar um fluxo para fazer avaliação de desempenho de sistemas computacionais. Nos dois cenários o resultado da composição dos fluxos definidos tem a mesma qualidade semântica baseada na requisição do usuário, mas usando diferentes serviços abstratos para resolver o problema.

Portanto, o objetivo principal desta tese é a proposta de um sistema onde é possível avaliar abordagens para composição automática de Web services baseado em parâmetros de QoS que dependem da execução para serem medidos.

Esta tese de doutorado está organizada em 6 capítulos, os quais são brevemente discutidos a seguir.

No capítulo 2 são apresentados conceitos detalhados sobre arquiteturas SOA e o que são os Web services, bem como o principio de funcionamento dessa solução para sistemas distribuídos, que permite comunicação entre arquiteturas e linguagens diferentes por meio de padrões XML (Bray et al., 1998).

No capítulo 3 são apresentados conceitos de composição de Web services, o funcionamento, linguagens disponíveis para criação de serviços compostos e como qualidade de serviço deve ser tratada em composição de serviços. Também é apresentado de forma detalhada como é o funcionamento da composição automática de Web services e algumas abordagens para se conseguir a composição automática de Web services.

No capítulo 4 é apresentado o sistema AWSCS, todo o funcionamento do sistema é apresentado de forma detalhada. É apresentada também a WSARch (Estrella, 2010), uma arquitetura para provisão de Web services com qualidade de serviço, utilizada para a implementação do sistema proposto nesta tese.

No capítulo 5 são apresentados os cenários propostos para testes do sistema AWSCS , a configuração do ambiente de experimentos e por fim a discussão dos resultados e conclusões obtidas por meio dos experimentos.

No capítulo 6 são apresentadas as conclusões e contribuições desta tese e os trabalhos futuros propostos como continuidade do trabalho desenvolvido. 


\section{2}

\section{SOA - Service Oriented Architecture}

\subsection{Considerações Iniciais}

$\mathrm{O}$ advento da Internet, o desenvolvimento de aplicações Web, as necessidades empresariais e as requisições de serviços trouxeram a demanda por uma nova arquitetura de software, onde existe a necessidade de integração de sistemas que são executados em sistemas operacionais e linguagens de programação diferentes. Surge, então, nesse cenário o conceito de SOA (Serviceoriented Architecture), como uma solução para esse problema, por meio da utilização dos Web services (Bih, 2006).

Neste capítulo serão apresentados os conceitos, o modelo e a arquitetura de SOA e Web services, tópicos de fundamental importância para o desenvolvimento desta tese de doutorado.

\subsection{Definições de SOA}

Segundo Bih (2006), SOA é formada por serviços que podem se comunicar por meio de passagem de mensagens simples, coordenando alguma atividade que precise de meios de conexão de serviços entre si.

Para um bom entendimento de SOA é preciso ter um bom conhecimento do termo serviço. Serviço é uma função bem definida e independente do contexto ou estado de outros serviços. A arquitetura SOA básica consiste de um serviço consumidor e um provedor de serviços, onde um serviço consumidor faz uma requisição para um provedor de serviços, que responde com o resultado para o serviço consumidor. O provedor de serviços pode também ser um consumidor 
de serviços. As conexões de requisição e resposta são definidas de maneira que seja possível que ambos os serviços possam entendê-la.

\subsubsection{Modelo SOA}

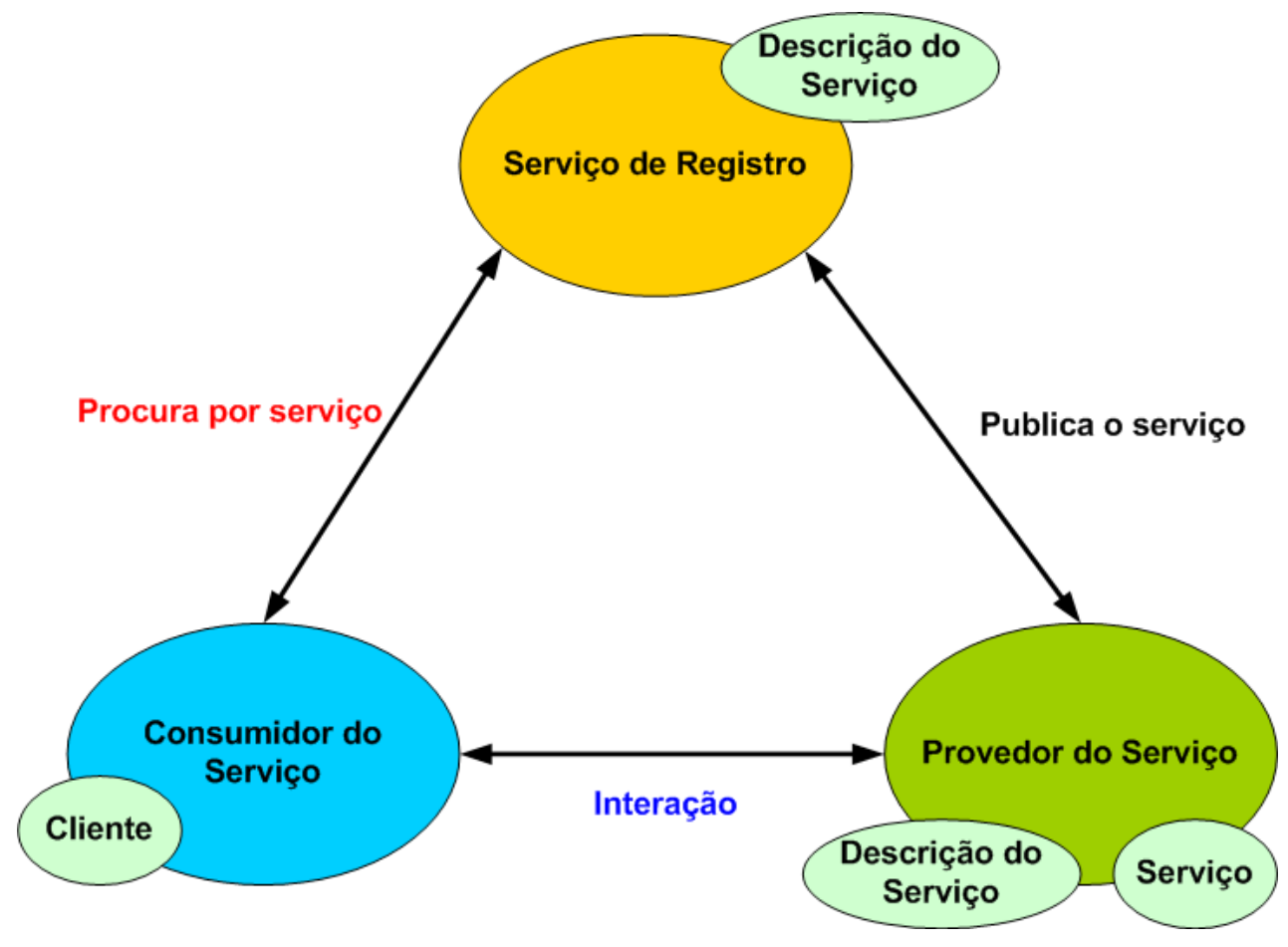

Figura 2.1: Arquitetura Orientada a Serviço (Bih, 2006)

No modelo apresentado na figura 2.1, o provedor de serviços fornece as interfaces de serviços para um software independente, o qual gerencia um conjunto específico de tarefas. O provedor de serviços pode representar os serviços de uma entidade de negócios ou pode representar simplesmente uma interface de serviço reutilizável de um subsistema.

O serviço de registro atua como um repositório. Muitas vezes os registros de serviços são exemplificados como as páginas amarelas de listas telefônicas, onde os serviços são registrados por categorias de serviços. O serviço de registro é onde os provedores de serviços publicam seus serviços.

O serviço consumidor é um nó na rede que descobre e invoca outros serviços para obter uma solução por meio de chamadas à operações dos serviços. Em alguns casos, o provedor pode estar no mesmo local que um consumidor de serviços e ser acessado por meio de uma rede local, ou em outros casos ele pode estar muito distante e ser acessado pela Internet. A natureza conceitual de SOA deixa a rede, os protocolos de transporte e os detalhes de segurança, para implementações específicas de SOA.

Essas três entidades de SOA interagem entre si por meio de três operações básicas: publicar, buscar e utilizar. O provedor de serviços publica serviços no serviço de registro. O consumidor de 
serviços busca o serviço que deseja, utilizando o serviço de registro, e então faz a utilização desse serviço.

\subsection{Web services}

Web services são uma implementação de SOA (Erradi e Maheshwari, 2005). A W3C define um Web service como uma aplicação identificada por uma URI (Uniform Resource Identifier), cujas interfaces e ligações são definidas, descritas e descobertas utilizando-se uma linguagem padrão, XML (Ferris e Farrell, 2003).

As interações entre Web services ocorrem tipicamente com chamadas feitas por um protocolo de comunicação baseado em XML, SOAP (Simple Object Access Protocol), para a interação de aplicações (Papazoglou, 2003). SOAP, é apresentado como um arcabouço em trocas de mensagens para uma nova geração de aplicações de computação distribuída, independente de plataforma e de linguagens de programação.

A principal função do SOAP é encapsular as chamadas a métodos remotamente distribuídos, que serão transportados, por sua vez, por algum protocolo de transporte, tal como o HTTP (Hyper Text Transport Protocol), utilizado para comunicação entre um cliente e um servidor Web (Comer, 1988). Além disso, as descrições de interfaces dos Web services são expressas usando a linguagem denominada WSDL(Thomas et al., 2003).

A arquitetura dos Web services conta com um serviço de diretório, que contém as descrições dos Web services, denominado UDDI (Universal Description Discovery and Integration). Esse protocolo funciona como um serviço de registros, sendo um importante componente da arquitetura orientada a serviços (Farkas e Charaf, 2003).

Uma arquitetura orientada a serviço é uma maneira lógica de construção de um sistema de software para prover serviços, ou para aplicações de usuários finais, ou para outros serviços distribuídos em uma rede, por meio de interfaces públicas disponíveis (nesse contexto destaca-se o WSDL) (Papazoglou, 2003). O UDDI possibilita aos clientes de Web services, localizarem serviços ou descobrirem seus detalhes, permitindo que registros operacionais sejam mantidos para diferentes propósitos em diferentes contextos (Leavitt, 2004).

\subsubsection{Modelo de Web services}

A arquitetura de Web services é baseada nas interações entre três entidades que são o provedor de serviços, o registro de serviços e o consumidor de serviços. As interações envolvem a publicação, a pesquisa e a ligação.

O provedor de serviços define uma descrição de serviço para o Web service e o publica nos registros de pesquisa ou a disponibiliza diretamente para serviços consumidores. Os serviços consumidores utilizam operações de pesquisa para localizar a descrição do serviço localmente ou nos 
registros de pesquisa e usa a descrição do serviço para conectar-se ao provedor de serviço e invocar ou interagir com a implementação do Web service. O provedor de serviços é uma construção lógica uma vez que um serviço pode ter características de provedor de serviço e de consumidor de serviço (Kreger, 2003).

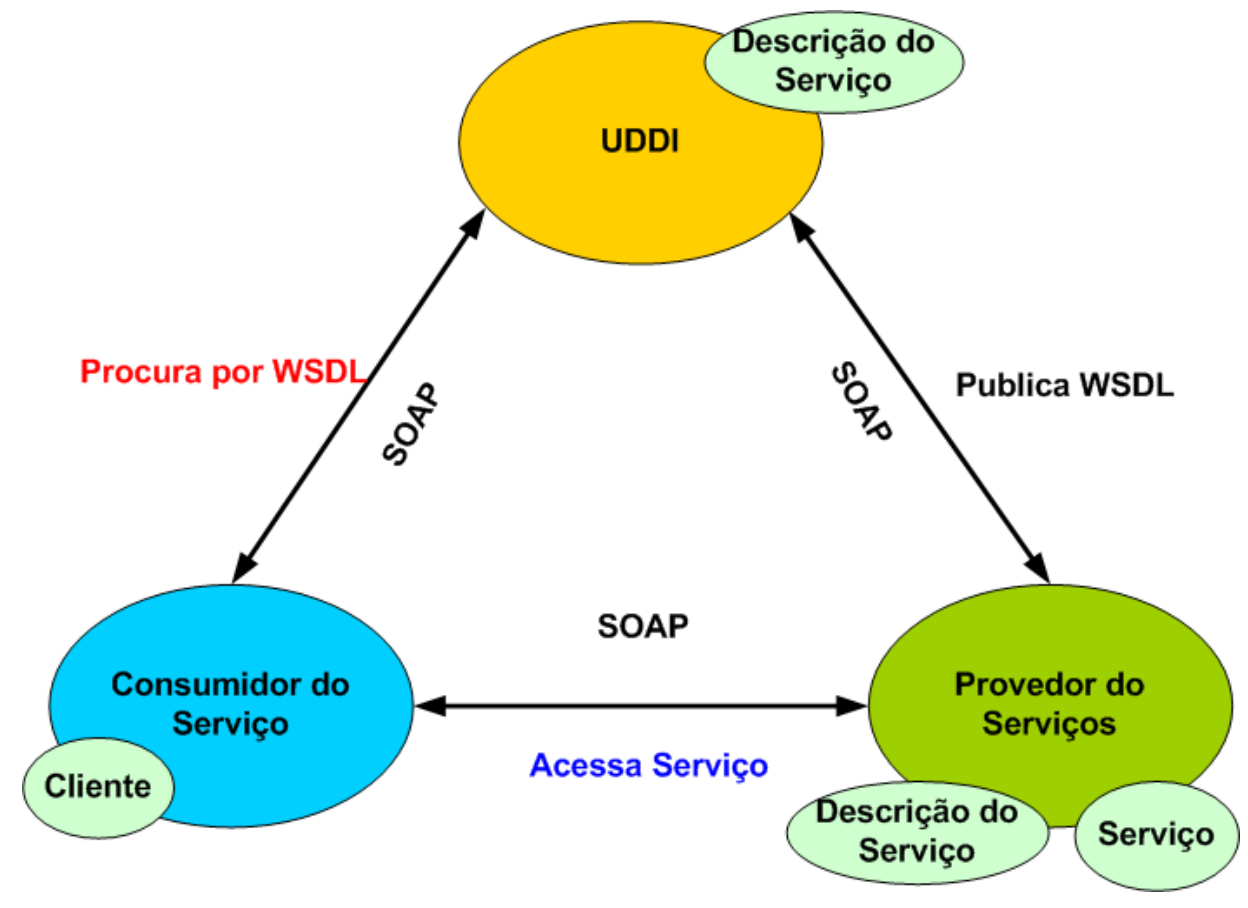

Figura 2.2: Modelo de Web services (Kreger, 2003)

A figura 2.2 ilustra o modelo de Web services. O modelo é composto de suas entidades e suas operações. É possível observar nessa figura que os Web services são uma implementação de uma arquitetura orientada a serviço onde as entidades e operações exercem as funções discutidas na subseção 2.2.1 deste capítulo.

\subsubsection{Ciclo de vida de Web services}

O desenvolvimento do ciclo de vida dos Web services inclui o requisito do projeto, publicação e tempo de execução para cada uma de suas entidades. Cada entidade possui requisitos específicos para cada elemento do desenvolvimento de seu ciclo de vida.

Segundo (Kreger, 2003) o desenvolvimento do ciclo de vida tem várias fases, as quais podem ser:

- Construção: Essa fase inclui o desenvolvimento e testes de um Web service, definição da descrição da interface do serviço e a definição da descrição da implementação do serviço. Os Web services podem surgir a partir de novas criações, transformações de aplicações existentes e composição de Web services existentes. 
- Publicação: Fase em que ocorre a publicação da interface do serviço e definições de implementação para o consumidor ou registro de serviços e também a publicação da parte funcional do Web service, geralmente em um provedor de serviços.

- Execução: Essa é a fase onde o Web service fica disponível para ser acessado. Neste estágio o Web service já está publicado, operando e acessível pela rede por meio de um provedor de serviços. Desta forma o consumidor de serviço pode finalmente encontrá-lo e utilizá-lo.

- Gerenciamento: A fase de gerenciamento cobre o gerenciamento e a administração do Web service. É importante considerar requisitos tais como segurança, disponibilidade, desempenho, qualidade do serviço e processos de negócio.

\subsubsection{Arquitetura de Web services}

Para permitir que as três operações (publicar, pesquisar e conectar) sejam realizadas de maneira interoperável, é preciso destacar a pilha conceitual dos Web services que contempla a estrutura de Web services, compreendendo padrões em cada nível. A figura 2.3 mostra de maneira conceitual uma pilha de Web services.

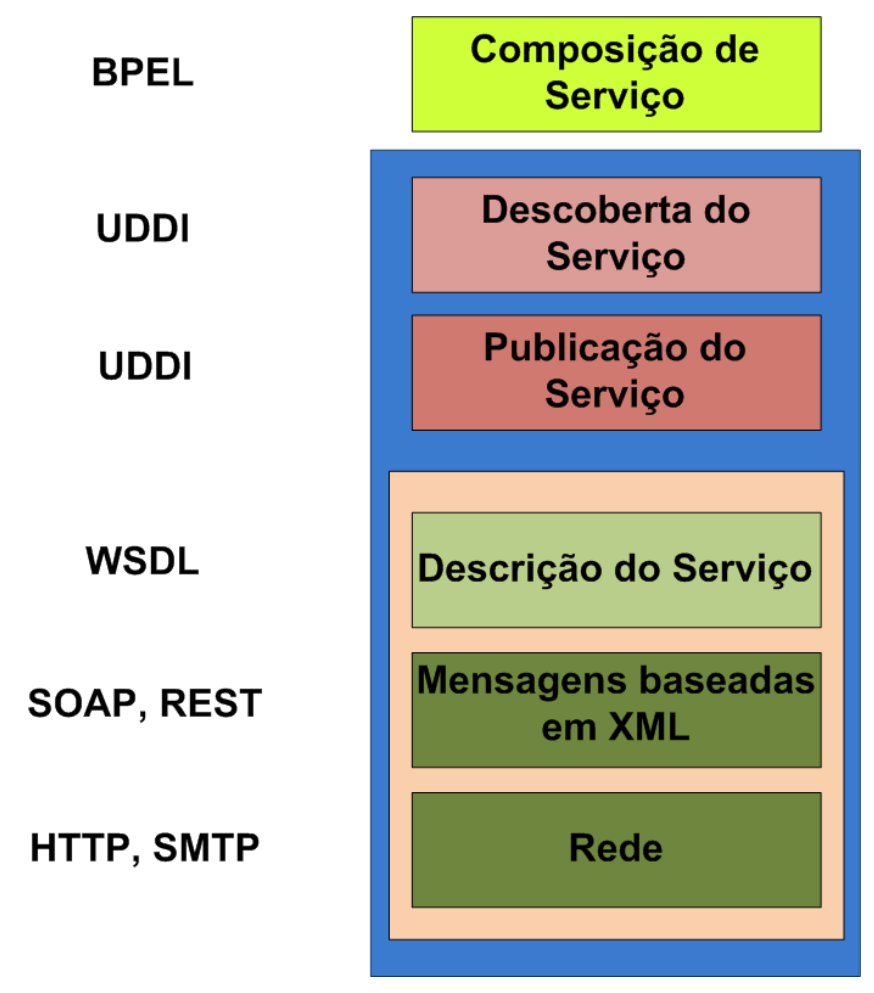

Figura 2.3: Pilha da estrutura de Web services(Kreger, 2003)

A base da pilha conceitual de Web services (Kreger, 2003) é a rede. Os Web services devem ser acessíveis pela rede para que possam ser acessados pelo consumidor de serviço. Os Web services que são publicamente disponíveis na Internet, geralmente utilizam protocolos de rede bem 
conhecidos. O HTTP é o protocolo padrão disponível na Web para Web services, apesar de ser possível utilizar outros protocolos como SMTP (Simple Mail Transfer Protocol) e FTP (File Transfer Protocol).

A camada de mensagens baseadas em XML representa o uso de XML como base para o protocolo de mensagem. SOAP é um protocolo baseado em XML escolhido por diversas razões. É o mecanismo padrão para ser o envelope para mensagens e chamadas de procedimentos utilizando XML. Pela simplicidade, pois é constituído basicamente de um HTTP POST com um envelope XML como carga. As mensagens SOAP suportam operações de publicação, pesquisa e conexão na arquitetura Web. O protocolo REST pode ser uma boa alternativa ao SOA já que possui desempenho melhor (Aihkisalo e Paaso, 2012), no entanto com menos recursos que o SOAP provê.

A camada de descrição de serviços apresenta a WSDL como padrão, necessária para dar suporte à interoperabilidade em Web services. Uma WSDL define a interface e os mecanismos de interação de serviços. A descrição é ainda necessária para especificar o contexto de negócio, QoS e relações de serviço com serviço. Documentos WSDL podem ser complementados por outros documentos de descrição de serviços para descrever os aspectos dos Web services.

Uma vez que os Web services são definidos para serem acessíveis pela rede via SOAP e representado por um serviço de descrição, as três primeiras camadas da pilha são necessárias para fornecer suporte ao uso de qualquer Web services. A pilha mais simples deve consistir de HTTP para a camada de rede, o protocolo SOAP para a camada de mensagens baseadas em XML e WSDL para a camada de descrição.

A camada de publicação de serviços inclui a produção de descrição do serviço e sua publicação. A descrição de serviços pode ser gerada manualmente ou montada a partir de definições de interfaces de serviços existentes. Desenvolvedores podem desenvolver manualmente toda a descrição do serviço, incluindo a entrada ao UDDI. Há ferramentas como o apache Axis2 (Perera et al., 2006) e apache jUDDI client (Stam e O'Ree, 2014) para gerar as partes de WSDL e potencialmente parte da entrada UDDI a partir de meta dados de modelos de programação e publicação dos Web services.

A publicação da descrição dos serviços pode ser feita utilizando uma variedade de mecanismos como, por exemplo, o jUDDI client. Esses mecanismos oferecem diferentes funcionalidades de acordo com grau de dinamicidade que a aplicação que utiliza o serviço exige. A descrição dos serviços pode ser publicada em múltiplos serviços de registro utilizando vários mecanismos diferentes. O caso mais simples é a publicação direta para o consumidor de serviço, no qual essa pode ser feita por e-mail, FTP ou até mesmo pela distribuição via media móvel. A publicação direta pode ocorrer após as duas partes da negociação entrarem em acordo sobre os termos de e-business via Web, ou após o consumidor do serviço pagar por ele. Nesse caso o consumidor do serviço poderá manter uma cópia local da descrição do serviço.

A camada de descoberta de serviços da pilha inclui a aquisição da descrição do serviço e o consumo das descrições. A aquisição pode utilizar uma variedade de mecanismos. Assim como 
na publicação de descrições de Web services a aquisição de descrições de Web services irá variar dependendo de como a descrição do serviço está publicada e quão dinâmica a aplicação deve ser. Consumidores de serviços podem encontrar Web services em duas fases diferentes de um ciclo de vida da aplicação, que são o projeto e o tempo de execução. No projeto, consumidores de serviço pesquisam por descrições de Web services e pelo tipo de interface que eles suportam. Em tempo de execução os serviços consumidores procuram por Web services baseando-se em como eles se comunicam ou utilizando aspectos de QoS, por exemplo.

$\mathrm{Na}$ abordagem de publicação direta, o consumidor de serviços armazena a descrição dos serviços em tempo de projeto, para então utilizá-la em tempo de execução. A descrição do serviço pode ser estaticamente representada na lógica do programa, armazenada em um arquivo ou em um simples repositório local de descrição de serviço.

Os consumidores de serviços podem conseguir uma descrição de serviço no tempo de projeto por meio de um repositório de descrição de serviço como o UDDI. Os vários tipos de UDDI apresentam implicações no número de Web services prontos para serem escolhidos. Dentre essas implicações estão a política de escolha, ou o número de prévias a serem feitas pelo consumidor antes de invocar o serviço. Aplicações UDDI de nível mais profissional exigem que prévias não sejam feitas para estabelecer confiança com o serviço. A seleção de serviço deve ser baseada no suporte da conexão, histórico de desempenho, QoS, proximidade ou balanceamento de carga.

Após um serviço ser localizado, o consumidor precisa processar a WSDL correspondente para poder, então, gerar requisições SOAP para o acesso ao serviço.

A camada de fluxo de serviços é onde os processos de negócios são definidos. Essa parte será abordada mais detalhadamente no capítulo 3.

\subsection{Qualidade de Serviço em Web services}

Qualidade de Serviços é referenciada como um conjunto de propriedades não funcionais de Web services, tais como desempenho, confiabilidade, disponibilidade e segurança. Com a difusão dos Web services, medidas de qualidade de serviço são utilizadas como uma aferição para diferenciar serviços (Kalepu et al., 2003). No entanto, garantir QoS em aplicações Web não é uma tarefa trivial devido às características imprevisíveis da Web (Farkas e Charaf, 2003).

Web services com suporte à QoS geralmente devem ser associados a um acordo de níveis de serviços SLA (Service Level Agreement), no qual é feito contrato formal da qualidade de serviços prestados entre provedores e clientes. Esse acordo geralmente envolve um terceiro componente responsável pela garantia de contrato. SLAs em Web services têm sido desenvolvidos para facilitar relacionamentos complexos entre provedores e clientes (Kalepu et al., 2003).

Qualidade de serviços em Web services é um assunto amplamente pesquisado e é possível encontrar na literatura uma sigla para referenciar especificamente qualidade de serviço em Web services que é QoWS (Quality of Web services) que segundo (Yu e Bouguettaya, 2010) se tornou 
principal critério para diferenciação de provedores de serviços que competem para oferecer Web services com funcionalidade equivalente. No trabalho apresentando em (Yu e Bouguettaya, 2010) é feito esforço para conseguir atualização de informações de QoWS em tempo de execução e conseguir fazer escolha de serviços utilizando múltiplos critérios de QoWS ao invés de apenas utilizar objetivos pré-definidos.

Em (Guo et al., 2008) é apresentado um framework para gerenciamento de QoWS, onde sua proposta utiliza um modelo de QoWS hexa dimensional que inclui:

- QoWS esperado: que representa a qualidade de serviço esperada pelo consumidor.

- QoWS contratado: que é a qualidade de serviço estabelecida por acordo SLA.

- QoWS fornecido: é a qualidade de serviço que é obtida por monitoração das requisições feitas aos provedores.

- QoWS percebida: é a qualidade de serviço obtida através da percepção do usuário ao utilizar o serviço.

- QoWS de transmissão: é a qualidade de serviço relativa ao desempenho da rede de comunicação.

- QoWS estatística, é a qualidade de serviço relativa à acessibilidade do serviço e representa a qualidade de serviço obtida em longo prazo, ela é obtida a partir da QoWS fornecida e QoWS percebida.

Por meio dessas seis QoWSs é possível representar vários requisitos das propriedades de QoS e descrever QoWS de maneira mais detalhada e objetiva. O gerenciador de QoWS é introduzido para garantir qualidade, ele adota SNMP (Simple Network Management Protocol) para capturar QoWS fornecida e percebida, e obter o desempenho fim a fim dos serviços, conseguindo assim uma representação estatística detalhada de QoWS em relação a qualidade de serviços em longo prazo.

A linguagem de definição de interface WSDL não oferece suporte a especificação de parâmetros de QoS, mas existem outras linguagens que fazem essa especificação e oferecem suporte à SLA como WSML (Web Service Modeling Language), WSLA (Web Service Level Agreement) e WSOL (Web Service Offer Language). Essas linguagens oferecem diferentes classes de serviços pré-definidos para distinguir os diferentes tipos de usuários(Zhou e Niemela, 2006).

A seguir serão apresentados alguns parâmetros de qualidade de serviço de acordo com (Kalepu et al., 2003):

- Disponibilidade: Disponibilidade é um aspecto de qualidade de serviço no qual um Web service está presente ou pronto para uso imediato, representado como uma porcentagem de tempo disponível de um serviço em um período de observação e está relacionado com sua 
confiabilidade. Para serviços frequentemente acessados um pequeno valor de período de observação fornece uma aproximação mais precisa para sua disponibilidade.

- Confiabilidade: É a probabilidade que um serviço irá responder no período de tempo esperado pelo consumidor e probabilidade do serviço executar sua funcionalidade de maneira correta. Este atributo caracteriza a confiança que um consumidor de serviços pode assumir no provedor de serviços.

- Custo: O Valor monetário cobrado pelo provedor de serviços pelo acesso feito ao serviço.

- Throughput: Representa o número de requisições que são finalizadas por determinado período de tempo. O aumento do throughput está diretamente relacionado ao tempo de resposta do sistema, pois quanto mais clientes ele conseguir atender em menos tempo, menor será a sobrecarga para receber novas requisições.

- Tempo de resposta: É o tempo que uma requisição demora a partir do momento que ela é iniciada para ser atendida até o momento em que o requisitante recebe a resposta dessa requisição. Este tempo inclui toda a sobrecarga e possíveis atrasos que ocorram na rede.

- Latência: Tempo gasto entre a chegada da requisição e o envio da resposta.

- Desempenho: É a medida feita utilizando métricas como Tempo de Resposta e Throughput. O desempenho é considerado bom quando o throughput é alto e o tempo de resposta é baixo.

- Segurança: A habilidade para garantir o não-repúdio das mensagens. Este atributo é importante para conseguir confiabilidade, confidencialidade e autenticidade dos provedores de serviços.

- Regularidade: Aspecto de qualidade de serviço que mostra se um Web service está em conformidade com as leis, regras, padronizações e acordos de níveis de serviços estabelecidos.

- Robustez/Flexibilidade: A habilidade de um serviço em contornar entradas inválidas, incompletas e conflitantes e gerar o resultado correto.

- Precisão: Avalia a probabilidade do serviço gerar erro.

- Reputação: É medido pela avaliação que os clientes do serviço atribuem a ele. No final de cada acesso isso pode ser coletado por meio de uma enquete sobre satisfação do usuário.

Estes são alguns dos parâmetros de QoS que podem ser utilizados para se definir os contratos SLAs. Os contratos SLAs podem utilizar diferentes parâmetros de QoS de acordo com a natureza e necessidade da aplicação. Por exemplo, serviços de jogos online, um parâmetro de QoS que influi muito para este tipo de aplicação é o tempo de resposta. Já para usuários de sistemas bancários online, um parâmetro de QoS muito importante para este tipo de aplicação é a segurança. 


\subsection{Considerações Finais}

Este capítulo apresentou uma visão geral do que é SOA e uma abordagem detalhada do funcionamento da arquitetura básica dos Web services. Foi apresentado a pilha da estrutura dos Web services e descritas todas as suas camadas para a permitir a construção de aplicações distribuídas com Web services, além de fazer uma introdução sobre qualidade de serviços relacionada a Web services.

No próximo capítulo serão abordados fundamentos sobre composição de serviços, complementando o assunto apresentado no presente capítulo com aspectos de QoS relacionados à composição de serviços, Web services semânticos e composição automática de Web services. 


\section{Composição de Web services}

\subsection{Considerações Iniciais}

A composição de Web services é um tópico importante na literatura de Web services, visto que um único Web service tem suas funcionalidades limitadas em relação a um processo de negócio complexo.

A arquitetura de Web services mostrada no capítulo 2 é satisfatória para interações clienteservidor, mas se for necessário combinar aspectos de vários serviços para gerar um novo serviço complexo, o ideal seria a utilização de composição de Web services para definir a execução dessas interações.

Um processo de negócio geralmente envolve mais de uma organização que possui serviços independentes e que precisam ser integrados para então fornecer ao cliente o resultado desejado. Nesse sentido fica estabelecida a importância de se pesquisar composição de Web service com QoS, pois assim é possível fornecer aos clientes um resultado otimizado para suas necessidades e condições de aquisição de serviço.

Neste capítulo serão abordados tópicos importantes sobre composição de serviços com QoS. Dessa forma, será apresentada uma introdução ao assunto, seguida de uma seção sobre QoS aplicada à composição de serviços. A linguagem que se pretende utilizar para o desenvolvimento deste trabalho será objeto de discussão e, por fim, serão apresentadas as ferramentas de implementação que serão utilizadas para auxiliar no desenvolvimento do trabalho. 


\subsection{Composição de Web services}

Um exemplo clássico de utilização de composição de Web services é o sistema de compra de pacote de viagens, onde uma empresa de reserva de hotéis, uma de aluguel de carros e uma de compra de passagens disponibilizam seus serviços como Web services. A composição desses três Web services resulta em um novo Web service composto para sistema de compra de pacote de viagem que coordenará a execução dos três serviços de maneira transparente ao cliente. Esse cenário apresentado mostra como é facilitada a integração entre empresas diferentes que passam a disponibilizar seus serviços como Web services por meio da composição de Web services. A padronização dos Web services permitem a integração entre empresas que utilizam plataformas de arquitetura de computadores e linguagens de programação diferentes. Isso torna possível a comunicação entre qualquer sistema, facilitando a criação de processos de negócios sem que seja preciso que códigos sejam reescritos para a interação entre empresas diferentes com sistemas distintos.

A composição de Web services está sendo utilizada também em grades computacionais, onde é feita a composição de Web services oferecidos pelas organizações virtuais componentes das grades, provendo assim Web services mais completos e complexos. Um exemplo disso é apresentando em (Senna et al., 2009), que utiliza a composição de Web services dinâmica para criar serviços compostos que se adaptem a dinamicidade dos ambientes de grades computacionais.

Em redes de sensores também têm se pesquisado composição de Web service, já que a tarefa de criar aplicações que utilizam redes de sensores é feita atualmente apenas por especialistas. Por exemplo, se um biólogo ou um meteorologista precisarem adaptar uma rede de sensores às suas necessidades, eles teriam que ser especialistas em redes de sensores para conseguir fazer isso (Reinke et al., 2009). Nesse sentido é proposta a utilização de SOA como maneira de acesso a sensores, onde as informações provenientes dos sensores são disponibilizadas como Web services, tornando possível fazer a composição dos sensores para a criação de aplicações com finalidades específicas.

Na composição de Web services dois grandes domínios se destacam: orquestração e coreografia de serviços (Kavantzas et al., 2005). A orquestração descreve o fluxo de execução coordenado por um engine (mecanismo) centralizado ou distribuído para fazer a integração dos serviços. A principal linguagem utilizada para se fazer orquestração é WS-BPEL. Um aspecto valioso do modelo de serviços é que podem ser criados novos Web services a partir da existência de outros, sem abandonar o paradigma de computação orientada a serviços (Weerawarana et al., 2005). Ou seja, os novos Web services compostos criados, podem ser acessados como Web services únicos.

A coreografia descreve a colaboração que cada participante deve ter, definindo, de um ponto de vista global, seu comportamento através de troca de informações para que ambos entrem em consenso sobre as regras de integração entre as entidades (Kavantzas et al., 2005). Para a colaboração funcionar com sucesso, as regras para interação entre todos os participantes devem ser definidas. Atualmente essas regras são descritas de forma discursiva. Por isso surgiu a necessidade de um padrão para descrever essas interações, de modo que não houvesse mais ambiguidade 
na documentação e responsabilidade dos participantes. A especificação WS-CDL (Web Services Choreography Description Language) tem como objetivo principal descrever a colaboração entre qualquer tipo de participante, de acordo com a plataforma suportada ou o modelo de programação para implementação do seu ambiente. A W3C, atualmente, considera obsoleta a especificação para coreografia de Web services.

Na literatura é comum haver confusão sobre os tipos de composição de Web services; manual ou automática, e estática ou dinâmica. Trabalhos como (Rao e Su, 2005) e (Dustdar e Schreiner, 2005) descrevem sobre uma classificação dos tipos de composição. A partir dessas classificações é possível chegar-se à conclusão de forma sucinta, de que composição manual e automática são duas grandes classificações onde, na composição manual um grafo contendo a descrição de execução de fluxo e referência lógica a Web services é planejado por um desenvolvedor. Na composição automática o fluxo é definido automaticamente, através de técnicas como inteligência artificial e semântica, usando como referência para definir o fluxo apenas as entradas e saídas fornecidas pelo usuário ao processo. Já a composição dinâmica e estática são classificações que podem ser aplicadas dentro de composição automática e manual. Para entender composição dinâmica e estática é importante entender os conceitos de Web service abstrato e Web service concreto. O Web service abstrato está relacionado a especificação do serviço que deverá ser executado, isso é, ele especifica o Web service a ser acessado, operação a ser acessada e parâmetros a serem passados. Já o Web service concreto se refere à implementação do Web service propriamente dita, que é a lógica a ser executada. Utilizando serviços relacionados à hotelaria como exemplo, pode-se dizer que quando um cliente diz que quer o serviço de um hotel qualquer, ele está se referindo a um serviço abstrato, mas quando o cliente diz que quer um serviço de determinado hotel, ele está se referindo ao serviço concreto. Nesse sentido, composição estática se refere à associação de cada Web service abstrato a um Web service concreto, em tempo de projeto. Na composição dinâmica os Web services concretos são selecionados para serem executados em tempo de execução.

A composição de Web services não é uma tarefa trivial e no trabalho apresentado em (Lu et al., 2007) o autor faz um estudo com o objetivo de verificar o que realmente existe em composição de Web services. Nesse trabalho o autor afirma que composição automática de Web services é difícil de ser obtida. Trabalhos que realizam pesquisa com esse tipo de composição geralmente trabalham com Web services não reais e em ambientes simulados. E ainda afirmam que realizar uma composição de Web services é mais difícil que fazer um novo programa de maneira convencional.

\subsubsection{Fases da composição}

É importante o estudo das fases da composição para que seja possível fazer uma avaliação de desempenho adequada, já que a composição de Web services é uma técnica complexa que envolve vários parceiros para que seus objetivos sejam atingidos com sucesso (Chandrasekaran et al., 2003). 
As fases da composição de um Web service são: planejamento, definição, análise da execução, análise da eficiência, fase de componentes do tempo de execução.

- O planejamento é a fase em que se discute qual tipo de composição e quais técnicas de busca pelos serviços são as mais apropriadas.

- Na fase de definição é feita uma representação da estrutura do processo de composição, em uma linguagem adequada para a resolução do problema.

- A análise da execução é responsável pela interpretação da especificação da composição, pela avaliação de desempenho e pelas técnicas de execução. Entre as técnicas de execução duas são destacadas como as mais importantes: a execução distribuída (coreografia), em que a responsabilidade de coordenar um processo de composição é distribuída entre os diversos provedores de Web services; e a execução centralizada (orquestração), em que a composição tem um único responsável por gerenciá-la.

- A fase de análise da eficiência é feita por meio de parâmetros de QoS, tais como o tempo de serviço. Também é analisada a habilidade para lidar com sobrecarga, são utilizados métodos matemáticos para avaliar a QoS de um Web service.

- Na fase de componentes do tempo de execução são analisados: o tempo que um serviço gasta para realizar somente a execução da tarefa; o tempo de transmissão das mensagens e o tempo de espera gerado em razão da sobrecarga no sistema.

Avaliar os Web services envolvidos em um processo de composição deve contemplar (Chandrasekaran et al., 2003):

- A descoberta do Web service envolvido no processo de composição que causa sobrecarga no sistema.

- O Web service que tem alta sobrecarga de comunicação gerada pelo processamento das mensagens.

- A capacidade de carga individual dos Web services envolvidos no processo, ou seja, a carga que cada Web service pode suportar efetivamente.

\subsection{QoS em composição de Web services}

Outros trabalhos também discutem a necessidade de se caracterizar parâmetros de QoS para o processo de composição (Gouscos et al., 2003) e (Tosic et al., 2002). Para os autores é preciso relacionar quais são os parâmetros de QoS que permitem a escolha do melhor serviço em determinada ocasião, dependendo das métricas ou das técnicas utilizadas. Encontrar um Web service 
adequado, em um grande conjunto que oferece funcionalidades semelhantes, pode ser uma tarefa vagarosa e o sucesso da escolha nem sempre estará garantido. Determinar as estimativas para as propriedades de QoS de um Web service é uma tarefa desafiadora e envolve (Sheth et al., 2002) uma combinação de estimativas de projetistas da aplicação e estimativas de QoS. As estimativas de QoS são paramétricas, tempo de resposta de um serviço que obtém um documento XML como entrada, dependerá do tamanho do documento.

Estimativas para Web services compostos podem ser desenvolvidas de dois modos, Atomicamente (para cada serviço) ou conjuntamente para a composição como um todo.

Ainda com relação à caracterização de QoS é interessante a especificação do comportamento de execução de um Web service, que pode ser feita utilizando-se de duas classes:

- Básica: Associa a cada dimensão de QoS do Web service um valor mínimo, médio e máximo. Exemplo: A dimensão do custo corresponde a um valor mínimo, médio e máximo associada à a execução de uma tarefa. Os valores especificados nessa classe são empregados por métodos matemáticos para computar métricas de QoS.

- Distribucional: Corresponde à especificação de uma constante ou de uma função de distribuição (exponencial, lognormal, normal, etc) que estatisticamente descreve o comportamento da tarefa em tempo de execução. Os valores são apresentados por meio de simulação para computar o fluxo de trabalho em termos de QoS.

Há diferentes categorias de QoS que definem requisitos para a seleção entre os serviços disponíveis para composição destacando-se (Jaeger e Ladner, 2005):

- Tempo de Execução: o tempo de execução é o tempo necessário para que o serviço seja executado mais a comunicação.

- Custo: o custo representa o montante de recursos necessários para o uso de um serviço, para o cálculo do custo na composição de serviços é necessário considerar que recursos são gastos a cada vez que um serviço é utilizado.

- Reputação: o conceito de reputação representa a qualificação do serviço fornecida pelos usuários aos serviços por eles utilizados, como por exemplo, o Skype (programa para ligação por voz sobre IP) pede aos usuários notas sobre a qualidade da ligação. Assim como a reputação é a média dos rankings dos usuários, na composição de serviços é utilizada a reputação de cada serviço individualmente.

- Disponibilidade: a disponibilidade de um serviço implica na probabilidade de que a invocação do serviço seja feita com sucesso e que o resultado seja entregue com as demais categorias de QoS atendidas. 
Avaliar cada categoria de QoS de algum Web service é importante, mas é preciso um método para calcular a QoS de uma composição como um todo. Para isso é necessário um modelo para a composição de Web services. Jaeger e Ladner (2005) explicam um modelo que facilita essa tarefa. Nesse modelo são apresentadas estruturas básicas de sequência de execução de Web service, onde a sequência que os Web service serão executados é pré-definida.

- Laço: a execução de um Web service será repetida algumas vezes.

- Separação AND seguida por uma junção AND: 'n' Web services são executados paralelamente e todos os Web services precisam terminar a execução com sucesso para que haja sincronização.

- Separação XOR seguida por uma junção XOR: para 'n' Web services prontos serem executados em paralelo apenas um é iniciado. A operação de sincronização considera apenas as tarefas que começaram a ser executadas.

- Separação OR seguida por uma junção OR: para 'n' Web services prontos para serem executados em paralelo mais que um, mas não todos os Web services são executados juntos. A sincronização precisa que todas as tarefas iniciadas juntas sejam executadas com sucesso.

- Separação OR seguida por uma junção m-out-of-n: para 'n' Web services prontos serem executados em paralelo, mais de um Web service é iniciado junto, mas não todos, e 'm' <= 'n' precisam ser finalizados com sucesso para que a sincronização seja feita.

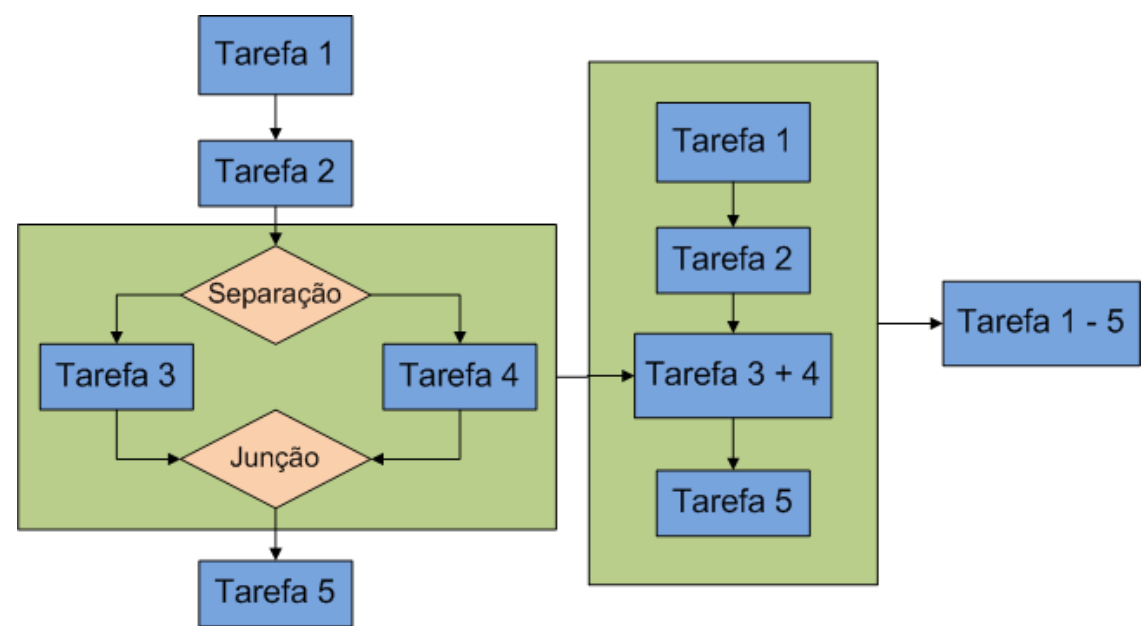

Figura 3.1: Grafo de Agregação - (Jaeger e Ladner, 2005)

Utilizando essas estruturas é possível agregar valores de QoS para cada um dos padrões descritos e, então, calcular uma QoS total para uma composição completa. Na figura 3.1 é possível ver um exemplo simples deste caso, onde as tarefas 3 e 4 são agregadas e então recebem um valor de QoS e se tornam semelhantes às outras tarefas, que também são agregadas formando uma única tarefa, recebendo assim, um valor final de QoS. 
É importante destacar que a análise do desempenho de uma composição de Web services na forma de execução não é uma técnica trivial, uma vez que tal processo requer que haja o controle sobre os Web services e os hosts envolvidos, e isso não pode ser alcançado em um ambiente como a Web, dada sua natureza dinâmica. Uma falha em um Web service, por exemplo, pode afetar todo o ambiente de avaliação, a menos que tal falha seja caracterizada no processo de composição e que seu comportamento também seja avaliado. Testar e simular Web services para avaliar o desempenho são duas novas áreas com poucos trabalhos abordados atualmente. Vale destacar que a qualidade de serviço resulta da interação entre a demanda do usuário, o comportamento do sistema sobre essa demanda e os recursos que esse comportamento requer (Woodside e Menasce, 2006). Caso isso não seja considerado (tais fatores), a tendência é o mal uso de recursos e uma QoS não controlada. Com um grande número de Web services, consumidores tendem a querer distinguir entre os bons e os maus provedores e as técnicas de QoS são uma maneira de se fazer essa distinção. Para atingir tal finalidade faz-se necessário mapear o que o usuário deseja, em relação ao que o provedor de Web services tem para oferecer (Taher et al., 2005).

O ponto principal deve ser o conhecimento do comportamento das aplicações e suas demandas por recursos. Outro problema é a dificuldade de descobrir esse comportamento. Apesar das dificuldades envolvidas, um estudo sobre composição de Web services é importante no cenário atual da Web, onde empresas, instituições financeiras e universidades trocam informações e necessitam a cada dia de algumas garantias que permitam às suas aplicações a correta realização de suas tarefas.

\subsection{Algoritmos para composição dinâmica de Web ser- vices}

Nesta seção serão comentados alguns algoritmos para seleção de Web services para composição de Web services.

O trabalho apresentado em (Cardellini et al., 2007) é relatado um modelo de seleção de Web services, que utiliza classes de usuários por meio de SLAs. O acordo para classes e serviços são escolhidos passo a passo. As classes adotadas são ouro, prata e bronze. Na classe ouro os melhores Web services são escolhidos para fazer parte da composição do Web service, na classe prata é feito uma parte da seleção com os melhores Web services e outra com os piores Web service e na classe bronze, os piores Web service são selecionados. Essa solução é interessante, uma vez que sempre prioriza clientes que paguem mais pelo serviço. No entanto, essa solução, por não considerar a visão do fluxo como um todo, pode prejudicar os clientes em situações que ocorrem em fluxo paralelo. Nesse caso, o cliente ouro poderia acessar Web services com menor custo e com tempo de resposta que não afetariam o tempo de resposta total do fluxo. A seleção do fluxo é feita por um broker.

No trabalho apresentado em (Grønmo e Jaeger, 2005), o autor apresenta uma abordagem para seleção de Web services em um fluxo composto, no qual é considerada a visão do fluxo como 
um todo e não os Web services de forma isolada. A ideia apresentada para seleção de Web services consiste em construir todas as combinações de Web services possíveis para o fluxo, fazer a normalização dos valores para permitir uma comparação mais justa, criar pesos para os atributos de QoS e, então, criar uma nota para cada uma das combinações. Também são levados em conta nessa nota fatores que, quanto menores melhores (tempo de resposta), e também fatores que quanto maiores são melhores (throughput). A proposta apresentada nesse trabalho é aplicada na escolha dos melhores Web services, sendo possível conceder pesos aos atributos de QoS mais importantes. Entretanto, nem sempre todos os clientes irão compartilhar a ideia de que aquele atributo que foi considerado mais importante é, de fato, o mais importante. Isso pode causar insatisfação no cliente pelo fato de o atendimento não ser realizado de acordo com suas preferências. Nesse contexto, o algoritmo de seleção Euclidiana pode sinalizar no sentido de uma maior satisfação do usuário, pelo fato do usuário decidir os critérios de quais combinações de atributos de QoS irão ser mais adequadas. No entanto, é necessário realizarem-se testes comparativos entre as abordagens e concluir qual delas é mais eficiente. Ainda em relação à abordagem de seleção de Web services para um fluxo composto, outros trabalhos importantes, que propõem solução para problemas de composição de Web services com QoS, devem ser mencionados: (Nguyen et al., 2006) e (Wang et al., 2006) que utilizam lógica Fuzzy para seleção de Web services, o trabalho apresentado em (Paoli et al., 2006) que utiliza modelos matemáticos para a solução do problema de seleção de Web services.

\subsection{Web semântica e Ontologia}

Segundo Berners-Lee et al. (2001) a Web semântica não é uma Web a parte e sim uma extensão da Web, na qual a informação terá significado bem definido, possibilitando que humanos e computadores possam cooperar de maneira mais eficiente. Em 2001 Berners-Lee já afirmava que em um futuro próximo isso conduziria novas funcionalidades como máquinas que sejam capazes de processar dados de maneira similar a que humanos fazem ao invés de simplesmente apresentá-los na tela.

A definição de Web semântica começa pela definição de "semântica", que significa "significado". O dado apresentado com seu significado permite que seu uso seja mais efetivo, atualmente a maioria dos dados são apresentados sem informações sobre o que ele significa, geralmente é necessário que o usuário faça análises sobre esses dados para compreendê-los (Hebeler et al., 2011).

Em (Hebeler et al., 2011) é apresentado como exemplo para motivação da pesquisa em Web semântica mecanismos de busca. É estimado que existe um número extremamente elevado de páginas Web publicadas na internet, o que torna uma tarefa complicada entre tanta informação conseguir resultados que realmente fazem parte do interesse do usuário. Para conseguir filtrar páginas que sejam relevantes ao usuário, existem os mecanismos de busca que atualmente levam em conta apenas a relevância sintática do conteúdo das páginas, fazendo com que o usuário faça ainda a parte mais difícil que é verificar de maneira exaustiva qual página tem o conteúdo (semântico) 
mais adequado a sua necessidade. Esse trabalho de filtrar as páginas Web pela semântica ainda não está disponível nos sistemas de busca justamente porque as páginas Web não possuem descrição semântica para serem processadas automaticamente pelos motores de busca.

\subsubsection{Ontologia}

A modelagem conceitual de ontologias na ciência da computação tem papel importante em áreas como banco de dados e projetos de sistemas de informação, engenharia de software, integração da informação, entre outras. Ontologia tem sido bastante importante na chamada Web semântica (Berners-Lee et al., 2001), neste contexto os recursos da Web têm sua semântica descrita pela associação entre um ou mais domínios de ontologia (Noy et al., 2001) .

Para definir ontologia é preciso primeiro apresentar os termos, vocabulário e taxonomia. Vocabulário é a coleção de termos utilizados na comunicação que não sejam ambíguos e não possuam redundância sem uma identificação explicita dessa redundância. Além disso, é esperado que um vocabulário tenha significados consistentes em todos contextos (Hebeler et al., 2011). Taxonomia é um vocabulário no qual os termos são organizados de maneira hierárquica, cada termo compartilha algum tipo de parentesco com um ou mais elemento da taxonomia. Um dos pontos positivos da utilização da taxonomia é a possibilidade de conseguir especialização ou generalização de termos.

Ontologia utiliza vocabulários reservados e predefinidos de termos para definir conceitos e relações entre eles para uma área específica de interesse ou domínio. Ontologia pode referir a um vocabulário ou uma taxonomia. Geralmente o termo se refere a um modelo formal baseado em lógica para descrever um domínio de conhecimento. Utilizando ontologias é possível expressar a semântica por trás do vocabulário de termos, suas interações e uso de contexto.

A Web semântica utiliza a combinação de um esquema de vocabulários, taxonomias e ontologias. RDFS (RDF Schema) provê um vocabulário específico para RDF que pode ser utilizado para definir taxonomias de classes e propriedades, domínios simples e intervalos de especificações para propriedades. A OWL (Web Ontology Language) provê uma linguagem expressiva para definir ontologias que capturam a semântica de um domínio de conhecimento.

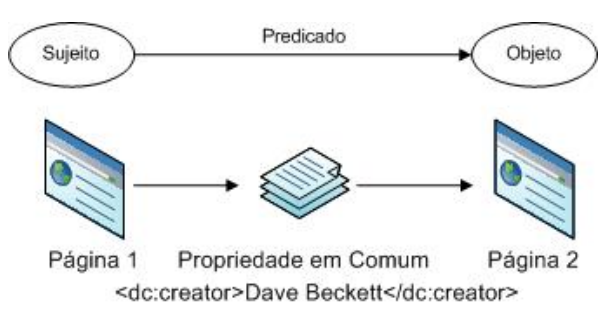

Figura 3.2: RDFS, a trinca básica - (Nakamura, 2012)

RDF permite fazer declarações sobre recursos identificados por URIs, essas declarações são formadas por uma trinca que associa um recurso (sujeito) com um valor (objeto) usando uma propriedade (predicado), a figura 3.2 apresenta esse modelo (Nakamura, 2012). RDF possui um 
modelo expressivo e extremamente poderoso para capturar informações, no entanto, RDF por si só não provê uma maneira de capturar o significado da informação que está modelando. Para isso é necessário desenvolver um vocabulário comum ou coleção de recursos que tenha significados bem definidos e que sejam utilizados de maneira consistente para descrever outros recursos. RDFS não é uma tentativa de definir estes vocabulários compartilhados, e sim prover uma linguagem com a qual seja possível desenvolver novos vocabulários compartilhados. Vocabulários RDFS descrevem os recursos das classes e propriedades sendo utilizados em um modelo RDF. Utilizando RDFS é possível organizar classes e propriedades em hierarquias de generalização ou especialização, definir associações entre classes e também a especificar e interpretar tipos de dados.

A OWL é uma extensão do vocabulário RDFS feita com recursos adicionais que podem ser utilizados para construir ontologias mais expressivas para a Web. OWL introduz restrições adicionais de acordo com a estrutura e conteúdo de documentos RDF com o objetivo de fazer com que computadores consigam processar e tomar decisões inteligentes. OWL utiliza RDF, RDFS, tipos de dados XML Schema e OWL namespaces.

A Web semântica é vista como o futuro da Web na qual a informação é disponibilizada juntamente com um significado explicito, facilitando máquinas a processarem automaticamente e integrarem informações disponíveis na Web. A Web semântica é construída sobre habilidades definidas pela linguagem XML para definir esquemas de etiquetas personalizadas e da abordagem flexível do framework RDF para representar dados. O primeiro nível necessário sobre RDF para Web semântica é uma linguagem para ontologia que consiga descrever formalmente o significado da terminologia utilizada em documentos Web. OWL foi projetada para satisfazer as necessidades para uma linguagem que defina ontologias para Web. OWL é uma das recomendações de maior notoriedade da W3C para Web semântica (McGuinness et al., 2004).

OWL provê três sub-linguagens projetadas para uso por comunidades específicas de programadores e usuários:

- OWL Lite é feita para usuários menos experientes com a necessidade de fazer classificações hierárquicas e restrições.

- OWL DL é feita para usuários que querem a máxima expressividade, enquanto mantém bom poder computacional (todas as conclusões são garantidas para serem computáveis) e capacidade de decisão (todas as computações terminarão em tempo finito).

- OWL Full é destinado a usuários que querem a máxima expressividade e liberdade sintática do RDF sem nenhuma garantia computacional. Por exemplo, em OWL Full uma classe pode ser tratada simultaneamente como uma coleção de indivíduos e como um indivíduo em seu próprio direito. OWL Full permite que uma ontologia aumente o significado do vocabulário pré-definido (RDF e OWL). É improvável que qualquer software de raciocínio seja capaz de suportar completamente cada recurso da OWL Full. 
Cada uma dessas sub-linguagens é uma extensão da predecessora mais simples, toda definição feita nas linguagens mais simples serão completamente interpretadas quando utilizadas em linguagens mais complexas.

Desenvolvedores de ontologias que adotarem OWL devem considerar qual sub linguagem melhor se encaixa em suas necessidades. A escolha entre OWL Lite e OWL DL depende da necessidade do usuário em ter construções mais expressivas previstas pelo OWL DL. A escolha entre OWL DL e OWL Full depende principalmente do grau no qual usuários precisem das ferramentas de auxílio para meta modelagem do RDFS. Quando OWL Full é utilizado em comparação ao OWL DL, apoio a tomada de decisão é menos previsível, já que implementações completas da OWL Full não existam no momento. OWL Full pode ser visto como uma extensão de RDF enquanto OWL Lite e DL pode ser visto como extensões de uma visão restrita de RDF. Todos os documentos OWL (Lite, DL, Full) são documentos RDF, e todo documento RDF é um documento OWL Full, mas apenas alguns documentos RDF serão de fato documentos OWL Lite e DL. Por esse motivo, é preciso ter cuidado quando um usuário quiser migrar documentos RDF para documentos OWL. Quando a expressividade de documentos OWL DL e Lite é considerada apropriada, algumas precauções têm que ser tomadas para garantir que o documento RDF original cumpra as restrições adicionais impostas pelo OWL DL e Lite.

\subsubsection{Web services semânticos}

Web services semânticos são baseados em duas tendências de grande importância na evolução da Web: Web services e Web semântica (Prazeres, 2009). A semântica aplicada em Web services está sendo uma boa justificativa da importância dos Web services no cenário atual da computação distribuída, já que a interoperabilidade é possível através de protocolos como Corba, no entanto com semântica associada a serviços existe uma possibilidade infinitamente maior de encontrar serviços publicados na Web que possam sanar as necessidades dos usuários.

Por meio da semântica os usuários e agentes de software poderão descobrir, acessar, compor e monitorar recursos na Web oferecendo serviços com propriedades particulares, além de tornar isso possível com um alto grau de automação se for da vontade do desenvolvedor do sistema. Ferramentas poderosas poderão ficar disponíveis por meio da descrição de serviços. OWL-S (formalmente DAML-S) é uma ontologia de Web service que torna essas funcionalidades disponíveis (Martin et al., 2004).

\subsection{Composição de Web services automática}

Existem os Web services abstratos, Web services atômicos e Web services compostos. Os Web services abstratos contêm apenas as descrições do Web service, mas não contém a implementação do Web services. 
Os Web services atômicos, contém a implementação do Web service, eles não interagem constantemente com outros Web services e com o usuário, um exemplo de Web service atômico é o serviço retorna o código postal quando o usuário submete ao serviço algum endereço.

Já em Web service composto, o serviço é feito com mais de um Web service atômico e geralmente necessita de uma interação maior entre o conjunto de Web services que estão sendo utilizados, um exemplo de Web service composto é a compra de livros de alguma loja virtual, onde os usuários procuram livros de acordo com seus critérios e opiniões de outros clientes e então decidirá se vai ou não realizar a compra, para então passar informações para entrega e pagamento do livro.

OWL-S é feita para dar suporte às duas categorias de serviços supracitadas, mas em Web service composto tem sido uma grande motivação para muitos elementos de ontologias. As três tarefas: descoberta automática de Web services, acesso automático a Web services e composição automática de Web services podem apresentar uma ideia dos tipos de tarefas que OWL-S torna possível.

1. Descoberta automática de Web services é um processo automatizado para localizar serviços que podem fornecer uma classe particular de funcionalidades de serviço, enquanto respeita algumas restrições impostas por determinados clientes. Um exemplo é um cliente que quer encontrar um serviço que vende passagens aéreas e aceita determinados cartões de crédito. Atualmente este tipo de tarefa deve ser executada por um ser humano que irá executar os serviços disponíveis e verificar quais possuem a funcionalidades requisitadas pelo cliente. Com OWL-S a informação necessária para a descoberta do Web service poderá ser especificada de maneira interpretável pelo computador através de marcações semânticas disponibilizadas nos sites Web e em um registro de serviço onde seja possível encontrar os Web services automaticamente.

2. Acesso automático a Web services, é o acesso automático a um Web service feito por um programa de computador onde esse programa recebe apenas uma descrição declarativa do Web service desejado, diferente de um programa que já esteja pré programado para executar determinado Web service. A execução de um Web service não é uma tarefa trivial, já que os Web services são acessados através de uma coleção de chamadas a operações remotas. OWL$S$ fornece uma API para interpretação computacional declarativa que inclui a semântica dos argumentos a serem especificados quando essas chamadas são executadas, e a semântica do que é retornado a essas chamadas quando o acesso é feito com sucesso ou falha. Um agente de software deve estar apto para interpretar essa semântica para compreender qual entrada é necessária para acessar o Web service e quais informações ele retornará.

3. Composição automática de Web services envolve seleção automática, composição e interoperação de Web services para executar tarefas mais complexas, dado o alto nível da descrição e objetivo. Por exemplo, o usuário pode ter a necessidade de fazer todo seu planejamento para uma viagem a uma conferência. Atualmente, o usuário precisa selecionar os Web services, especificar a composição manualmente e ter certeza que todos os Web services necessários para realizar a composição foram criados de maneira que ele contribua para o objetivo 
da aplicação. Com OWL-S a informação necessária para selecionar e compor Web service são agregadas ao provedor de Web service. Softwares podem ser escritos para manipular essas representações juntamente com a especificação do objetivo da tarefa para cumpri-la automaticamente. Para possibilitar isso OWL-S possui especificações declarativas dos prérequisitos, consequências da aplicação de cada Web service e uma linguagem para descrever a composição e interações do fluxo.

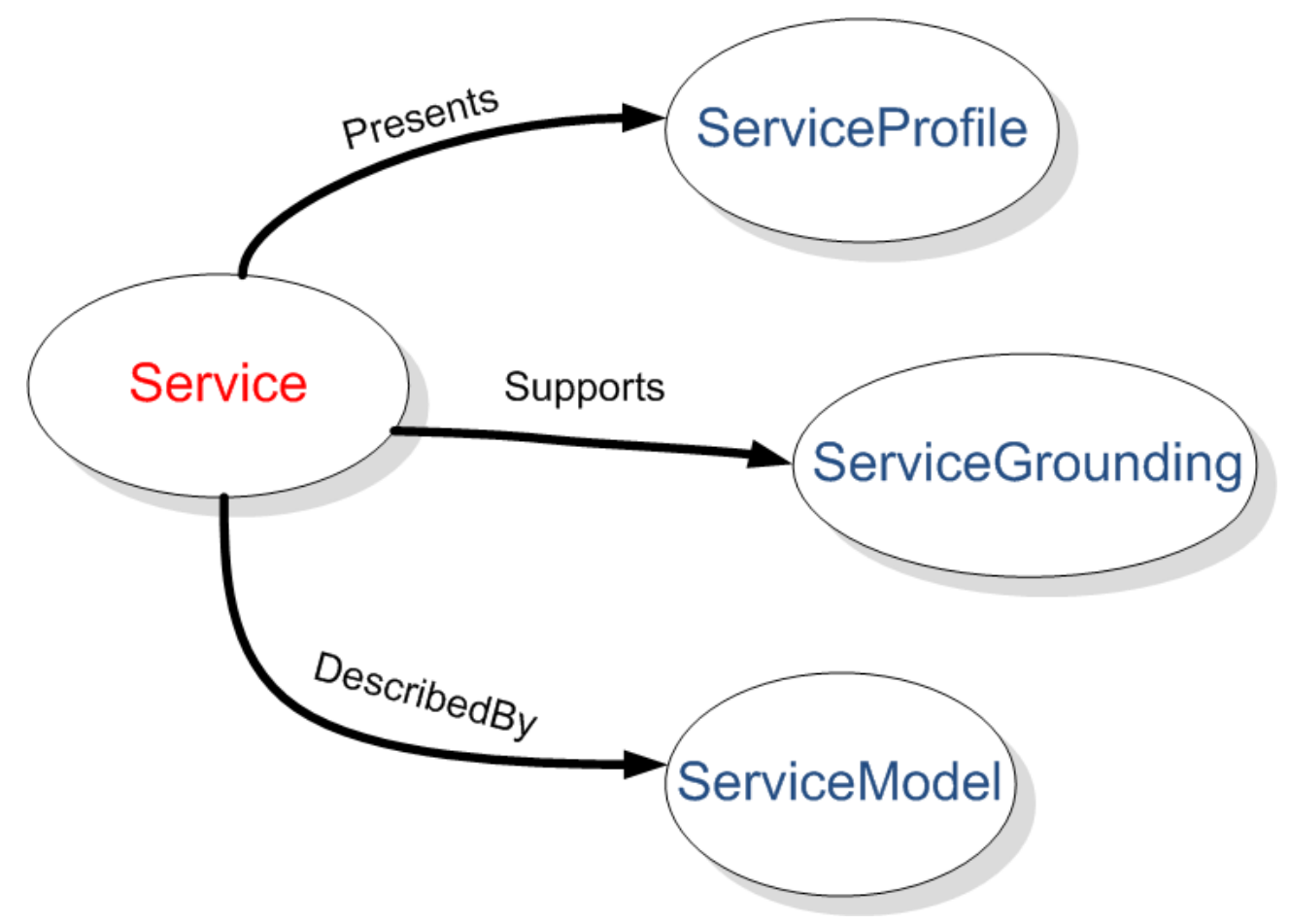

Figura 3.3: Ontologia de serviços em alto nível - (Martin et al., 2004)

Na figura 3.3 a classe "Service"é um ponto de referência organizacional para um Web service, uma instância de "Service"existirá para cada Web service publicado. As propriedades "presents", "describedBy"e "supports"são propriedades de "Service", as classes "ServiceProfile", "ServiceModel"e "ServiceGrounding"são respectivamente referenciadas por essas propriedades. Cada instância de "Service"apresenta (present) uma descrição "ServiceProfile". O serviço é descrito por (describedBy) uma descrição "ServiceModel"e da suporte (support) a uma descrição "ServiceGrounding". Os detalhes dos perfis, modelos e fundamentos podem variar muito de um tipo de serviço para outro. Mas cada uma dessas três perspectivas do serviço fornece um tipo de informação essencial sobre o serviço.

Em termos gerais, o "ServiceProfile"fornece as informações necessárias para que um agente consiga descobrir um serviço, enquanto o "ServiceModel"e "ServiceGrounding", em conjunto, fornecem informações suficientes para que um agente faça uso do serviço, uma vez que ele é encontrado.

O perfil de serviço "ServiceProfile"contém informações relativas as funcionalidades do serviço, de uma forma que é adequada para um agente do serviço de busca determinar se o serviço atende 
às suas necessidades. Esta forma de representação inclui uma descrição do que o serviço pode realizar, as limitações da aplicabilidade do serviço, qualidade do serviço e os requisitos que o solicitante do serviço deve satisfazer para usar o serviço com êxito.

O modelo de serviço "ServiceModel"especifica ao cliente como usar o serviço, detalhando o conteúdo semântico da requisição, as condições em que os resultados específicos irão ocorrer e quando necessário, os processos que conduzem a esses resultados. Ele descreve como solicitar o serviço e o que acontece quando o serviço for utilizado. Para os serviços não triviais (aqueles composto por várias etapas ao longo do tempo), esta descrição pode ser usada por um agente do serviço de busca em pelo menos quatro maneiras diferentes:

1. Para realizar uma análise mais aprofundada de saber se o serviço atende as suas necessidades.

2. Para compor as descrições do serviço a partir de múltiplos serviços para executar uma tarefa específica.

3. Durante o ciclo de vida do serviço, para coordenar as atividades dos diferentes participantes

4. Monitorar a execução do serviço

A fundamentação do serviço "ServiceGrounding"especifica os detalhes de como um agente pode executar um serviço. Normalmente, um fundamento especifica um protocolo de comunicação, formatos de mensagens e outros detalhes específicos do serviço. Além disso, a fundamentação deve especificar, para cada tipo de semântica de entrada ou de saída requerida na "ServiceModel", uma forma inequívoca de elementos de troca de dados desse tipo com o serviço, ou seja, as técnicas de serialização empregadas.

A ontologia para serviços específica apenas duas restrições de cardinalidade: um serviço pode ser descrito por, no máximo, um modelo de serviço, e uma ligação à fundamentação deve ser associada com exatamente um serviço. A ontologia deliberadamente não especifica qualquer cardinalidade mínima para as propriedades present ou describedby.

\subsubsection{Algoritmos para composição Automática de Web services}

Na literatura é possível encontrar inúmeras propostas de algoritmos para composição automática de Web services, nessa seção são discutidas algumas dessas propostas. A apresentação desta seção apresenta uma grande variedade de propostas para composição automática de Web services, assim justificando a proposta deste trabalho que ajudará a implementar sistemas para composição automática a identificar pontos fortes e fracos em relação as abordagens propostas pelos autores desses algoritmos.

O algoritmo de composição automática é muitas vezes dividido em duas partes, o matchmaking e a seleção dos Web services. O matchmaking é responsável pela criação dos links semânticos entre os Web services disponíveis. O link semântico é feito por meio da conexão lógica entre as entradas 
e saídas dos Web services. Essa conexão lógica é feita por meio da análise do ServiceProfile. Quando o matchmaking termina sua tarefa, se tem como resultado da sua execução um grafo com todas as possibilidades de utilização em conjunto dos Web services disponíveis. Após isso é feito a seleção dos Web services que de fato serão utilizados para atingir o objetivo que o cliente requisitou ao sistema.

Um exemplo de matchmaking clássico é o proposto em (Paolucci et al., 2002), onde é feita a combinação completa de todos os Web services disponíveis no registro de serviços. O resultado é um grafo com todas as possibilidades de links semânticos entre os Web services. Essa foi uma abordagem pioneira, no entanto o desempenho dessa abordagem costuma ser bastante ruim em ambiente com um número muito grande de Web services disponíveis.

Para melhorar o desempenho de matchmaking, outros trabalhos foram propostos como apresentado em (Yang et al., 2012), onde o autor propões o desenvolvimento de um matchmaking híbrido. Em (Wei et al., 2011), é proposto o SAWSDL-iMatcher, um matchmaking que pode ser personalizado, por isso o usuário pode adicionar estratégias personalizadas no matchmaking de acordo com os requisitos da aplicação.

Em (Pop et al., 2010) é apresentada uma abordagem onde o matchmaking é feito com a modelagem da composição de serviços com processo multicamadas que cria uma estrutura de grafo em conjunto com uma matiz de links semânticos. Nesse trabalho o modelo clássico de grafos é acrescido de novos conceitos de agrupamento de serviços e links semânticos por similaridade. Os links semânticos por similaridade são definidos entre serviços em camadas diferentes do grafo e são armazenados em uma matriz de links semânticos. Para fazer a composição o trabalho propõe um algoritmo imuno-inspirado que utiliza o modelo de grafo incrementado e a matriz de links semânticos para selecionar a melhor solução de composição utilizando como critério os atributos de QoS e qualidade semântica. Segundo (Pop et al., 2010) os resultados experimentais provaram que a composição proposta e os métodos de seleção forneceram uma solução de composição ótima.

No trabalho (Prazeres, 2009), é utilizado o matchmaking proposto em (Paolucci et al., 2002) que gera um grafo direcionado e sem diferenciação de custos, no qual foi aplicado o algoritmo de Dijkstra para cálculo do melhor caminho (Dijkstra, 1959). Resultados de experimentos indicaram que apesar de completar uma composição com as funcionalidades requisitadas pelo usuário, essa composição não tinha como resultado serviços com a funcionalidade esperada. Para resolver esse problema foram aplicados custos relativos à funcionalidade dos serviços com o objetivo de tornar as composições obtidas próximas às composições esperadas como ideais em relação ao que o usuário requisitou.

Outra abordagem interessante é a proposta por (Lin-feng e Yong, 2010), onde é proposta a composição semiautomática, onde através da teoria do espaço quociente as opções de serviços com alta granularidade (muitos serviços que atendem a mesma solução) são reduzidos a serviços de baixa granularidade (grupo pequeno de serviços com mesma funcionalidade) para que o usuário escolha entre as opções sugeridas pelo algoritmo as que melhor atende suas necessidades. 
Em (Hatzi et al., 2012) são utilizadas técnicas de inteligência artificial para o planejamento da composição automática de Web services semânticos. O autor utiliza OWL-S para fazer as descrições de Web services, e transforma essas descrições OWL-S em um problema de planejamento descrito de forma padronizada usando PDDL (Planning Domain Definition Language), enquanto que a informação semântica é utilizada para a melhoria do processo de composição, bem como para aproximar a composição de serviços às melhores soluções quando soluções exatas não são encontradas. Resolução, visualização, manipulação e avaliação dos serviços compostos produzidos são realizadas, enquanto que, ao contrário de outros sistemas, a independência de planejadores específicos é mantida.

Em (Yu e Reiff-Marganiec, 2009) é apresentado um novo aspecto, composição por contexto de informação, que leva em conta na escolha dos serviços a fazerem parte da composição propriedades não funcionais, a colaboração e histórico de comunicação entre serviços e restrições de colaboração de negócios entre diferentes organizações. Segundo o autor uma grande vantagem em relação a outras abordagens é tolerância a falha.

Muitos outros trabalhos na literatura relativos a algoritmos para composição automática de Web services podem ser facilmente encontrados, no entanto ferramentas e metodologias para avaliar quais algoritmos tem bom tempo de resposta, solução mais adequada para a solicitação do cliente e provisão de QoS ainda não estão disponíveis para serem instalados e utilizados.

Devido a essa carência de ambientes para avaliação de desempenho de algoritmos para composição de Web services tanto automática quanto manual que se encaixa o objetivo principal deste projeto que é avaliar o desempenho de algoritmos para composição de Web services.

\subsection{Considerações Finais}

Para a escrita deste capítulo foi feito um levantamento bibliográfico sobre composição de Web services, assunto central deste projeto de pesquisa. Os tipos, fases e técnicas de composição foram investigados para conseguir um entendimento claro de como é o processo para montar um fluxo de serviços.

Foram apresentados trabalhos relacionados que investigam QoS em composição de Web services e algumas técnicas para conseguir estipular QoS para um fluxo de serviço como um todo a partir de informações de QoS de serviços de forma individual. Entender como se define QoS em composição de Web services é bastante importante no contexto deste projeto, que pretende conseguir composição de Web services provendo QoS.

Foi feita uma introdução a Web semântica, que segundo Berners-Lee et al. (2001), deverá ser o futuro da Web. A Web semântica é foco de pesquisa do criador da Web, e tem como foco principal, facilitar a busca de conteúdos específicos para as necessidades particulares de cada usuário. Esse objetivo pode ser alcançado por meio da adição de informações semânticas aos recursos disponí- 
veis na Web, possibilitando que computadores identifiquem os significados informados para cada recurso.

Foram também apresentados os Web services semânticos que tornam possível a composição automática, fazendo assim possível que usuários leigos possam, por meio do uso de descrições semânticas obter Web services, até então inexistentes, que sejam capazes de realizar as tarefas por ele desejadas.

No próximo capítulo será apresentado em detalhes o sistema AWSCS. O sistema AWSCS tem como objetivo a avaliação de desempenho de testes funcionais de fluxos de composição de Web services gerados por algoritmos para composição Automática de Web services. 



\section{AWSCS(Automatic Web Service Composition System)}

\subsection{Considerações Iniciais}

Neste capítulo são apresentados o modelo arquitetural, o funcionamento do sistema proposto e protótipo implementado para avaliação de desempenho, bem como testes funcionais de fluxos de composição de Web services gerados por algoritmos para composição Automática de Web services.

Nas diversas pesquisas existentes que abordam como fazer composição automática de Web services, normalmente se apresentam algoritmos para a composição automática de Web services, mas geralmente não se apresenta uma avaliação do comportamento do fluxo resultante do algoritmo em termos de execução.

Pouca pesquisa é feita no sentido de avaliar e comparar essas propostas. Não foram encontrados trabalhos na literatura disponível que tentem avaliar o comportamento da execução em um ambiente real. Os trabalhos encontrados na literatura sobre avaliação de desempenho de Web services são (He et al., 2008), (Fang et al., 2010), (Jing e Yu-yue, 2010) e (Juan e Hao, 2012). Em (He et al., 2008), é proposto um ambiente baseado em simulação para a composição de Web services, a composição é modelada por meio do uso de redes de Petri. Nesse trabalho também não é considerada a avaliação de desempenho de composição de Web services automática.

Em (Fang et al., 2010) é apresentada uma abordagem de como se escolher o melhor fluxo por meio do uso de redes de Petri estocásticas. Apesar de ser um trabalho bastante interessante, é um trabalho que utiliza modelos analíticos para a avaliação de desempenho dos serviços compostos, 
impossibilitando, assim, tratar os impactos que a sobrecarga pode gerar no sistema como um todo, por exemplo.

Em (Jing e Yu-yue, 2010) são utilizados também redes de Petri estocásticas. Neste trabalho são apresentadas técnicas de como avaliar composição manual dinâmica. Depois de ter o fluxo criado manualmente é possível fazer qual escolha de serviços concretos seriam a melhor opção de acordo com a QoS de cada serviço.

Em (Juan e Hao, 2012) também é apresentada uma abordagem que utiliza filas de redes de Petri, para modelar fluxos BPEL. Os autores utilizam simulação para avaliar o desempenho da composição. Neste trabalho é avaliada a variação do tempo de resposta médio.

Os trabalhos citados nesta seção apresentam o que foi encontrado na literatura em relação à avaliação de desempenho em composição de Web services. A maioria destes trabalhos não oferece a possibilidade de avaliar algoritmos para composição automática de Web services. Outro ponto em comum entre estes trabalhos é que eles utilizam modelos analíticos ou simulação. O problema com a utilização destas abordagens é que fica muito difícil descrever analiticamente ou simular como seria o comportamento da execução da composição, já que vários fatores podem influenciar nos resultados, como sobrecarga no sistema, tipos de máquinas utilizadas nos provedores, tipos de clientes que fazem acesso ao sistema, etc.

Por esse motivo, neste trabalho de doutorado optou-se pelo uso de prototipação. Foi implementado um protótipo de um sistema para a composição automática de Web services chamado AWSCS (Automatic Web Service Composition System). Com este sistema é possível publicar algoritmos para composição automática em um mesmo ambiente para que seja possível fazer uma comparação entre as propostas testadas de maneira justa e então poder-se tomar uma decisão de qual abordagem é melhor.

O principal objetivo desta tese de doutorado é propor um sistema onde seja possível fazer a avaliação da composição de Web services, baseado em atributos de QoS que dependem da execução para serem medidos, uma vez que não foram encontrados sistemas com propósito semelhante. $\mathrm{O}$ AWSCS é fundamental para atingir este objetivo, observando-se que nenhum outro sistema com este mesmo objetivo foi encontrado.

Neste capítulo são apresentados detalhes do funcionamento do protótipo AWSCS, proposto nesta tese de doutorado.

\subsection{Modelo arquitetural do AWSCS}

O AWSCS é um ambiente onde é possível a comparação entre as abordagens de composição de Web services. A comparação é feita baseado no desempenho real da execução do Web service composto. Nesta tese de doutorado são apresentadas algumas das funcionalidades as quais objetivou a criação deste sistema, no entanto ele não está limitado a estas. 
O modelo arquitetural do AWSCS contempla todos os passos da composição automática de Web services. Além disso permite que se faça a avaliação de desempenho de maneira modular, por meio da inserção de monitores que gravam diversas informações em um servidor de $\log s$, o LogServer.

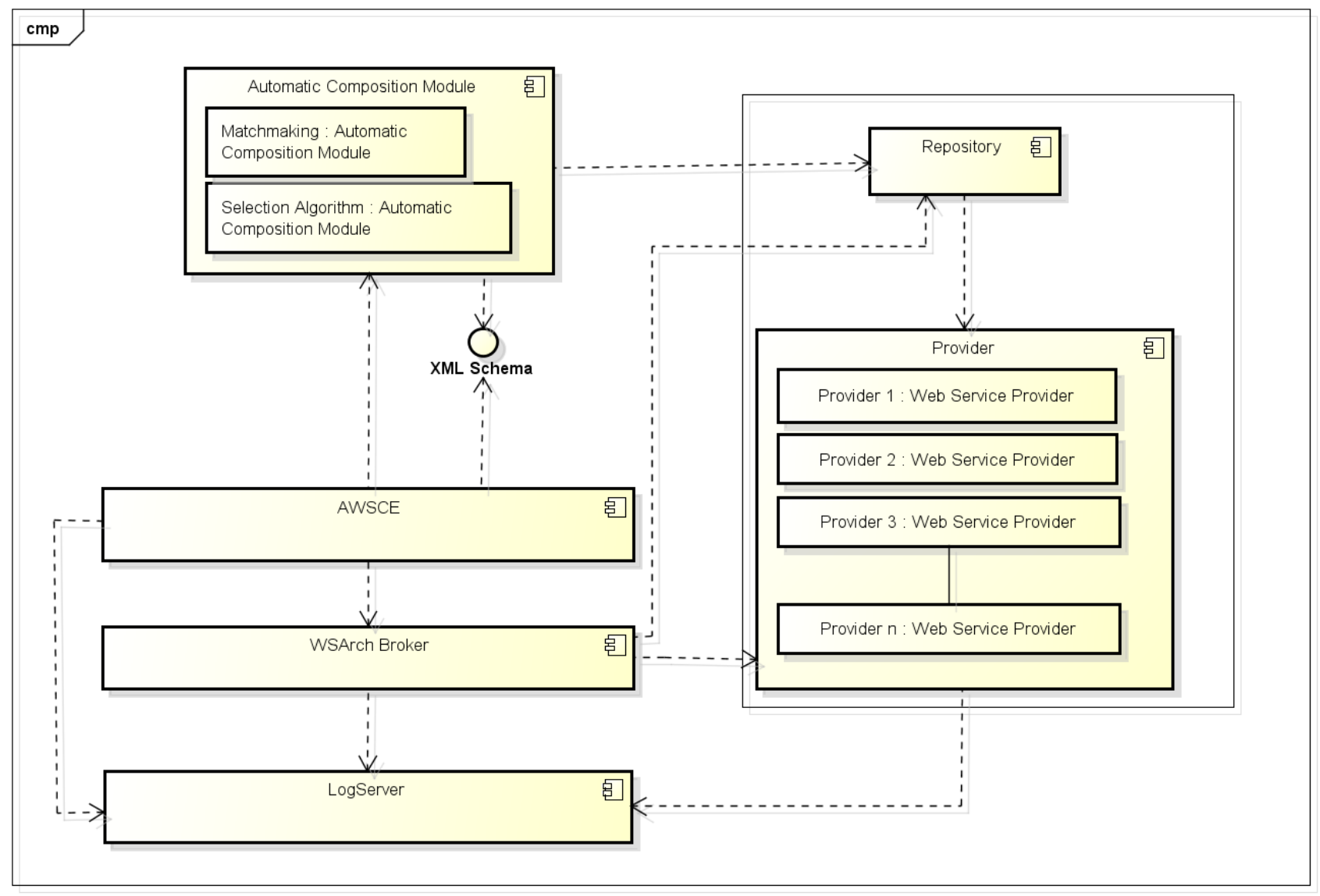

Figura 4.1: Modelo arquitetural AWSCS

Na figura 4.1 é apresentado um diagrama de componentes onde são mostrados os módulos principais que compõem o modelo arquitetural para avaliação de desempenho utilizando o AWSCS.

- AWSC Matchmaking + AWSC Selection Algorithm: onde estão publicados o matchmaking e o algoritmo para seleção de serviços. Eles são responsáveis por encontrar Web services candidatos e criar a descrição do fluxo de execução que será capaz de resolver a requisição do usuário. O matchmaking acessa o "Repository" para obter informações dos serviços semânticos disponíveis. (Como não foram encontradas implementações de algoritmos para composição automática, este módulo foi simulado)

- AWSCE(Automatic Web service Composition Execution: responsável por receber o fluxo de execução resultante do módulo "AWSC Matchmaking + AWSC Selection Algorithm". Neste módulo é feita o controle da execução de maneira apropriada dos Web services, garantindo que serviços paralelos e sequenciais sejam executados de maneira correta. 
- Service Provider Repository: módulo no qual são publicadas as descrições semânticas e interface para execução dos serviços.

- WSArch Broker: módulo responsável por fazer com que o contrato de SLA seja atingido, para isso ele procura por um serviço concreto que atenda o SLA estabelecido para atendimento do cliente.

- LogServer: banco de dados onde todos os registros de execução são salvos para análise posterior.

- Web service Providers: provedores de Web services onde a implementação do serviço é executada.

- Monitor: código inserido nos módulos WSArch Broker e AWSCE para fazer a medição dos tempos gastos em cada parte da execução dos serviços.

\subsubsection{Diagrama de Sequência do AWSCS}

Na figura 4.2 é apresentado um diagrama de atividades que ajuda a entender como é feita a utilização do AWSCS.

Quando um usuário faz uma requisição para o sistema ela vai ser tratada pelo módulo WSArch Broker, que irá identificar se a requisição é para serviço composto ou simples, se for para serviço composto o módulo AWSCE irá coordenar a execução composta, se não, o WSArch Broker irá fazer a execução do serviço concreto. Caso seja composição composta serão seguidas as seguintes etapas:

1. WSArch Broker encaminha a requisição ao módulo AWSCE.

2. Módulo AWSCE requisita ao módulo de composição automática a descrição do fluxo a ser executado.

3. Módulo de composição automática busca pelas descrições semânticas dos Web services, gera o fluxo, contendo os serviços abstratos, que são capazes de atender as exigências dos clientes e o retorna ao módulo AWSCE que será o responsável por coordenar a execução.

4. Módulo AWSCE faz a validação do fluxo pelo módulo XMLVerifier e então começa a execução do serviço composto.

5. No módulo AWSCE para cada serviço a ser executado uma thread é criada. Quando a thread não depende da execução de um serviço anterior ou o serviço anterior já terminou a execução, ela é disparada. Utilizando esse mecanismo é possível garantir a execução dos serviços em paralelo, sequencialmente e também fazer a sincronização da execução desses Web services. A execução do serviço é feita propriamente pelo módulo WSArch Broker. 


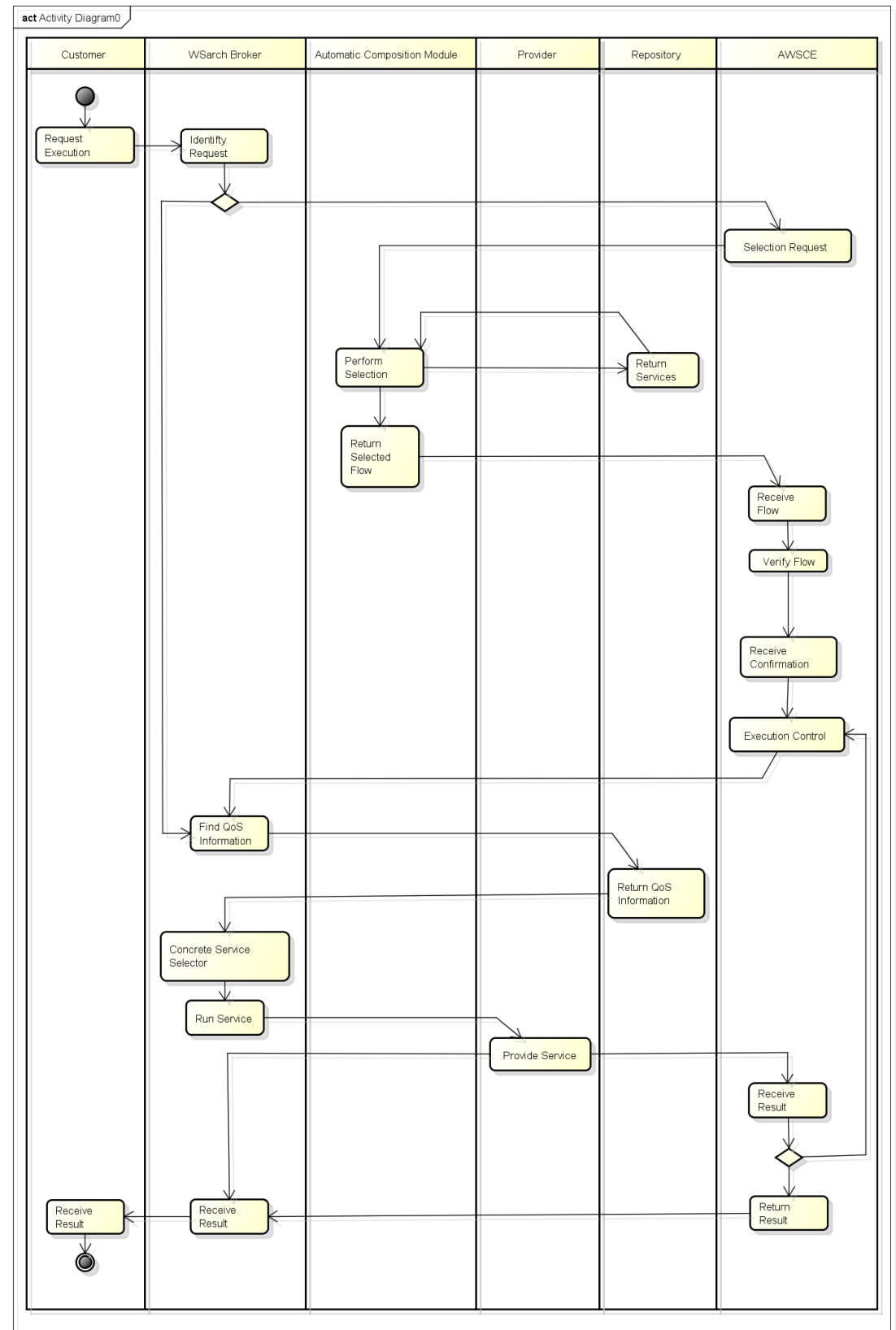

Figura 4.2: Diagrama de Atividades do AWSCS

6. No módulo WSArch Broker, antes da execução do serviço é feito uma busca no módulo Repository por Web services concretos para cada Web service abstrato. A busca é feita para que o Web service escolhido seja capaz de atender o SLA estabelecido entre cliente e Provedor.

7. Após o serviço concreto ser encontrado o módulo WSARch Broker faz então a execução do Web service junto ao provedor do mesmo. O provedor retorna o resultado da execução ao módulo AWSCE.

8. No módulo AWSCE é verificado se existe alguma nova requisição a ser feita, se existir execução na fila, volta ao item 5. Se não, o resultado da composição é enviado ao cliente. 
Os módulos AWSCE e WSARch Broker são os módulos chave para o funcionamento do AWSCS. Na seção 4.3 serão apresentados detalhes do módulo AWSCE e na seção 4.4 os detalhes da WSARch.

\subsection{Módulo AWSCE - Automatic Web Service Composi- tion Execution}

Nesta seção serão apresentados detalhes do funcionamento do AWSCE, que é o módulo responsável por gerenciar a execução dos serviços compostos.

Para o funcionamento desta arquitetura ser possível, a primeira tarefa foi definir como seria possível que o resultado de um algoritmo para composição automática pudesse ser executado automaticamente, sem que fosse preciso a compilação dos arquivos, criação dos partnerlinks (ligações entre o serviço composto com as implementações dos serviços que são executados) e publicação do Web service composto em um Engine de composição de Web service, que é como funciona, quando se utiliza o BPEL.

Para conseguir fazer a execução de maneira automática, definiu-se que um arquivo XML contendo toda a descrição da execução do Web service composto que deve ser gerado pelo algoritmo de composição de Web services. Para que esse arquivo XML seja compatível com o AWSCE foi criado um XML schema que define o padrão que deve ser seguido na criação do arquivo XML.

O XML Schema apresentado na figura 4.3 é formado por três elementos básicos que se encontram dentro da Tag principal CompositeService: CompositionName; Service; Connection.

- CompositeService: Tag utilizada para identificar o nome da composição.

- Service: Para cada Web service que compõe o fluxo é criada uma tag Service. Em Service estão contidas as informações básicas necessária para executar o Web service. Esta tag é composta por 5 elementos:

- ID: identificador único do Web service, cada Web service deve conter seu ID.

- Name: Corresponde ao nome do "Web service"a ser executado.

- Operation: Corresponde ao nome da operação do Web service que será executado.

- Parameters: Corresponde aos parâmetros de entrada da execução da operação. É um tipo complexo, já que uma operação pode ter nenhum ou vários parâmetros. Um parâmetro pode ser tanto uma variável contendo o resultado de um outro Web service, como pode também ser um valor que é inicializado devido a alguma especificação feita pelo usuário que requisitou um Web service composto.l

- Class: Classe do serviço a ser executado, pode ser definido como Bronze, Silver e Gold.

- Output: Saída da Execução do Web service. 


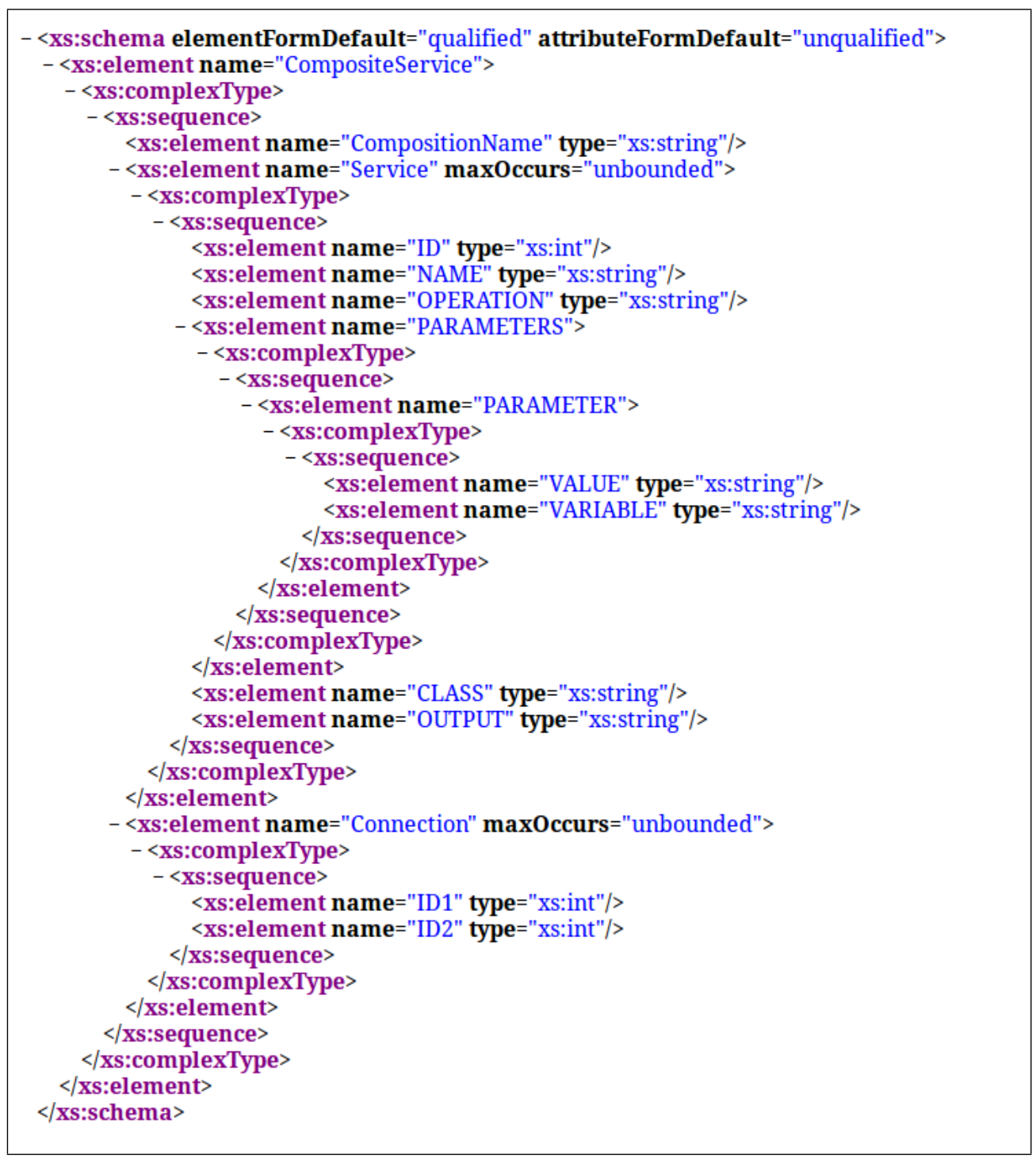

Figura 4.3: Fluxo de Execução - XML Schema

- Connection: A tag Connection é responsável por identificar a ordem de execução dos Web services. É composto pelas tags ID1 e ID2. É por meio das conexões que se define o fluxo de execução em formato de um grafo dirigido. A tag ID1 identifica o Web service que precisa ser executado antes que o Web service identificado por ID2 possa ser acessado.

Na figura 4.4 é apresentado de maneira simplificada o Diagrama de Classe do módulo AWSCE, responsável pela execução do Web service composto. O funcionamento do módulo começa pela classe AWSCE que faz a requisição à classe GenerateFlow, responsável por iniciar o algoritmo para composição automática. A classe GenerateFlow responde à classe AWSCE com o arquivo XML com a descrição do fluxo. A classe AWSCE então chama a classe ServiceDispatcher. A classe ServiceDispatcher faz a chamada a classe XMLParser que irá validar o fluxo por meio da classe XMLValidation e então ler o arquivo XML e extrair as informações para poder executar os Web services. 


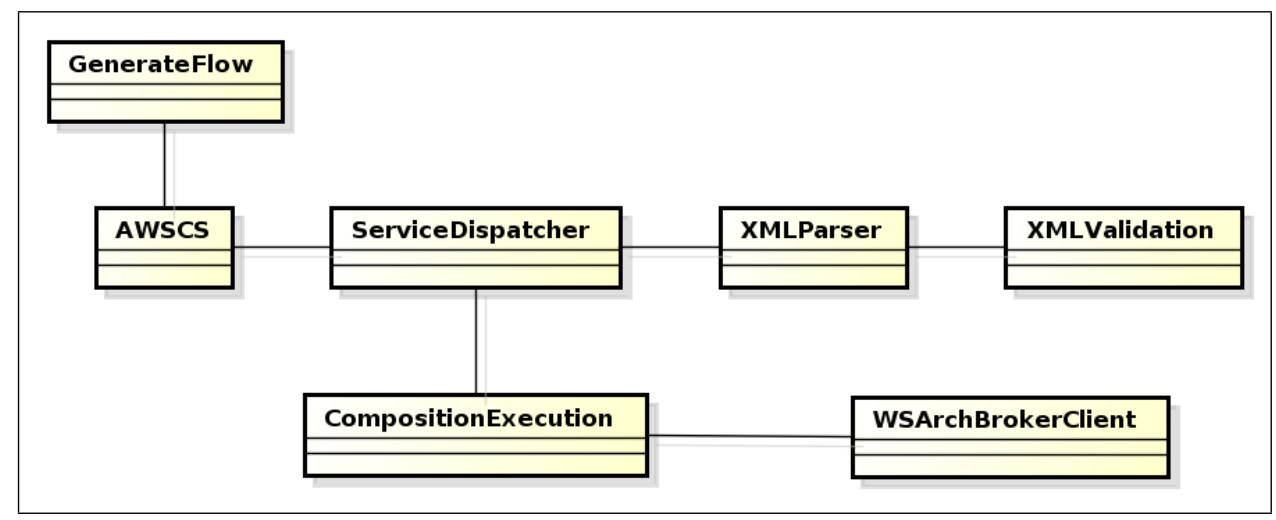

Figura 4.4: Diagrama de Classe Simplificado - AWSCE

A classe ServiceDisaptcher, cria uma Thread CompositionExecution para cada Web service a ser executado. Na classe CompositionExecution, é verificado se o Web service está pronto para execução, ou seja, se os Web services dos quais sua execução depende estão finalizados. Quando está pronto para ser executado, é chamado a classe WSARchBrokerClient que será responsável por fazer a requisição ao Broker da arquitetura WSARch, que é apresentado na seção 4.4.

O sistema AWSCS pode ser publicado tanto no modo stand alone, onde ele é utilizado como uma aplicação comum na máquina do usuário, como também ele pode ser publicado como um Web service possibilitando que ele atenda requisições remotas para o gerenciamento e controle de execução de Web services compostos.

\subsection{WSARch}

A arquitetura WSARCH é uma proposta de arquitetura para a provisão de Web services com qualidade de serviço. A arquitetura tem como objetivo melhorar a provisão dos Web services utilizando-se de critérios de QoS.

A figura 4.5, mostra de forma geral, como é o funcionamento da arquitetura WSARCH. Dentre os componentes dessa arquitetura se destacam:

- Provedor de serviços: Disponibiliza Web services para o cliente. A localização desse serviço deve ser registrada num repositório denominado UDDI. Além disso, o provedor de serviços também disponibiliza ao broker informações sobre a qualidade do serviço oferecido aos clientes.

- Broker: Responsável por realizar a busca de um serviço de acordo com as necessidades do Web service cliente. Deve também gerenciar informações de QoS vindas do provedor de serviços. Outro subcomponente importante é a negociação. O broker tentará obter o melhor serviço de acordo com as informações disponíveis sobre o provedor. Caso contrário, uma decisão deve ser tomada para que ou o serviço seja atendido com critérios de QoS relaxados ou não seja mais atendido. 


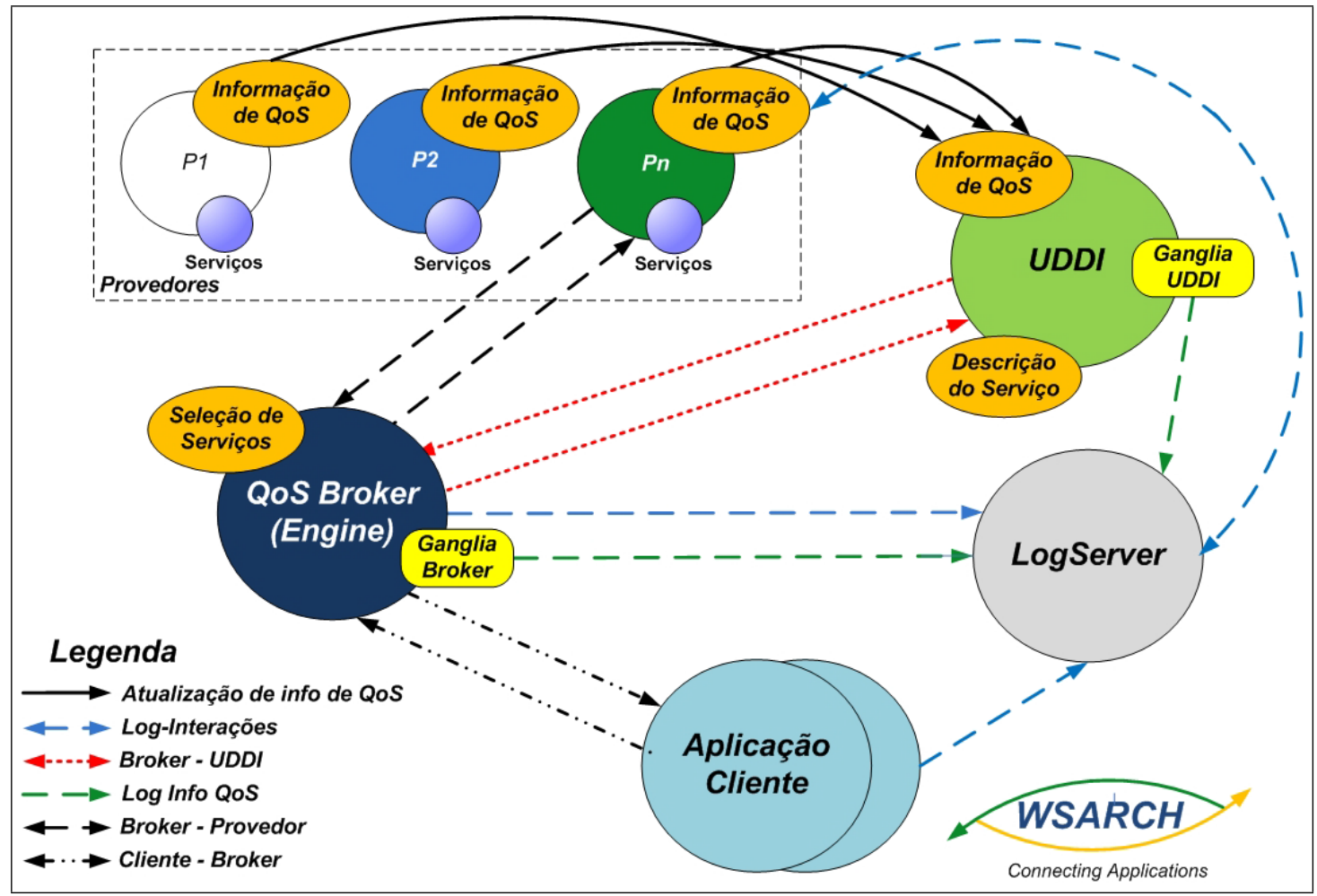

Figura 4.5: Arquitetura WSArch

- UDDI: repositório onde ficam armazenados informações sobre a localização e forma de acesso aos provedores e respectivos Web services oferecidos. Além disso, pode armazenar informações de QoS dos Web services e também as descrições semânticas dos Web services.

- Cliente: Este faz o papel de solicitante de um determinado serviço. O cliente solicita ao broker o Web service que deseja acessar e também informações de QoS. No sistema AWSCS o AWSCE faz o papel de cliente da arquitetura WSArch.

- Log Server: Recebe informações dos componentes da arquitetura, e mantém as transações armazenadas para verificação. É responsável por armazenar também os valores de QoS que o cliente obteve com a execução do Web service. Para esta tese de doutorado, além dos Web services acessados, foi criado um módulo para fazer o registro da execução do Web service composto como um todo no Log Server.

\subsection{Ferramentas utilizadas para desenvolvimento do AWSCS}

O sistema foi desenvolvido utilizando a linguagem JAVA, Apache Tomcat, Apache Axis2 e jUDDI. 


\subsubsection{Apache Tomcat}

Atualmente a Web não possui apenas páginas estáticas, mas também inúmeras páginas dinâmicas, as quais, em sua maioria, contêm conteúdos que são gerados de acordo com a interação do usuário com o site. CGI (Common Gateway Interface) é o mecanismo original que tornou possível a dinamicidade existente em páginas Web. Posteriormente a Microsoft lançou o ASP (Active Server Pages) que permitia a execução de scripts dentro de código HTML. O ASP teve enorme sucesso e foi o catalisador para a linguagem Java para Web, surgindo inicialmente na Web por meio dos applets, aplicações que são executadas no navegador do cliente (Moodie e Mittal, 2007).

A grande contribuição de Java para Web começou com o surgimento dos Servlets. Servlet é uma solução que oferece ao programador Java uma interface para criação de aplicações que podem ser disponibilizadas em servidores Web.

O Tomcat tem sua origem nos desenvolvimentos mais recentes para Servlets. A Sun Microsystems criou o primeiro contêiner de Servlet, Java Web Server, para demonstrar sua solução. No entanto, este servidor não era muito robusto. Ao mesmo tempo, a ASF (Apache Software Foundation) criou o JServ, um engine para Servlets integrada aos servidor Web Apache.

Em 1999, a Sun Microsystems doou o código do Java Web Server para Apache e os dois projetos foram fundidos dando origem ao Tomcat. A versão 3.x foi a primeira da série Tomcat e foi descendente direta do código original provido pela Sun Microsystems para a Apache.

\subsubsection{Apache Axis2}

O Apache Axis2 (Apache eXtensible Interaction System) é um engine para processamento de mensagens SOAP que possui implementações para Java e C++. Diferentemente do Axis 1.0, o Axis2 apresenta diversas melhorias, principalmente em relação ao desempenho e também em relação à modularidade. A arquitetura do Axis2 é separada em componentes (módulos), e subdivide-se em componentes do núcleo e componentes não pertencentes ao núcleo (Perera et al., 2006).

O Axis2 é disponibilizado por meio de um servidor independente que é pouco robusto ou como Web Archive (WAR). WAR é uma forma de distribuição de aplicações Web, onde a aplicação é empacotada em um arquivo mantendo um padrão de pastas para que a aplicação possa ser instalada em qualquer contêiner de servlet. Isso permite instalar o engine axis2 em servidores de aplicação mais robustos como o Apache Tomcat ou outros.

\subsection{3 jUDDI}

Na literatura sobre Web services é apresentado também um protocolo para serviços de diretório que contém as descrições dos Web services, denominado UDDI (Universal Description Discovery and Integration). Esse protocolo funciona como um registro de serviços sendo um importante componente da arquitetura orientada a serviços (Farkas e Charaf, 2003). 
O UDDI permite ainda aos clientes do sistema localizar serviços ou descobrir seus detalhes e permite que registros operacionais sejam mantidos para diferentes propósitos em diferentes contextos. O jUDDI é uma implementação Java open source da especificação do UDDI para Web services (Stam e O'Ree, 2014).

\subsection{Considereções Finais}

Neste capítulo foram apresentados, de maneira detalhada, todos os módulos utilizados na implementação do AWSCS. Com isso é possível ter um entendimento mais claro que como funciona todos os passos do funcionamento do sistema para que se possa entender como foram feitos os experimentos para teste do sistema, e também ajuda a entender os resultados provenientes dos teste.

No capítulo 5, são apresentados cenários de testes criados e respectivos resultados para que seja possível entender como funciona na prática este sistema, e resultados que são possíveis de se obter a partir do AWSCS. 



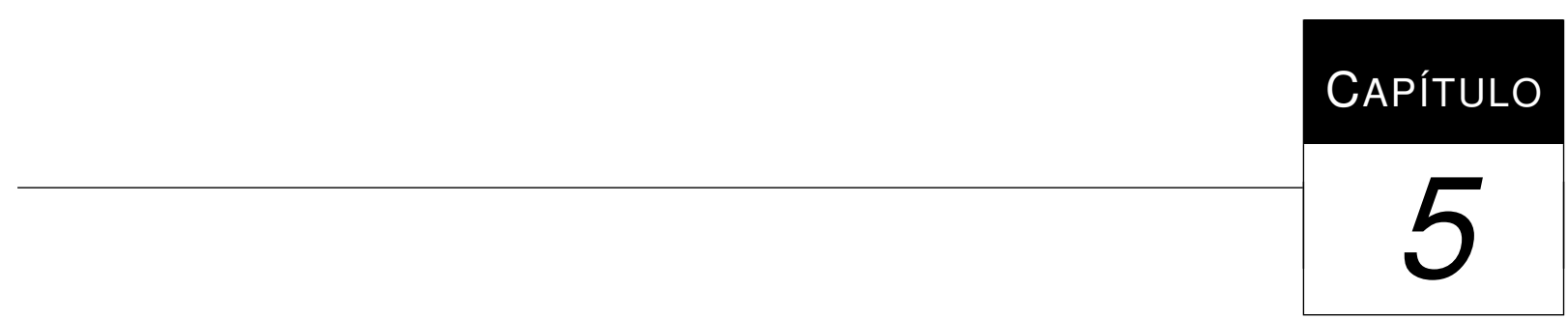

\section{Experimentos}

\subsection{Considerações Iniciais}

Neste capítulo são apresentados os experimentos realizados para demonstrar o sistema proposto nesta tese de doutorado, por meio de testes em diferentes fluxos de Web services. A análise dos resultados é feita com base nos valores dos atributos de QoS obtidos da execução dos Web services. Para isso foram feitos estudos de casos, visando a demonstrar o funcionamento e a adequabilidade do sistema AWSCS ao objetivo proposto, que é exatamente propor e implementar um sistema onde seja possível fazer a avaliação de composição de Web services, baseado em atributos de QoS que dependem da execução para poderem ser medidos.

Como nenhum algoritmo para composição automática foi encontrado para download e teste na literatura disponível para o desenvolvimento desta tese, com o objetivo de teste do AWSCS, fluxos empíricos foram modelados e implementados. Dois cenários foram propostos e executados no AWSCS.

Em um primeiro cenário dois fluxos foram desenvolvidos com o objetivo de resolver um problema de planejamento de viagem. No segundo cenário dois fluxos foram desenvolvidos com o objetivo de criar um fluxo para fazer avaliação de desempenho de sistemas computacionais. Em ambos os cenários o resultado da composição dos fluxos definidos têm a mesma qualidade semântica baseada na requisição do usuário, mas usando diferentes Web services concretos para resolver o problema.

Além disso, é apresentado todo o ambiente utilizado para fazer os experimentos, contendo a quantidade de máquinas reais e virtuais utilizadas, qual a finalidade de cada máquina no ambiente 
projetado, qual conexão de rede foi utilizada na intercomunicação entre as máquinas e ferramentas auxiliares utilizadas para execução dos experimentos.

\subsection{Ambiente de Experimento}

O ambiente utilizado para a realização dos testes foram dois clusters, um que tem como função principal hospedar a WSArch e outro que é utilizado para experimentos gerais. Os clusters ficam localizados no LaSDPC (Laboratório de Sistemas Distribuídos e Programação Concorrente) no ICMC-USP. As especificações das máquinas que compõem o cluster são apresentadas nas tabelas

\section{1 e 5.2 .}

Tabela 5.1: Configuração do cluster WSArch

\begin{tabular}{|c|c|c|c|}
\hline \multicolumn{4}{|c|}{ Ambiente WSARCH } \\
\hline & $\begin{array}{c}\text { Broker, LogServer } \\
\text { e UDDI }\end{array}$ & Hosts & $\begin{array}{l}\text { Máquinas Virtuais } \\
\text { (Provedor) }\end{array}$ \\
\hline Processador & \multicolumn{2}{|c|}{$\begin{array}{l}\text { AMD Processor } \\
\text { Vishera } 4.2 \mathrm{Ghz}\end{array}$} & 2 Virtual Processor \\
\hline Memória & \multicolumn{2}{|c|}{$\begin{array}{l}32 \text { GB RAM DDR3 } \\
\text { Corsair Vegeance }\end{array}$} & 2 GB RAM \\
\hline Disco Rígido & \multicolumn{2}{|c|}{$\begin{array}{l}\text { HD 2TB Seagate } \\
\text { Sata III 7200RPM }\end{array}$} & $50 \mathrm{~GB}$ \\
\hline Sistema Operacional & \multicolumn{2}{|c|}{$\begin{array}{c}\text { Linux Ubuntu Server } \\
12.0464 \text { Bits LTS }\end{array}$} & $\begin{array}{c}\text { Linux Ubuntu Server } 12.04 \\
64 \text { Bits LTS }\end{array}$ \\
\hline \multirow{3}{*}{ Ferramentas } & Java JDK 1.7 & \multirow{3}{*}{ Qemu / KVM } & Java JDK 1.7 \\
\hline & Apache Axis2 1.5 & & Apache Axis2 1.5 \\
\hline & Apache Tomcat 7.0 & & Apache Tomcat 7.0 \\
\hline
\end{tabular}

Tabela 5.2: Configuração do cluster

\begin{tabular}{|c|c|}
\hline \multicolumn{2}{|c|}{ Cluster } \\
\hline Processador & Intel ${ }^{\mathrm{R}}$ Core $^{\mathrm{TM}}$ 2 Quad Processor Q9400 \\
\hline Memória & 8 GB RAM DDR3 Kingston \\
\hline Disco Rígido & HD 160GB Seagate Sata II 7200RPM \\
\hline Sistema Operacional & Linux Ubuntu Server 12.04 64 Bits LTS \\
\hline Ferramentas & Java JDK 1.7 \\
\hline
\end{tabular}

Na figura 5.1 é apresentado um esquema, contendo a quantidade de máquinas utilizadas, e como elas estão conectadas entre si. Toda a rede utilizada é Gigabit.

No cluster WSArch, apresentado na tabela 5.1, foram utilizados 4 máquinas físicas para hospedar os provedores, no entanto cada máquina física carrega 3 máquinas virtuais e cada máquina virtual hospeda um provedor de Web services, gerando um total de 12 provedores de Web services. Para cada máquina virtual existe, na máquina real, uma placa de rede Gigabit dedicada para a máquina virtual. O Broker, UDDI, LogServer e PEESOS cada um foi hospedado em uma máquina real. 
No segundo cluster, apresentado na tabela 5.2, foram hospedados os clientes e também o sistema AWSCS versão stand alone. Portanto para este experimento foram utilizados 5 máquinas com o sistema AWSCS publicado.

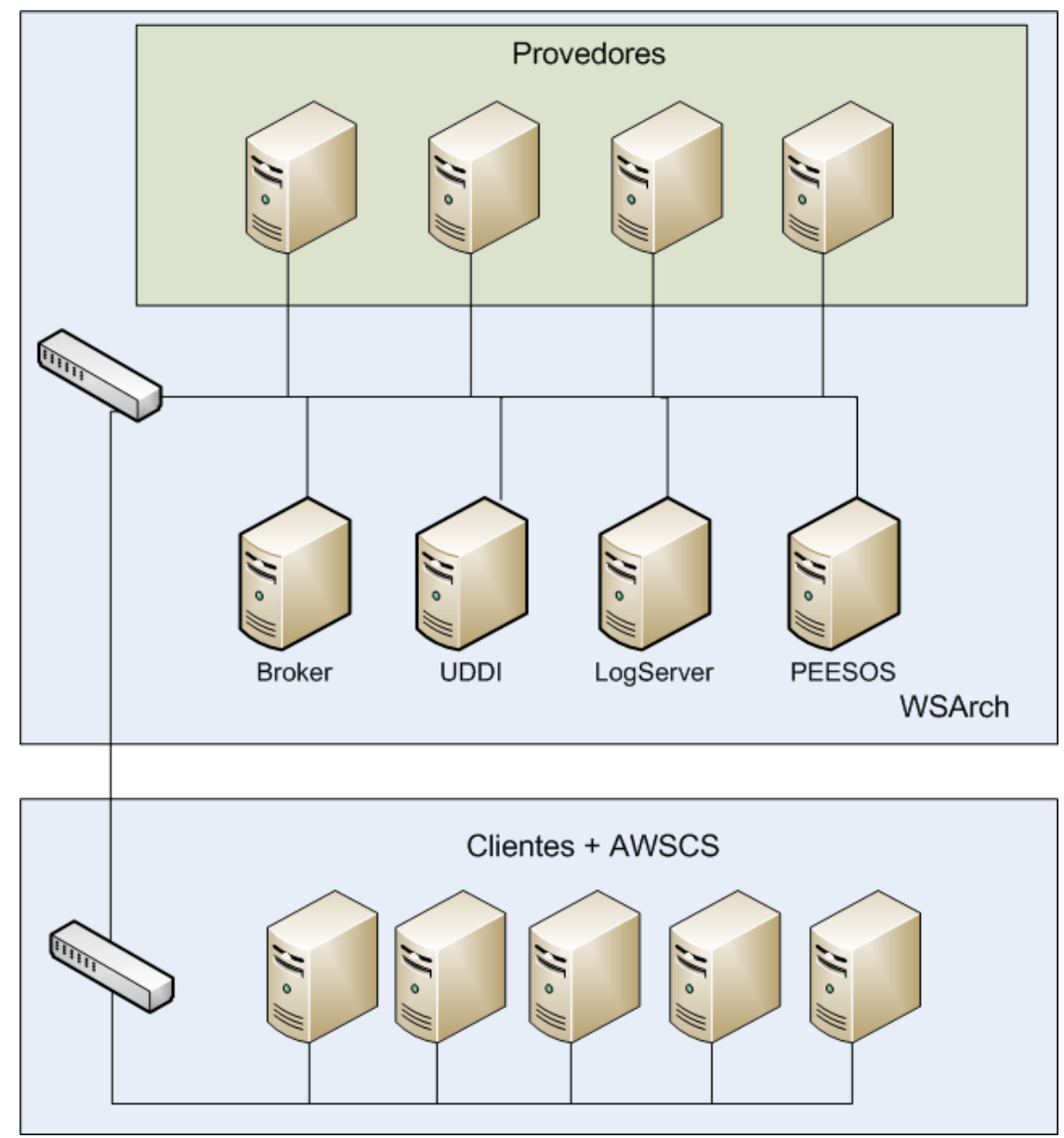

Figura 5.1: Ambiente de Experimento

\subsubsection{Algoritmo de Seleção}

Em (Taher et al., 2005) é proposta a seleção de Web Service para garantia de QoS utilizando-se o algoritmo de distância Euclidiana. A distância Euclidiana é calculada por meio da equação 5.1. O objetivo do algoritmo, neste contexto, é encontrar o Web service com valores de QoS, o mais próximo possível do valor requisitado pelo cliente.

$$
\sqrt{\left(x_{j}-x_{k}\right)^{2}+\left(y_{j}-y_{k}\right)^{2}}
$$

É importante destacar que este algoritmo é para seleção de Web services concretos para a composição e não abstratos. Por isso, este algoritmo tem como único propósito prover QoS na execução e não conseguir a composição automática de Web services. Para o provimento de QoS no contexto deste projeto a seleção dos Web services foi feita por meio dos seguintes critérios: 
- Para a classe Gold o algoritmo visa, para o tempo de resposta buscar o Web service com menor tempo de resposta possível. Para a reputação o objetivo também é buscar o Web service com melhor reputação possível. Já o custo não é prioridade minimizá-lo, mas como também não é prioridade maximizá-lo, é definido para que o algoritmo tente atingir um custo médio. Dessa maneira os atributos de QoS custo e tempo de resposta são a prioridade para a classe Gold.

- Para a classe Silver o algoritmo tem como objetivo, atingir todos os objetivos por meio dos valores médios de cada um dos atributos de QoS disponíveis do Web service.

- Para a classe Bronze o algoritmo tem como objetivo principal minimizar o custo, já os demais atributos são relaxados.

\subsubsection{PEESOS}

Para fazer o planejamento e execução dos experimentos foi utilizada a PEESOS (Planejamento e Execução de Experimentos em Sistemas Orientados a Serviços), como uma ferramenta auxiliar (Nunes et al., 2014). PEESOS é uma ferramenta cujo foco é permitir o planejamento de capacidade e sua execução em SOA. Ela instrui o usuário a realizar um experimento fatorial completo a partir de um conjunto de entradas padrão e oferece um ambiente de testes real, no qual a carga de trabalho é gerada por meio de um ambiente colaborativo.

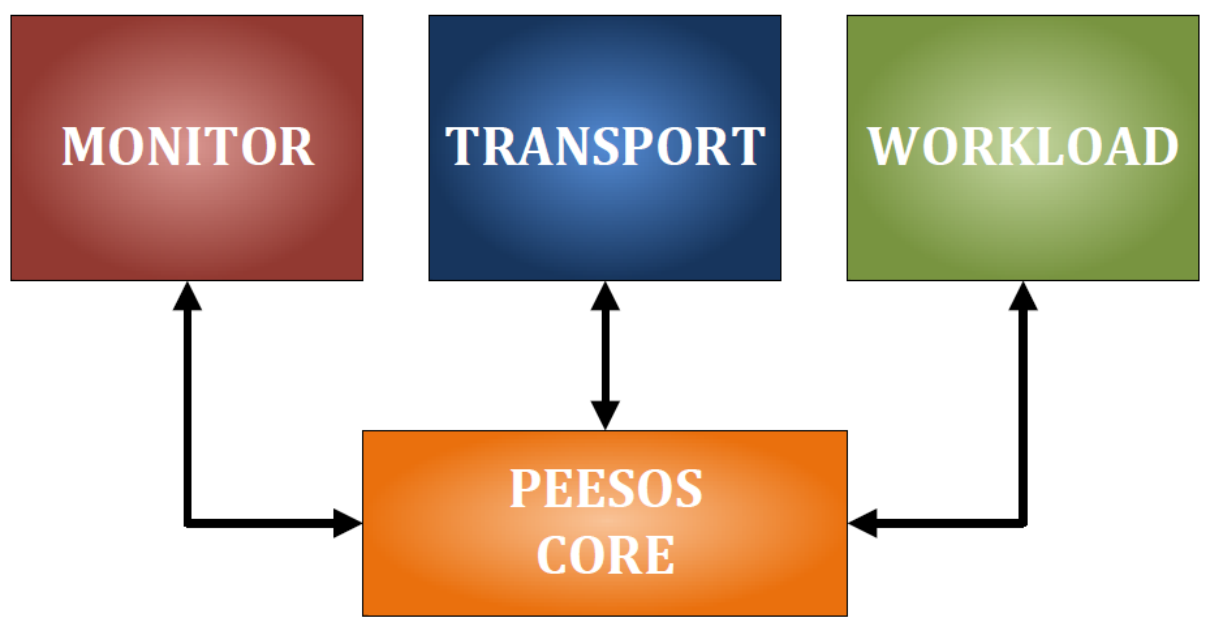

Figura 5.2: Componentes da PEESOS (Nunes et al., 2014)

A estrutura geral da PEESOS é apresentada na figura 5.2. A ferramenta é composta por quatro módulos, os quais são descritos a seguir:

- Módulo Monitor: possui um conjunto de métodos destinados a monitorar disponibilidade dos dispositivos clientes. Toda a informação coletada por este monitor é armazenada em um banco de dados relacional. A localização e disponibilidade dos dispositivos clientes são 
obtidas exclusivamente por meio de uma aplicação que utiliza sockets baseada no modelo cliente-servidor.

- Módulo Transport: possui um conjunto de métodos para transferir dados para clientes. Os dispositivos clientes recebem dados por meio da aplicação cliente. Os dados transferidos para eles podem conter a aplicação que realiza a requisição para os provedores de serviço e as instruções para executar a aplicação cliente.

- Módulo Workload: possui um conjunto de métodos para geração de modelos de carga de trabalho sintética usados para controlar as requisições dos clientes. Estes modelos se baseiam na distribuição de probabilidade para gerar os dados da carga de trabalho.

- Módulo Core: principal módulo da ferramenta contém o conjunto de métodos utilizados para gerenciar o planejamento de experimento e sua execução. Este módulo realiza sincronização entre os módulos. Utiliza o módulo Monitor para determinar quais clientes estão disponíveis para o experimento. O módulo Workload é acionado para gerar a carga de trabalho. Em seguida, o módulo Core, por meio do módulo Transport faz a transferência dos arquivos a serem utilizados no experimento, para os clientes selecionados.

Todos os experimentos realizados nesta tese de doutorado foram feitos com auxílio da PEESOS.

\subsection{Cenário 1}

Na tabela 5.3 são apresentados os contratos SLAs para cada Web service utilizado nos fluxos de composição do cenário 1. Para cada classe do Web service é estipulado um valor que nunca deve ser ultrapassado no caso do tempo de resposta e custo, para a reputação este valor nunca deve ser menor que o requisitado. Estes contratos SLAs são estabelecidos de acordo com as ofertas de QoS disponíveis para cada Web service.

Para usuários da classe Gold, em termos de tempo de resposta, é definido que este usuário consiga o menor tempo de resposta e a melhor reputação possível, para o custo do Web service, o contrato é relaxado, já que usuário da classe Gold pode pagar pelo serviço. Para o usuário da classe Silver o SLA é estabelecido no valor médio para os 3 atributos de QoS utilizados nesta seleção. O usuário da classe Bronze tem como prioridade o menor custo possível, tendo o relaxamento do atendimento tanto do tempo de resposta quanto na reputação.

No cenário 1, foram elaborados dois fluxos com o objetivo de resolver um problema de planejamento de viagem. A qualidade semântica foi considerada igual para os dois fluxos, já que o intuito deste trabalho é avaliar a execução dos mesmos. A requisição considerada para elaboração do fluxo é composta por pedido de hospedagem, transporte para a cidade de destino e volta, traslado dentro da cidade e alguns eventos para entretenimento. 
Tabela 5.3: Acordos SLAs

\begin{tabular}{|c|c|c|c|c|c|c|c|c|c|}
\hline \multirow{2}{*}{ SLA } & \multicolumn{3}{|c|}{$\begin{array}{c}\text { Tempo } \\
\text { de Resposta }\end{array}$} & \multicolumn{3}{c|}{ Custo } & \multicolumn{3}{c|}{ Reputação } \\
\cline { 2 - 10 } & Gold & Silver & Bronze & Gold & Silver & Bronze & Gold & Silver & Bronze \\
\hline Hotel & 7000 & 10000 & 13000 & 200 & 130 & 60 & 3 & 2 & 1 \\
\hline TripBus & 5250 & 6125 & 7000 & 40 & 35 & 30 & 3 & 2 & 1 \\
\hline CityBus & 4250 & 5625 & 7000 & 3 & 3 & 3 & 3 & 2 & 1 \\
\hline Event 1 & 4500 & 5750 & 7000 & 53 & 31,5 & 10 & 3 & 2 & 1 \\
\hline Event 2 & 6500 & 7250 & 8000 & 30 & 25 & 20 & 3 & 2 & 1 \\
\hline Event 3 & 5000 & 6500 & 8000 & 70 & 45 & 20 & 3 & 2 & 1 \\
\hline Night Event & 5000 & 6500 & 8000 & 70 & 45 & 20 & 3 & 2 & 1 \\
\hline Roost & 6000 & 10000 & 14000 & 152 & 81 & 40 & 3 & 2 & 1 \\
\hline Flight & 5400 & 6350 & 7300 & 120 & 110 & 100 & 3 & 2 & 1 \\
\hline Taxi & 4250 & 5125 & 6000 & 30 & 330 & 30 & 3 & 2 & 1 \\
\hline Event Packet & 6500 & 14250 & 22000 & 203 & 126,5 & 50 & 3 & 2 & 1 \\
\hline
\end{tabular}

Na figura 5.3 é apresentado o fluxo 1. O fluxo 1 é formado pelo Web service Hotel relativo a hospedagem, TripBus relativo ao transporte para a cidade destino, CityBus para o traslado interno e os Web services Event1, Event2, Event3 e Night Event para entretenimento.

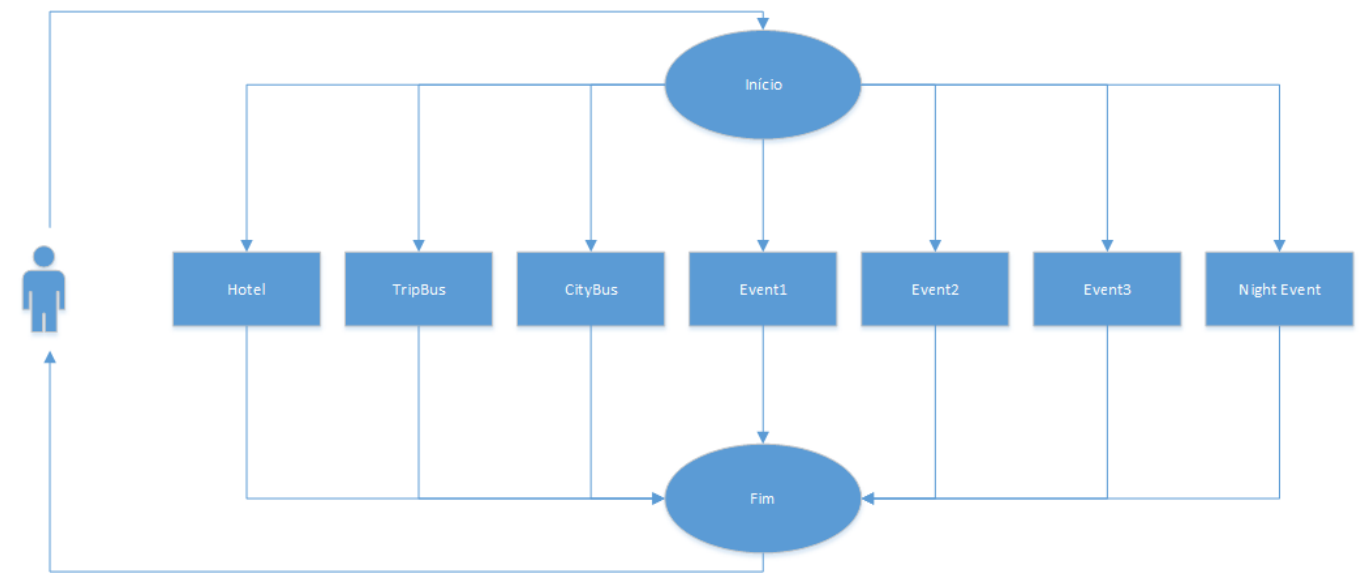

Figura 5.3: Fluxo 1

O fluxo 2, apresentado na figura 5.4, é composto pelos Web services Roost como serviço de hospedagem, Flight para a viagem até a cidade destino, Taxi para o traslado interno e o Web service Event Package, um pacote de eventos responsável por proporcionar o entretenimento ao cliente.

\subsubsection{Experimento 1}

No primeiro experimento do cenário 1, o objetivo foi avaliar o comportamento da execução dos Web services compostos, fluxo 1 e fluxo2, em um cenário onde todos os Web services acessados fossem da mesma classe, a Gold. Na tabela 5.4 são apresentados os fatores e níveis para o experimento 1 do cenário 1 .

Os experimentos foram executados seguindo a combinação fatorial completo e replicação de 10 vezes para cada execução, resultando para este primeiro experimento 40 execuções. Para o 


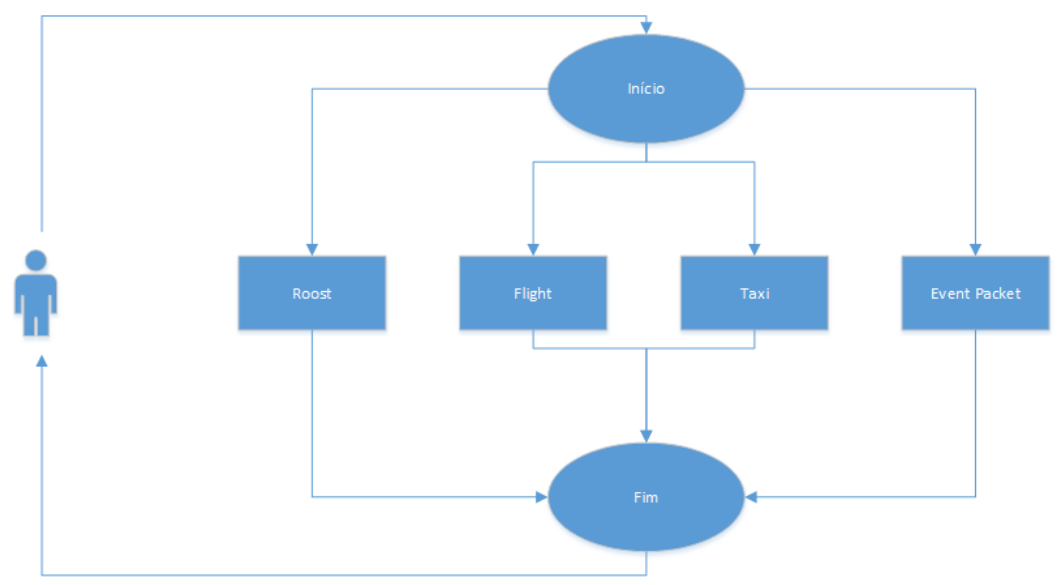

Figura 5.4: Fluxo 2

cálculo do intervalo de confiança foi utilizado $95 \%$ de confiança. A carga utilizada para este experimento é composta por 50 clientes e as execuções são controladas pela PEESOS. A execução segue uma distribuição exponencial, também gerada pela PEESOS, para disparar as requisições destes 50 clientes. O intervalo de disparo das requisições para o experimento 1 são de 3 segundos e 9 segundos.

Tabela 5.4: Planejamento Experimento 1

\begin{tabular}{|c|c|c|}
\hline Fator & Nível 1 & Nível 2 \\
\hline $\begin{array}{c}\text { Algoritmo de Composição } \\
\text { Automática }\end{array}$ & Fluxo 1 & Fluxo 2 \\
\hline Carga & Rajadas a cada 9s & Rajadas a cada 3s \\
\hline
\end{tabular}

Na tabela 5.5 estão especificados os contratos SLA que a execução deve obedecer. Apesar de no cenário 1 todos os Web services serem executados paralelamente, o contrato de tempo de resposta é estabelecido 2 segundos a mais que o tempo de resposta do Web service com o maior tempo de resposta. Isso acontece, porque o sistema necessita de um tempo para montar a chamada e fazê-la ao Web service. Se não acrescentar esse tempo seria impossível cumprir o contrato SLA em qualquer condição que o sistema se encontre.

Tabela 5.5: SLAs definidos

\begin{tabular}{|c|c|c|}
\hline SLA & Fluxo 1 & Fluxo 2 \\
\hline Tempo de Resposta & $9000 \mathrm{~ms}$ & $8000 \mathrm{~ms}$ \\
\hline Custo & $\mathrm{R} \$ 466$ & $\mathrm{R} \$ 505$ \\
\hline Reputação & 3 Estrelas & 3 Estrelas \\
\hline
\end{tabular}

$\mathrm{Na}$ figura 5.5 são apresentados os gráficos referentes aos resultados dos fluxos A e B, onde requisições foram disparadas em rajadas a cada 3 segundos. Para os atributos de QoS custo e reputação, gráficos (b) e (c) respectivamente, não é preciso calcular média ou intervalo de confiança, já que estes atributos não estão associados a execução e replicação da execução do experimento, e sim das escolhas dos Web services a serem executados feitas pelo algoritmo apresentado na seção 5.2.1. 
Analisando-se os resultados é possível afirmar que em termos de reputação ambos os fluxos conseguiram atingir o objetivo que era de conseguir a melhor reputação possível. Em termos de custo é possível perceber que o fluxo 1 obteve valores consideravelmente mais baixos, isso se deve ao fato da definição dos tipos de Web services escolhidos, já que no fluxo 1 a viagem entre as cidades é feita por ônibus, enquanto no fluxo 2 é feita utilizando avião. No fluxo 1 o transporte local é por ônibus, já no fluxo 2 é feito por táxi.

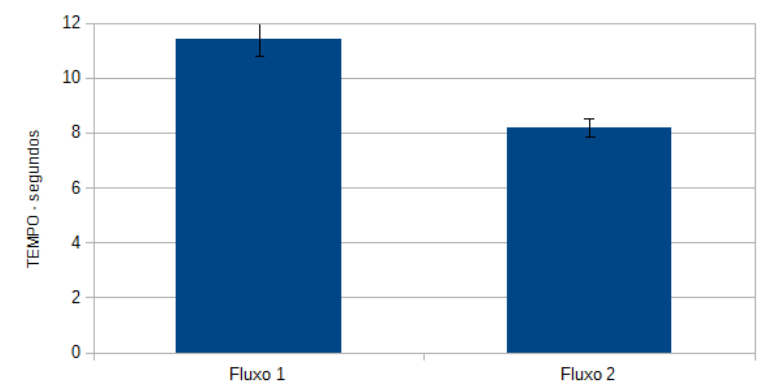

(a) Tempo de resposta

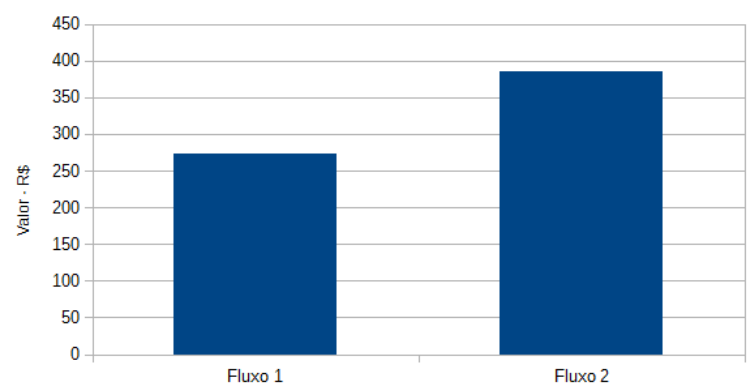

(b) Custo

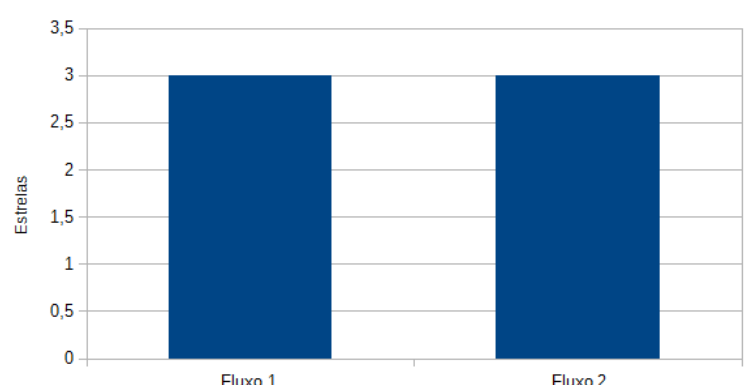

(c) Reputação

Figura 5.5: Fluxo 1 x Fluxo 2 - rajadas a cada 3000ms

Em relação ao tempo de resposta que é um atributo de QoS que depende da execução para ser medido, apesar dos Web services fornecerem um contrato SLA de atendimento, em situações de certa sobrecarga no sistema esses contratos falham e então só com a medição é possível conseguir avaliar os impactos da sobrecarga do sistema na execução dos Web services.

Para a situação de sobrecarga apresentada no gráfico (a) da figura 5.5, onde 50 clientes disparam execuções em rajadas a cada 3 segundos. O fluxo 1 obteve um desempenho consideravelmente pior que o do fluxo 2, já que a média do resultado ultrapassa o limite do contrato em 2 segundos, já o fluxo 2, na média fica pouco acima do seu limite de SLA que foi definido em 8 segundos. Mostrando que, apesar de utilizar serviços diferentes, no experimento 1 o fluxo 2 conseguiu ser mais eficiente que o fluxo 1 , com esta carga submetida ao sistema.

Na figura 5.6 são apresentados os resultados para o experimento 1, no entanto, os clientes dispararam as requisições em rajadas a cada 9 segundos, sobrecarregando pouco o sistema. Como os valores obtidos para os atributos de QoS custo e reputação não são afetados pelo comportamento 
da execução, e os clientes eram todos da mesma classe novamente, a "Gold", os resultados se repetiram, como é possível observar nos gráficos (b) e (c) da figura 5.6.

No gráfico (a) da figura 5.6 é possível notar que o fluxo 2 consegue se manter aproximadamente 2 segundos abaixo da SLA estabelecida, cumprindo assim o contrato para todas as requisições. Já o fluxo 1, consegue na maioria das vezes cumprir o contrato SLA, no entanto para alguns casos isso não aconteceu, já que o intervalo de confiança ficou um pouco acima dos 9 segundos.

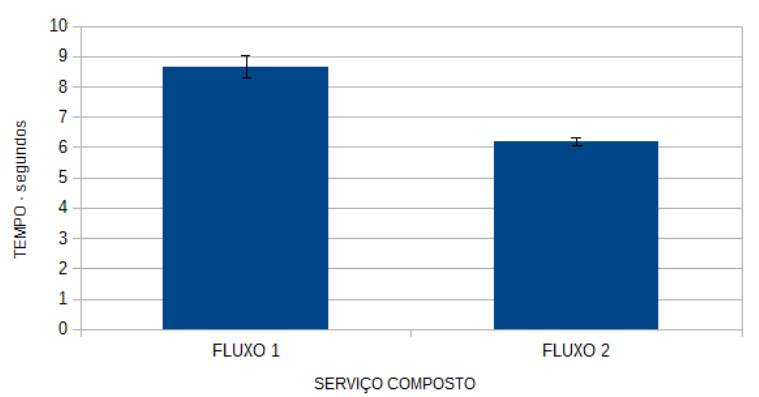

(a) Tempo de resposta

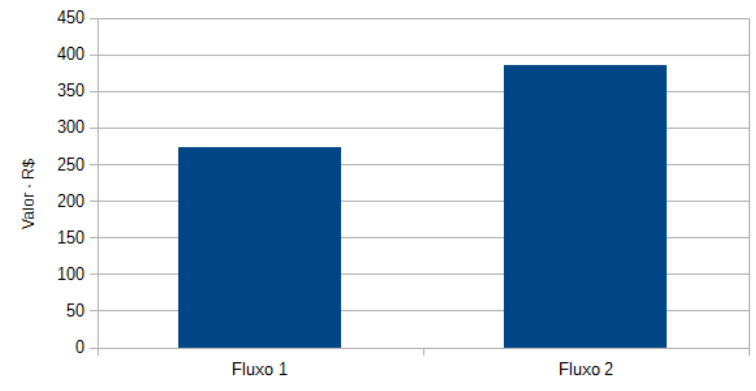

(b) Custo

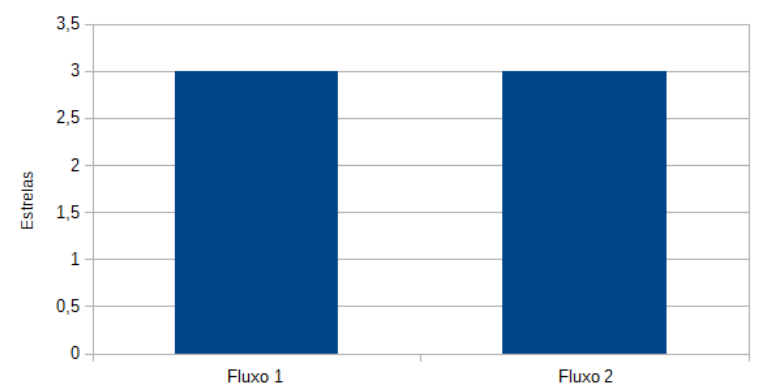

(c) Reputação

Figura 5.6: Fluxo 1 x Fluxo 2 - rajadas a cada 9000ms

Na figura 5.7 são apresentados os fatores que mais influenciaram no experimento. Como os atributos de QoS custo e reputação são fixos, ou seja, não variam de acordo com a execução, não faz sentido fazer este tipo de cálculo para tais fatores, já que sempre resultaria em $100 \%$ para o algoritmo e $0 \%$ para a carga, por isso na figura 5.7 é apresentado a influência de fatores apenas para o tempo de resposta. O cálculo adotado nesta tese de doutorado e utilizado para aferir a influência de fatores foi feito baseado nas técnicas apresentadas no livro (Jain, 1991).

No caso deste primeiro experimento é possível notar que a execução é fundamental para quantificar o quanto o fluxo utilizado influencia no tempo de resposta, já que, o fluxo utilizado na execução tem $41 \%$ de influência nos resultados deste experimento, como é possível observar no gráfico apresentado na figura 5.7.

Além dos resultados já apresentados, é possível também obter por meio do AWSCS, qual foi o resultado por Web service executado, e não apenas dos Web service composto como um todo. Na figura 5.8 são apresentados os tempos de resposta médio com seus intervalos de confiança 


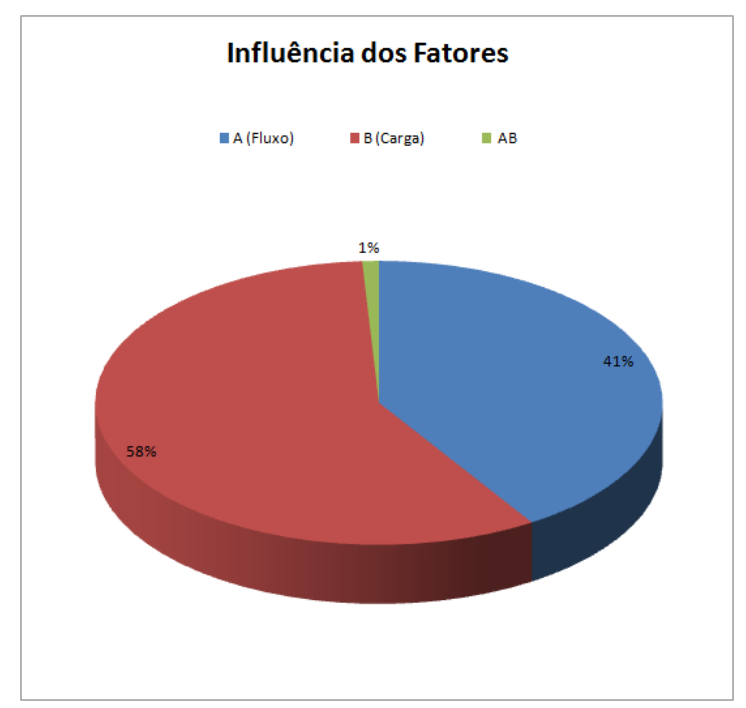

Figura 5.7: Fluxo 1 x Fluxo 2 - Influência dos Fatores

para a execução de cada Web service de maneira individual. Este tempo de resposta é medido da requisição feita pelo AWSCS ao Provedor de Web services.

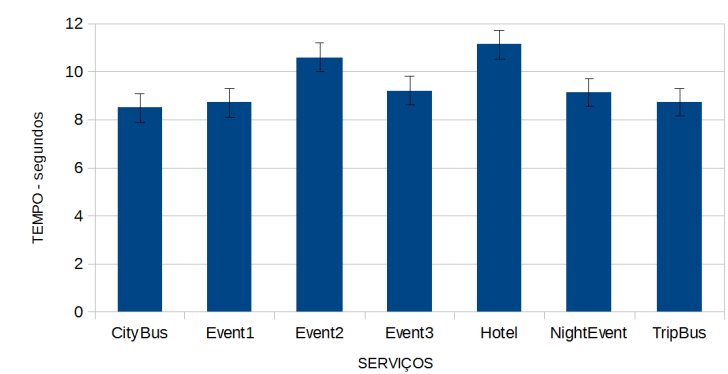

(a) Tempo de resposta - Fluxo 1 - rajadas a cada $3 \mathrm{~s}$

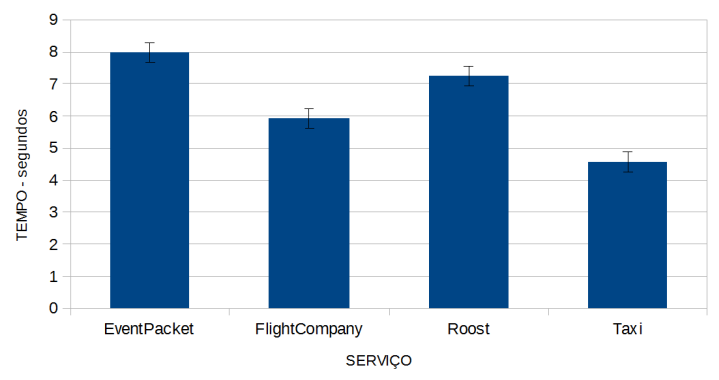

(c) Tempo de resposta - Fluxo 2 - rajadas a cada $3 \mathrm{~s}$

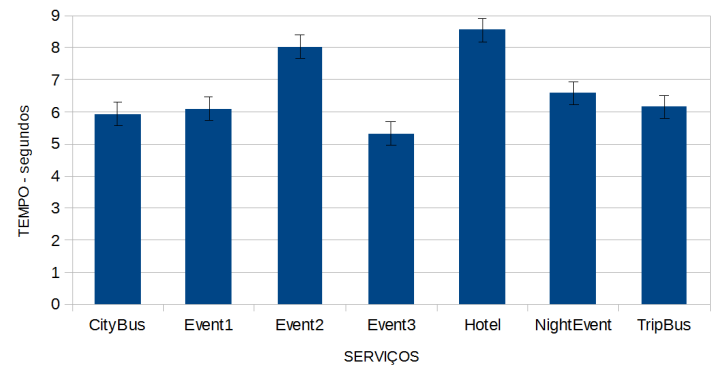

(b) Tempo de resposta - Fluxo 1 - rajadas a cada 9s

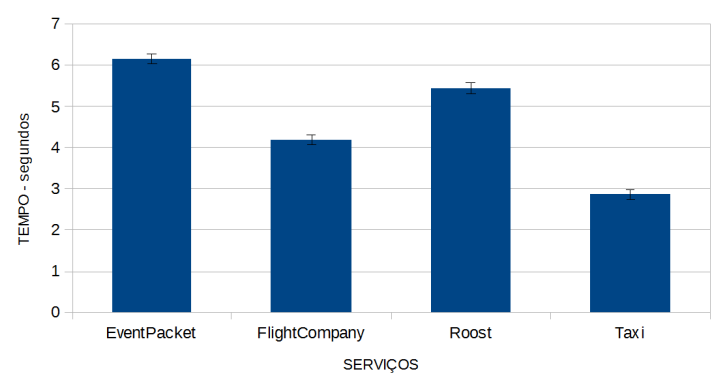

(d) Tempo de resposta - Fluxo 2 - rajadas a cada 9s

Figura 5.8: Tempo de resposta por Web service

Na figura 5.9 são apresentados os custos para utilização de cada Web service individualmente. Como os resultados para o custo são independentes da carga submetida ao sistema, não é necessário apresentar o valor do custo para cada situação de carga. 


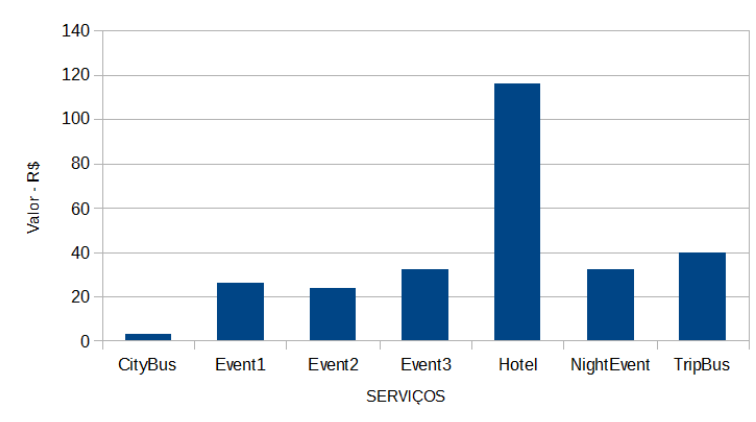

(a) Custo - Fluxo 1

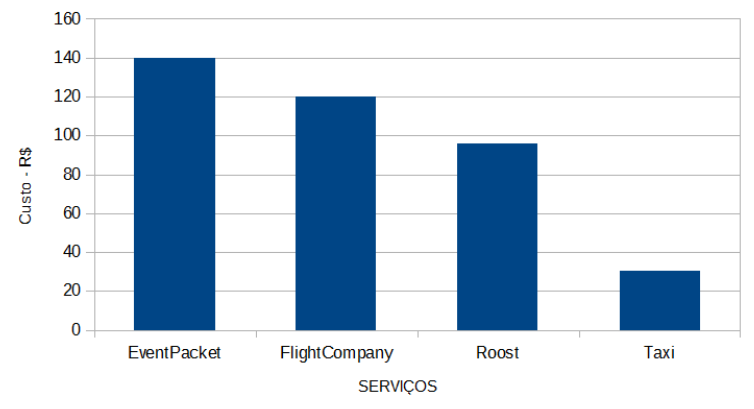

(b) Custo - Fluxo 2

Figura 5.9: Custo por Web service

Na figura 5.10 são apresentadas a reputação de cada Web service individualmente. Para a reputação, assim como para o custo, o resultado é independente da carga submetida ao sistema, por isso não é necessário apresentar a reputação para cada situação de carga.

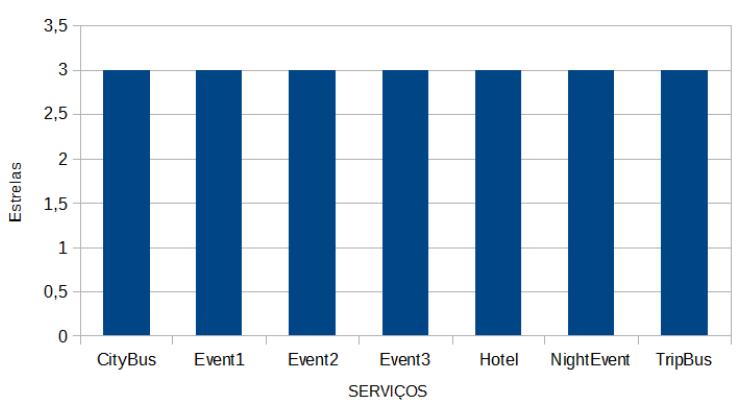

(a) Reputacao - Fluxo 1

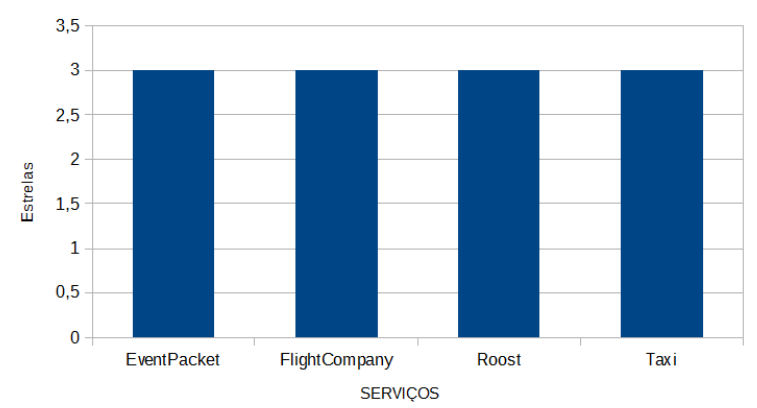

(b) Reputacao - Fluxo 2

Figura 5.10: Reputação por Web service

\subsubsection{Experimento 2}

No experimento 2, o objetivo foi avaliar os fluxos 1 e 2, em um cenário onde a SLA era diferente para 5 tipos de clientes utilizados. Na tabela 5.6 são apresentadas as classes para cada Web service acessado. Na tabela 5.7 são apresentados os SLAs definidos para cada um dos 5 clientes de cada fluxo.

O planejamento do experimento 2 é apresentado na tabela 5.8, com dois níveis para o fator fluxo, fluxo 1 e 2, e 2 níveis para o fator Carga, rajadas a cada 9 e 1 segundos.

Assim como no experimento 1, os experimentos foram executados seguindo a combinação fatorial completo e replicação de 10 vezes para cada execução. Apesar de no experimento 2 ser feita a utilização de 3 fatores e o terceiro fator tendo 5 níveis, foram feitas 40 execuções, já que os 5 clientes eram sempre disparados de maneira concorrente entre si e não isoladamente. Para o cálculo do intervalo de confiança foi utilizado $95 \%$ de confiança. A carga utilizada para este experimento 
Tabela 5.6: Classes de QoS para cada Web service e cliente

\begin{tabular}{|c|c|c|c|c|c|}
\hline \multicolumn{7}{|c|}{ Fluxo 1 } \\
\hline Cliente & C1 & C2 & C3 & C4 & C5 \\
\hline Hotel & bronze & silver & gold & gold & bronze \\
\hline Citybus & bronze & silver & gold & silver & bronze \\
\hline Tripbus & bronze & silver & gold & silver & gold \\
\hline Event1 & bronze & silver & gold & gold & silver \\
\hline Event2 & gold & silver & gold & silver & silver \\
\hline Event3 & bronze & silver & bronze & bronze & silver \\
\hline NightEvent & bronze & silver & gold & gold & silver \\
\hline \multicolumn{7}{|c|}{ Fluxo 2 } \\
\hline Cliente & C1 & C2 & C3 & C4 & C5 \\
\hline Roost & bronze & silver & gold & gold & bronze \\
\hline Taxi & bronze & silver & gold & silver & bronze \\
\hline FlightCompany & bronze & silver & gold & silver & gold \\
\hline EventPacket & silver & silver & gold & silver & silver \\
\hline
\end{tabular}

Tabela 5.7: SLAs definidos para cada cliente

\begin{tabular}{|c|c|c|c|c|c|}
\hline \multicolumn{7}{|c|}{ Fluxo 1 } \\
\hline Cliente & C1 & C2 & C3 & C4 & C5 \\
\hline Tempo de Resposta & $14000 \mathrm{~ms}$ & $12000 \mathrm{~ms}$ & $10000 \mathrm{~ms}$ & $10000 \mathrm{~ms}$ & $14000 \mathrm{~ms}$ \\
\hline Custo & 173 & 314,5 & 416 & 406 & 239,5 \\
\hline Reputação & 1 & 2 & 3 & 2 & 2 \\
\hline \multicolumn{7}{|c|}{ Fluxo 2 } \\
\hline Cliente & C1 & C2 & C3 & C4 & C5 \\
\hline Tempo de Resposta & $16000 \mathrm{~ms}$ & $12000 \mathrm{~ms}$ & $8000 \mathrm{~ms}$ & $12000 \mathrm{~ms}$ & $14000 \mathrm{~ms}$ \\
\hline Custo & 260 & 437,5 & 505 & 418,5 & 296,5 \\
\hline Reputação & 1 & 2 & 3 & 2 & 2 \\
\hline
\end{tabular}

é composta por 50 clientes, 10 clientes de cada tipo, e as execuções são controladas pela PEESOS. A execução segue uma distribuição exponencial, também gerada pela PEESOS, para disparar as requisições destes 50 clientes. $\mathrm{O}$ intervalo de disparo das requisições para o experimento 2 são de 1 segundo e 9 segundos.

Tabela 5.8: Planejamento Experimento 2

\begin{tabular}{|c|c|c|c|c|c|}
\hline Fator & Nível 1 & Nível 2 & Nível 3 & Nível 4 & Nível 5 \\
\hline $\begin{array}{c}\text { Algoritmo de Composição } \\
\text { Automática }\end{array}$ & Fluxo 1 & Fluxo 2 & - & - & - \\
\hline Carga & Rajadas a cada 9s & Rajadas a cada 1s & - & - & - \\
\hline Clientes & C1 & C2 & C3 & C4 & C5 \\
\hline
\end{tabular}

Na figura 5.11 são apresentados os resultados para o tempo de resposta para as execução do fluxo 1 e fluxo 2. Em casos onde as rajadas ocorrem a cada 1 segundo, isso implica em uma maior carga ao sistema, quando comparado a rajadas disparadas a cada 9 segundos. Assim como no experimento 1, o cliente C3 que requisita a maioria dos Web services em classe Gold para ambos os fluxos, obteve melhor desempenho no fluxo 2 que o fluxo 1 . No caso dos demais clientes, todos obtiveram melhor desempenho no fluxo 1 que no fluxo 2 para sobrecarga baixa, rajadas a cada 
9 segundo. Situação que mudou para sobrecarga alta, rajadas a cada 1 segundo, onde todas as execuções para todos o clientes do fluxo 2 obtiveram desempenho melhor que os do fluxo 1 .

Analisando-se os SLAs do fluxo 1 com baixa sobrecarga, é possível perceber que para os clientes $\mathrm{C} 1, \mathrm{C} 2$ e C4, os SLAs de tempo de resposta foram respeitados, para o cliente C3, ficou na média aproximadamente 2 segundos acima do SLA e para o cliente C5, ficou na média, alguns décimos de segundo acima do SLA estabelecido. Em situação de alta sobrecarga, é possível observar que para o fluxo 1, todos os clientes desrespeitam o SLA e o atraso na entrega do resultado variou bastante de acordo com o SLA contratado por cada cliente.

Em relação aos SLAs do fluxo 2 com baixa sobrecarga, é possível observar que apenas os clientes $\mathrm{C} 1$ e C3, conseguem respeitar o SLA, tendo desempenho nessa situação pior que o fluxo 1, já para sobrecarga alta, com o fluxo 2, apesar de como no fluxo 1 não conseguir respeitar o SLA para nenhum cliente, é possível observar que proporcionalmente no acordo de SLA para o fluxo 2, o atraso na entrega da resposta é menor que para o fluxo 1 , fazendo com que em um cenário de sobrecarga alta, o fluxo 2 tenha melhor desempenho para o tempo de resposta que o fluxo 1 .

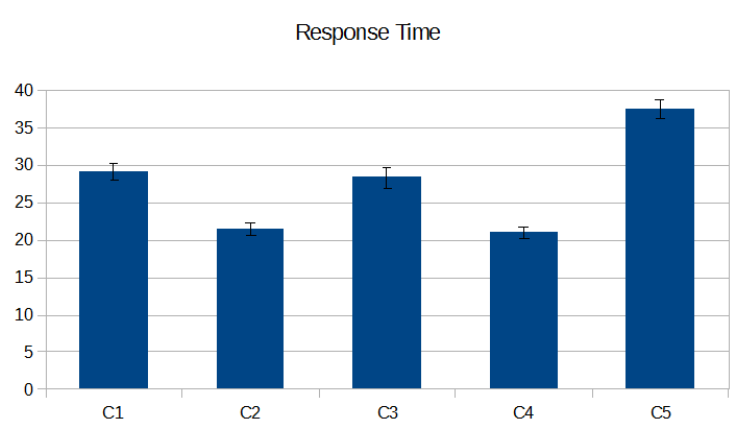

(a) Tempo de resposta - Fluxo 1 - rajadas a cada $1 \mathrm{~s}$

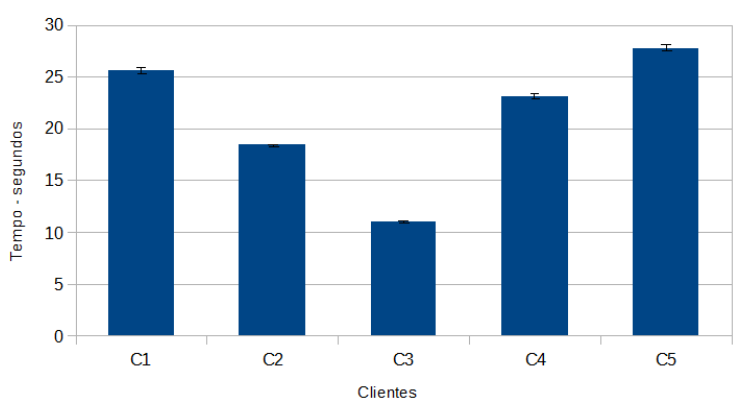

(c) Tempo de resposta - Fluxo 2 - rajadas a cada $1 \mathrm{~s}$

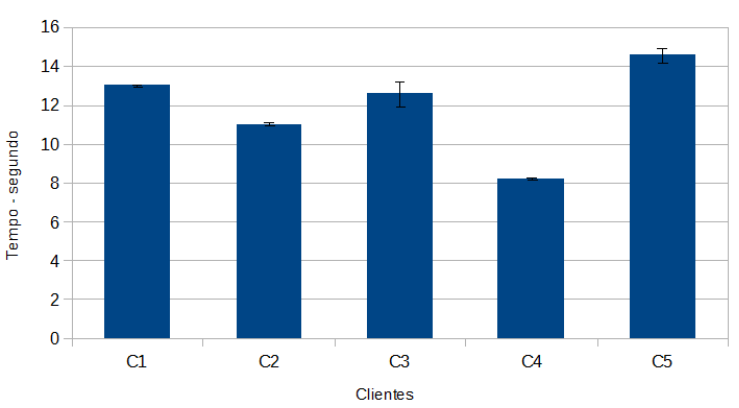

(b) Tempo de resposta - Fluxo 1 - rajadas a cada $9 \mathrm{~s}$

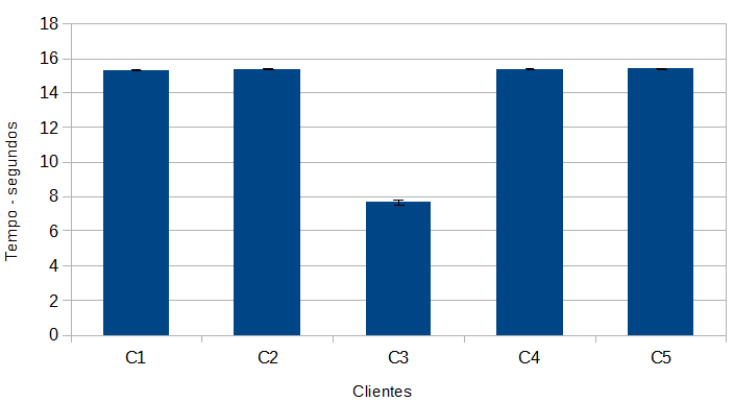

(d) Tempo de resposta - Fluxo 2 - rajadas a cada 9s

Figura 5.11: Tempo de resposta Fluxo 1 x Fluxo 2 - QoS Diferente para cada cliente

Na figura 5.12 são apresentados os custos para os SLAs dos Web services contratados por cada um dos 5 clientes. Assim como no experimento 1 todos os 2 fluxos conseguem atender os contratos SLA, e novamente, o fluxo 1 tem o custo menor em relação ao fluxo 2 independente do SLA do cliente. 


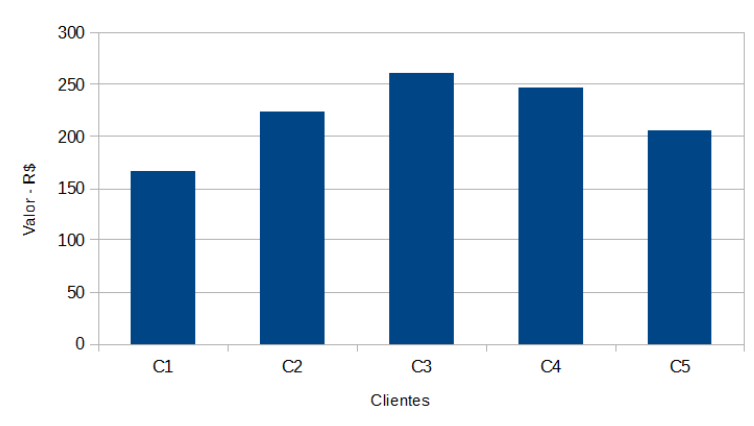

(a) Custo - Fluxo 1

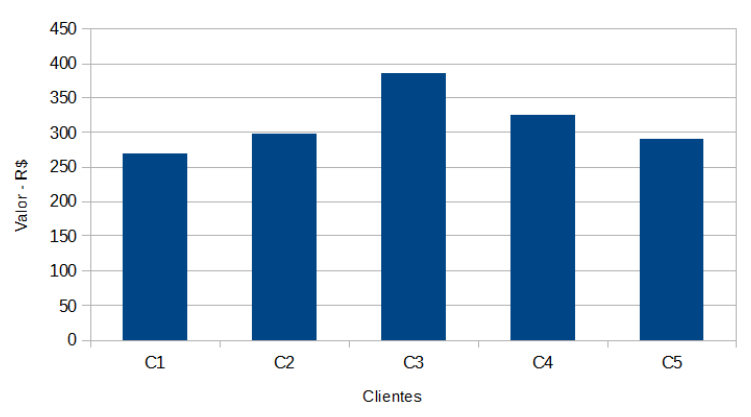

(b) Custo - Fluxo 2

Figura 5.12: Custo Fluxo 1 x Fluxo 2 - QoS diferente para cada cliente

Na figura 5.13 são apresentadas as reputações para os SLAs dos Web services contratados por cada um dos 5 clientes. Em relação à reputação é possível observar que em ambos os fluxos, os contratos SLAs são respeitados e também atingindo valores bastante similares para ambos os casos, até porque o intervalo de valores que a reputação permite ser atingido é relativamente restrito.

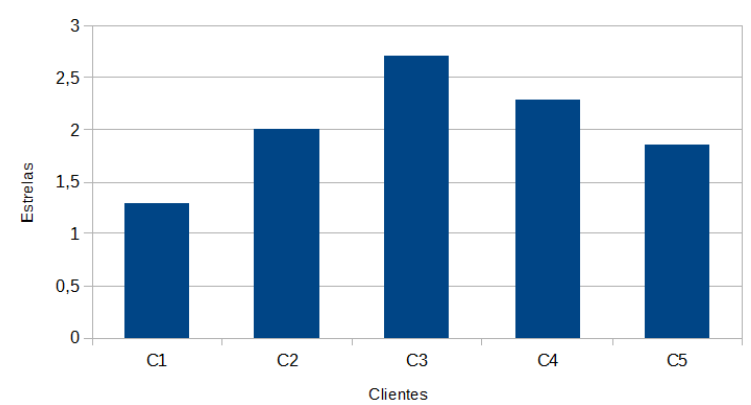

(a) Reputação - Fluxo 1

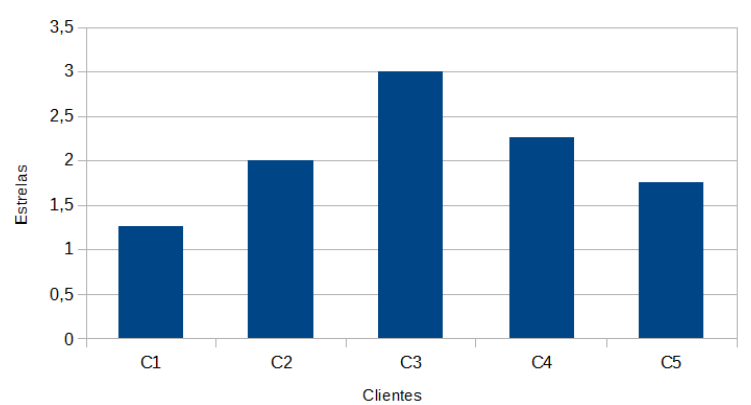

(b) Reputacao - Fluxo 2

Figura 5.13: Reputação Fluxo 1 x Fluxo 2 - SLA diferente para cada cliente

Para o experimento 2 do cenário 1, foi muito difícil fazer a análise de influência de fatores, pelos seguintes motivos:

- O primeiro motivo é que são 5 clientes diferentes, gerando 5 níveis no fator tipos de cliente, sendo que a influência de fatores só é possível isolando níveis 2 a 2 . Por isso se decidiu apresentar a influência de fatores para apenas algumas combinações do fator tipos de cliente. As combinações utilizadas foram $\mathrm{C} 1$ com $\mathrm{C} 2, \mathrm{C} 1$ com $\mathrm{C} 3$ e $\mathrm{C} 2$ com C3.

- Como a variação da carga é muito alta, na maioria dos cálculos feitos, somente ela influenciava no resultado do experimento. Por isso se decidiu isolar a carga na análise de influência de fatores. Assim são apresentados dois gráficos para influência de fatores para cada combinação, um para carga baixa e outro para carga alta.

Na figura 5.14 são apresentados os gráficos com a porcentagem que os fatores tipo de fluxo e tipo de cliente impactaram nos resultados. Na figura 5.14 a influência dos fatores é calculada 
com os níveis tipos de cliente C1 e C2 isolados. No gráfico (a) são apresentados os resultados onde as requisições eram disparadas em rajadas a cada 1 segundo e no gráfico (b) rajadas a cada 9 segundos.

$\mathrm{Na}$ influência de fatores apresentada no gráfico (a) é possível observar que o tipo de cliente influenciou em $84 \%$ e o fator fluxo influenciou em $16 \%$, já a interação entre os dois fatores não influenciou nestes resultados. No gráfico (b), em uma situação de baixa sobrecarga no sistema, o cenário já se inverte completamente. Neste caso, o fluxo foi o fator que mais influenciou, chegando a $85 \%$ de influência, enquanto o fator tipo de cliente influenciou em $7 \%$. A interação dos dois fatores, influenciou em $8 \%$ para esta situação do experimento.

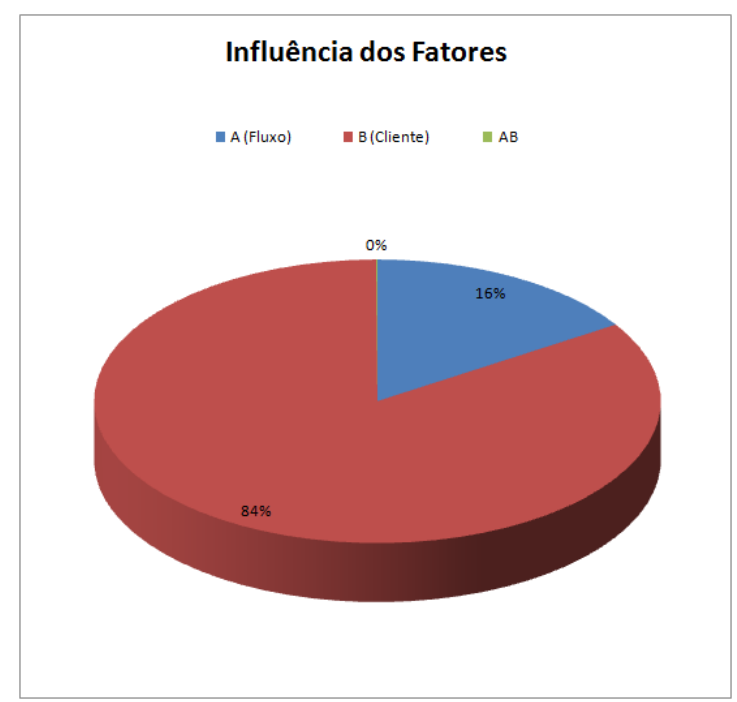

(a) Rajadas a cada $1 \mathrm{~s}$

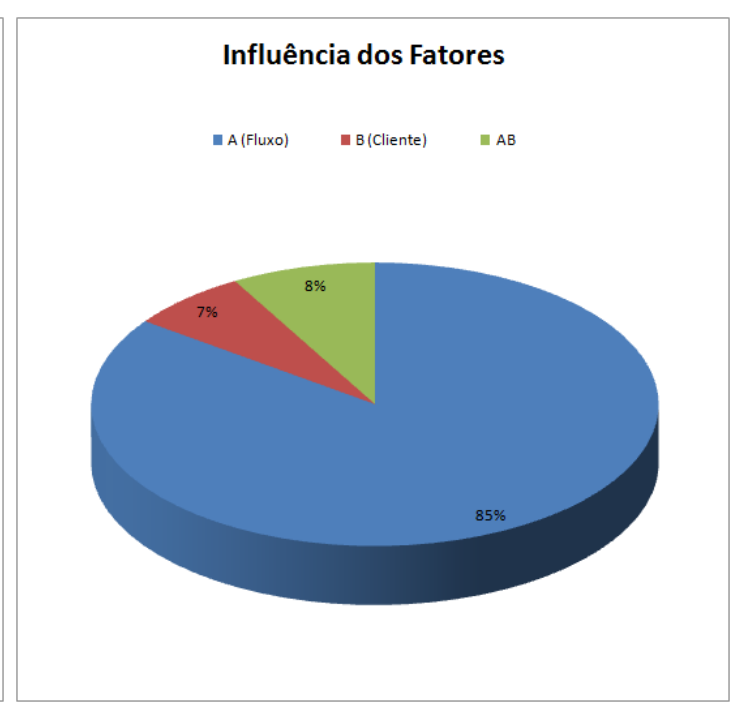

(b) Rajadas a cada $9 \mathrm{~s}$

Figura 5.14: Influência de Fatores C1 com C2 - Tempo de Resposta

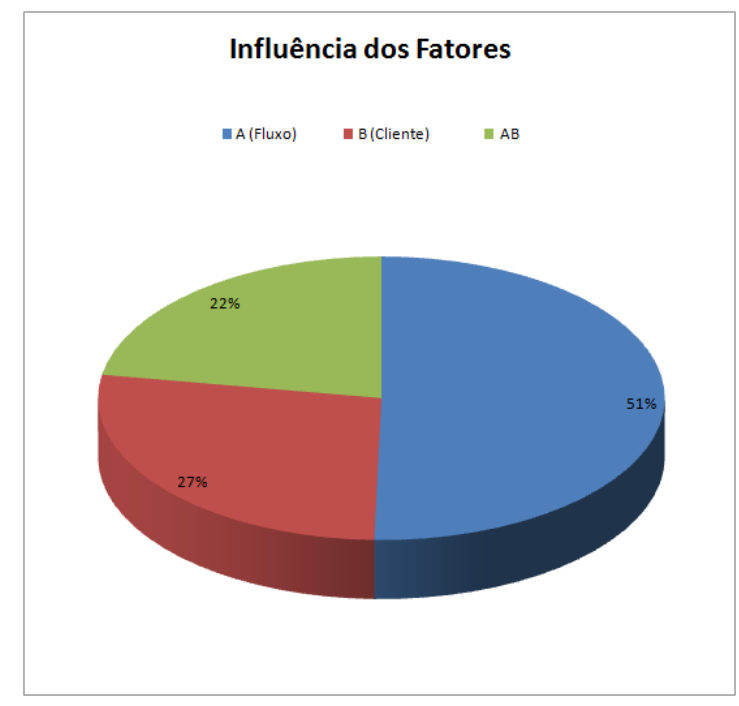

(a) Rajadas a cada $1 \mathrm{~s}$

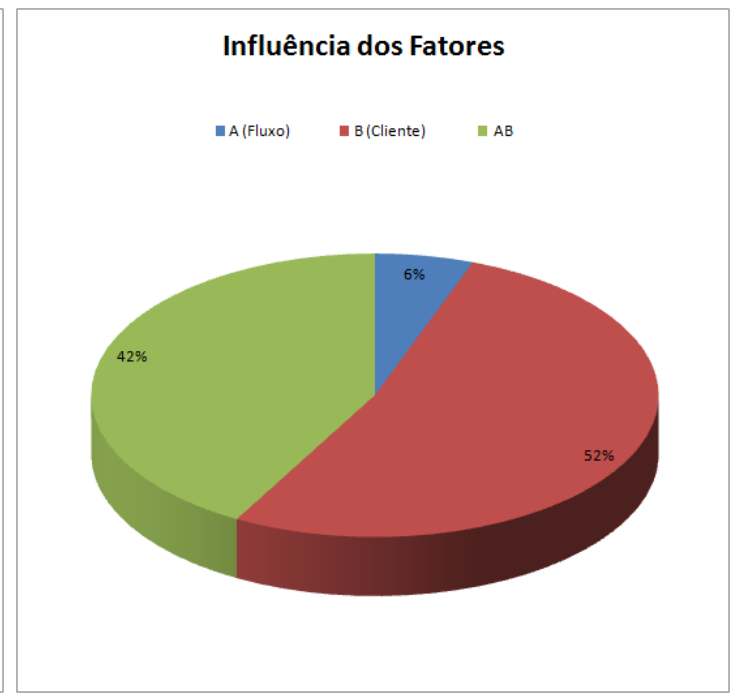

(b) Rajadas a cada $9 \mathrm{~s}$

Figura 5.15: Influência de Fatores C1 com C3 - Tempo de Resposta 
Na figura 5.15 são apresentadas as influências dos fatores para os clientes C1 e C3 de maneira isolada. Quando se analisa a influência dos fatores para esses clientes, é possível observar que a influência de fatores obteve comportamento completamente diferente se comparado com as influências apresentadas na figura 5.14.

No gráfico (a) da figura 5.15, onde é aplicada alta sobrecarga, a influência de fatores apresentada aponta que nestes resultados o fator fluxo influenciou em $51 \%$, o fator cliente $27 \%$ e a interação entre os dois fatores $22 \%$. No gráfico (b) da figura 5.15, novamente a influência dos fatores se inverte, neste caso, o fator tipo de cliente influenciou em $52 \%$ no resultado, o fluxo influenciou em $6 \%$ e a interação dos fatores influenciou em $42 \%$.

Na figura 5.16 são apresentadas as influências dos fatores para os clientes C2 e C3. Para os resultados da influência de fatores com esta combinação foi obtido mais um cenário completamente distinto.

No gráfico (a) da figura 5.16, onde há sobrecarga alta, o fator tipo de fluxo influenciou em $67 \%$ no resultado, o fator tipo de cliente, isoladamente, influenciou $0 \%$, mas a interação dos dois fatores teve influência de 33\%. No gráfico (b) da figura 5.16 são apresentadas as influencias de fatores para baixa sobrecarga, novamente com resultados totalmente diferentes. Neste caso o fator fluxo influenciou $0 \%$ isoladamente, o fator tipo de cliente influenciou $31 \%$ nos resultados e a interação dos dois fatores influenciou em $69 \%$.

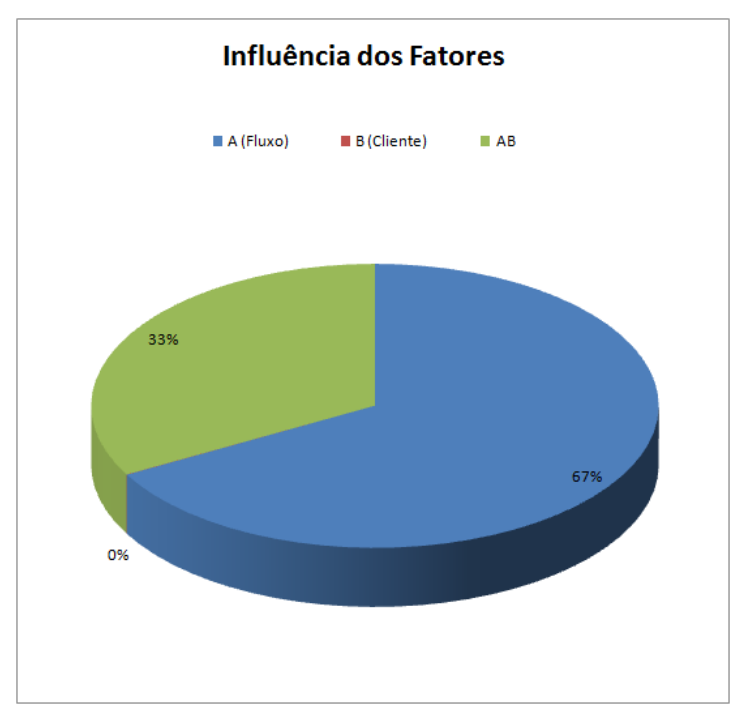

(a) Rajadas a cada $1 \mathrm{~s}$

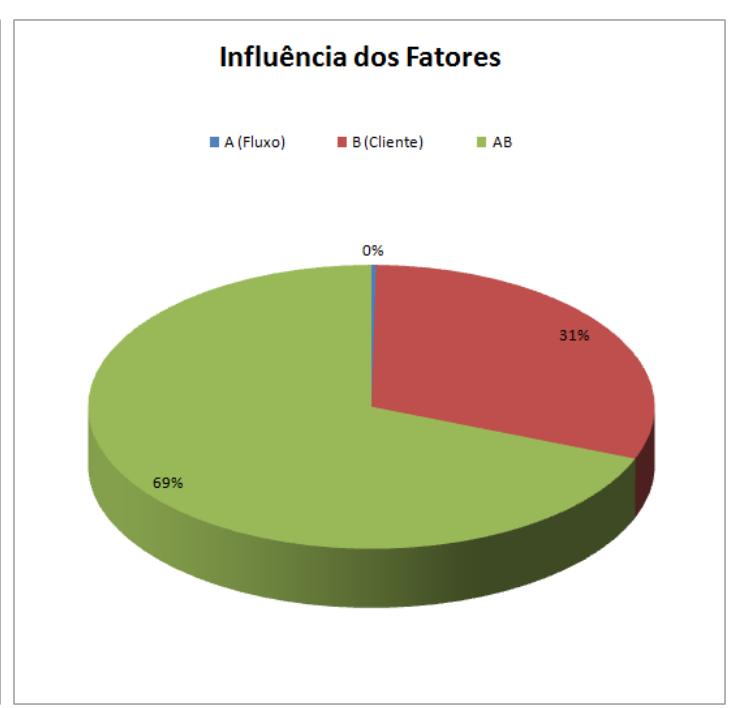

(b) Rajadas a cada $9 \mathrm{~s}$

Figura 5.16: Influência de Fatores $C 2$ com C3 - Tempo de Resposta

Na figura 5.17 são apresentadas as influências dos fatores para os clientes (a) C1 e C2, (b) C1 e C3 e (c) C2 e C3, considerando a variável de resposta custo.

No gráfico (a) da figura 5.17, a influência dos fatores apresentada aponta que nestes resultados o fator fluxo influenciou em $80 \%$, o fator cliente $18 \%$ e a interação entre os dois fatores $2 \%$. No gráfico (b) da figura 5.17, o fator fluxo influenciou em 54\% no resultado, o fator cliente influenciou 
em $46 \%$ e a interação dos fatores influenciou em $0 \%$. No gráfico (c), novamente o fator que mais influenciou no resultado foi o fluxo com $60 \%$, o fator cliente influenciou em $27 \%$ e a interação dos fatores influenciou $4 \%$.

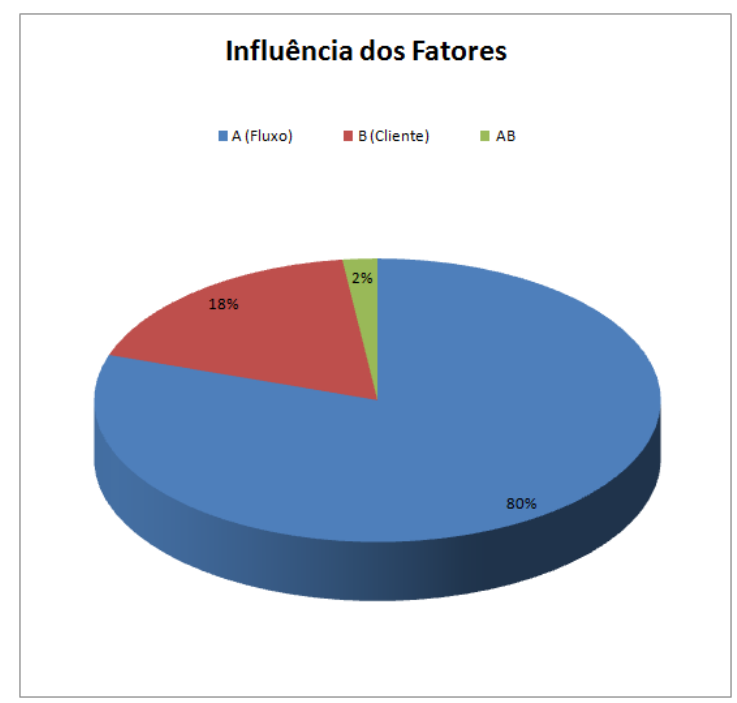

(a) $\mathrm{C} 1$ com $\mathrm{C} 2$

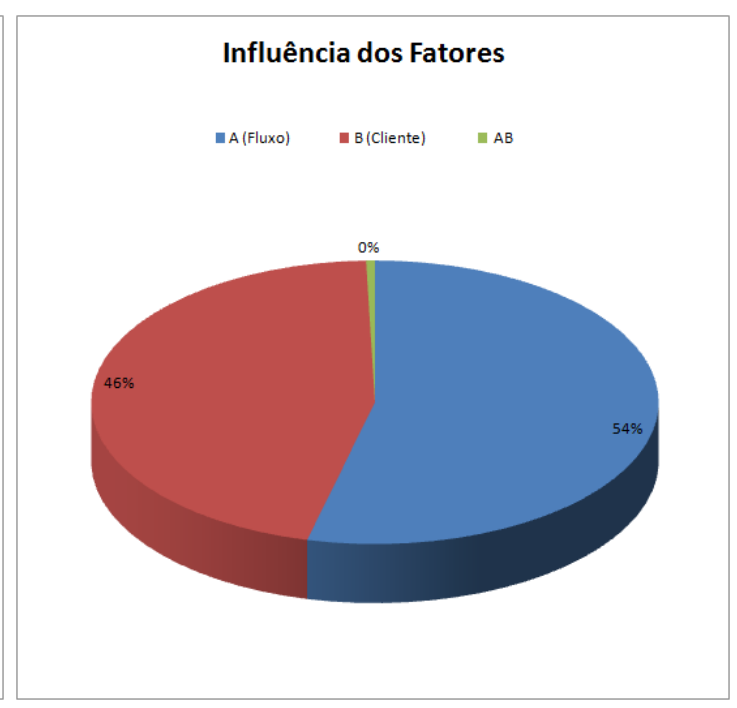

(b) $\mathrm{C} 1$ com $\mathrm{C} 3$

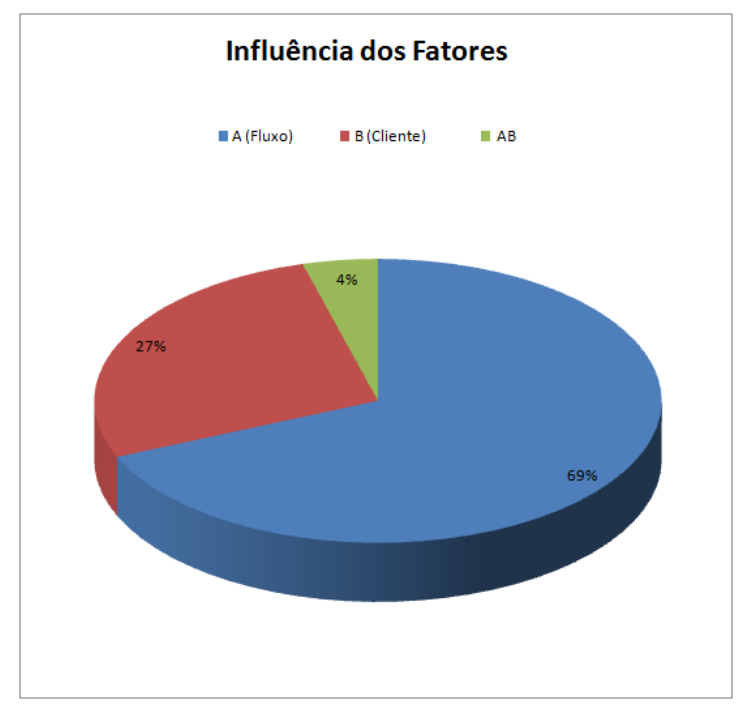

(c) $\mathrm{C} 2$ com $\mathrm{C} 3$

Figura 5.17: Influência de Fatores - Custo

Na figura 5.17 são apresentadas as influências dos fatores para os clientes (a) C1 e C2, (b) C1 e C3 e (c) C2 e C3, considerando a variável de resposta reputação.

No gráfico (a) da figura 5.17, a influência dos fatores apresentada aponta que nestes resultados o fator fluxo influenciou em $80 \%$, o fator cliente $18 \%$ e a interação entre os dois fatores $2 \%$. No gráfico (b) da figura 5.17, o fator fluxo influenciou em 54\% no resultado, o fator cliente influenciou em $46 \%$ e a interação dos fatores influenciou em $0 \%$. No gráfico (c), novamente o fator que mais influenciou no resultado foi o fluxo com $60 \%$, o fator cliente influenciou em $27 \%$ e a interação dos 
fatores influenciou 4\%. Com isso é possível observar que no caso do custo, o fator fluxo foi o que mais influenciou nos resultados.

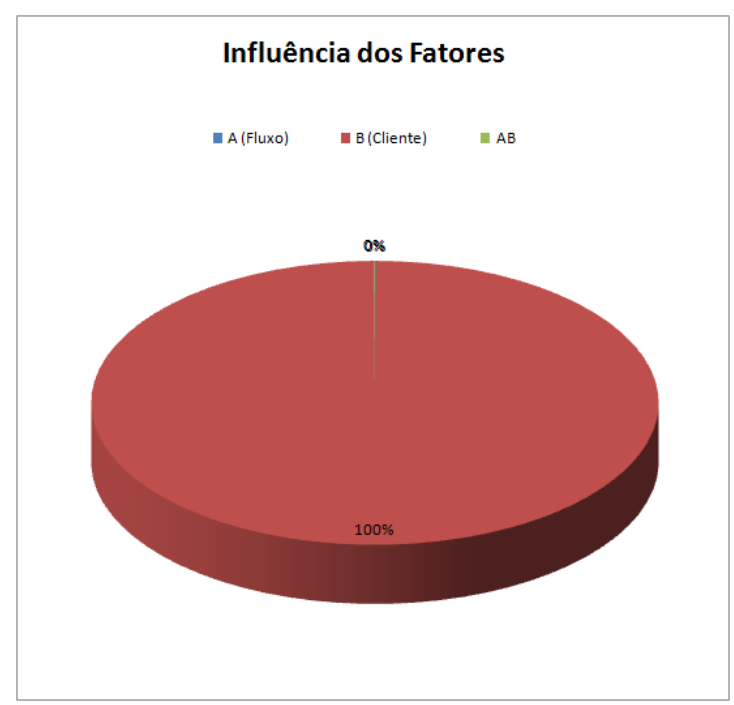

(a) $\mathrm{C} 1 \mathrm{com} \mathrm{C} 2$

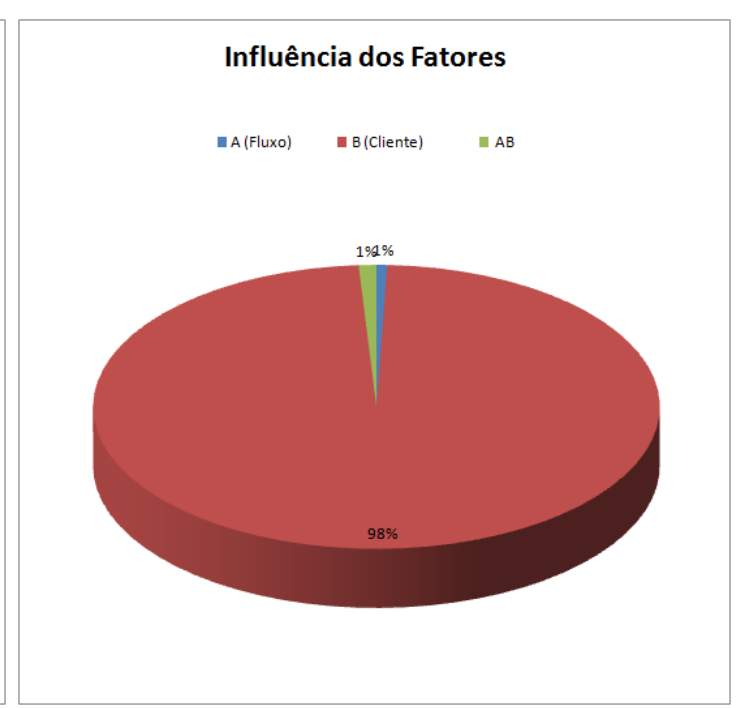

(b) $\mathrm{C} 1$ com $\mathrm{C} 3$

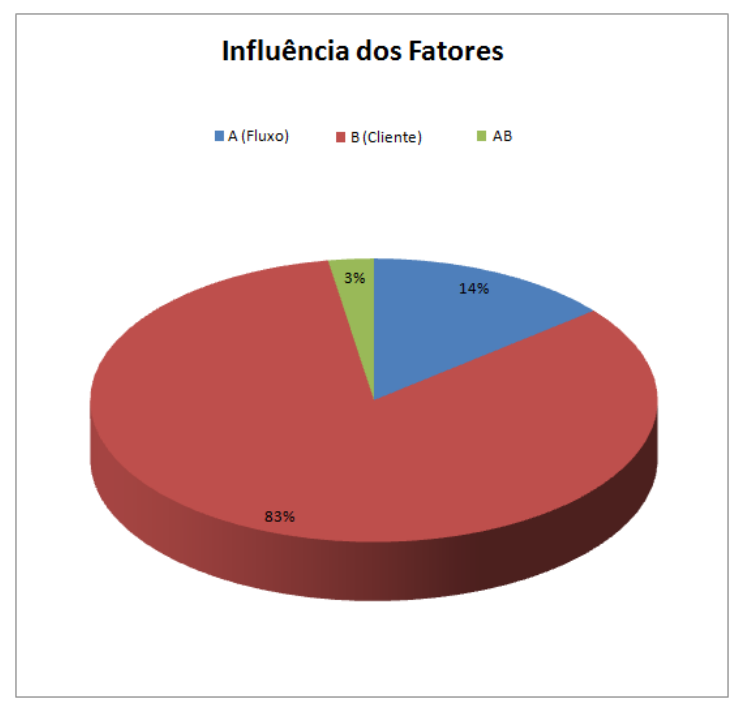

(c) $\mathrm{C} 2$ com $\mathrm{C} 3$

Figura 5.18: Influência de Fatores - Reputação

Na figura 5.18 são apresentadas as influências dos fatores para os clientes (a) C1 e C2, (b) C1 e C3 e (c) C2 e C3, considerando a variável de resposta reputação.

No gráfico (a) da figura 5.18, é possível observar que a influência dos fatores para o fator tipo de cliente influenciou em $100 \%$, o fator cliente $0 \%$ e a interação entre os dois fatores $0 \%$. No gráfico (b) da figura 5.18, o fator clientes influenciou em $98 \%$ no resultado, o fator fluxo influenciou em $1 \%$ e a interação dos fatores influenciou em $1 \%$. No gráfico (c), novamente o fator que mais influenciou no resultado, dessa vez não absolutamente, foi o clientes com $83 \%$, o fator fluxo influenciou em $14 \%$ e a interação dos fatores influenciou $3 \%$. 
No caso da reputação, ao contrário do custo, é possível observar que o fator influenciou praticamente de maneira absoluta foi os tipos de cliente.

\subsection{Cenário 2}

Na tabela 5.3 são apresentados os acordos SLAs para cada Web services disponível de acordo com a classe do Web service. Estes acordos SLAs são estabelecidos conforme as ofertas de QoS disponíveis para cada Web service. Para usuários da classe Gold, em termos de tempo de resposta, é definido que este usuário consiga o menor tempo de resposta e a melhor reputação possível, e o custo do Web service tem o contrato relaxado, já que usuário da classe Gold pode pagar pelo serviço. Já o usuário da classe Bronze tem como prioridade o menor custo possível, tendo o relaxamento do atendimento tanto do tempo de resposta quanto na reputação.

Tabela 5.9: Acordos SLAs

\begin{tabular}{|c|c|c|c|c|c|c|c|c|c|}
\hline \multirow{2}{*}{ SLA } & \multicolumn{3}{|c|}{$\begin{array}{c}\text { Tempo de } \\
\text { Resposta }\end{array}$} & \multicolumn{3}{c|}{ Custo } & \multicolumn{3}{c|}{ Reputação } \\
\cline { 2 - 10 } & Gold & Silver & Bronze & Gold & Silver & Bronze & Gold & Silver & Bronze \\
\hline Average & 3500 & 4500 & 5250 & 8 & 5 & 3 & 3 & 2 & 1 \\
\hline Confidence Interval & 1500 & 2275 & 3000 & 1,20 & 0,80 & 0,30 & 3 & 2 & 1 \\
\hline Standard Deviation & 2200 & 3250 & 4400 & 2 & 1,25 & 0,50 & 3 & 2 & 1 \\
\hline Graph-Effects & 1700 & 2250 & 3000 & 8 & 5 & 2 & 3 & 2 & 1 \\
\hline Computing Effects & 3200 & 4500 & 5700 & 4 & 3 & 1 & 3 & 2 & 1 \\
\hline Graph-Results & 2500 & 3000 & 4500 & 3,20 & 2,30 & 1,30 & 3 & 2 & 1 \\
\hline ConfInt + StdDeviation & 1500 & 2500 & 3500 & 18 & 14 & 10 & 3 & 2 & 1 \\
\hline Computing Effects + Graph & 2000 & 3500 & 5000 & 18 & 14 & 10 & 3 & 2 & 1 \\
\hline
\end{tabular}

No cenário 2, foram elaborados dois fluxos com o objetivo de resolver um problema de avaliação de desempenho. Assim como no cenário 1, a qualidade semântica foi considerada igual para os dois fluxos. A requisição considerada para elaboração do fluxo é composta por pedido de cálculo de média, cálculo de influência dos fatores, geração do gráfico para influência dos fatores, cálculo do desvio padrão, cálculo de intervalo de confiança da média e geração do gráfico com os resultados.

Na figura 5.19 é apresentado o fluxo 3. O fluxo 3 é formado pelo Web service Average relativo ao cálculo da valor médio da amostra, Computing Effects responsável por calcular o impacto de cada fator no resultado do experimento, Graph-Effects para gerar o gráfico que apresenta a influência dos fatores, o Web service Standard Deviation para calcular o desvio padrão, o Web service Confidence Interval para calcular o intervalo de confiança e o Web service Graph-Results que gera o gráfico que apresenta os valores das médias com barras de erros representado o intervalo de confiança.

Na figura 5.20 é apresentado o fluxo 4. O fluxo 4 é formado pelo Web service Average relativo ao cálculo da valor médio da amostra, Computing Effects responsável por calcular o impacto de cada fator no resultado do experimento, Graph-Effects para gerar o gráfico que apresenta a influência dos fatores, o Web service ConfInt + StdDeviation para calcular o desvio padrão e o intervalo de 


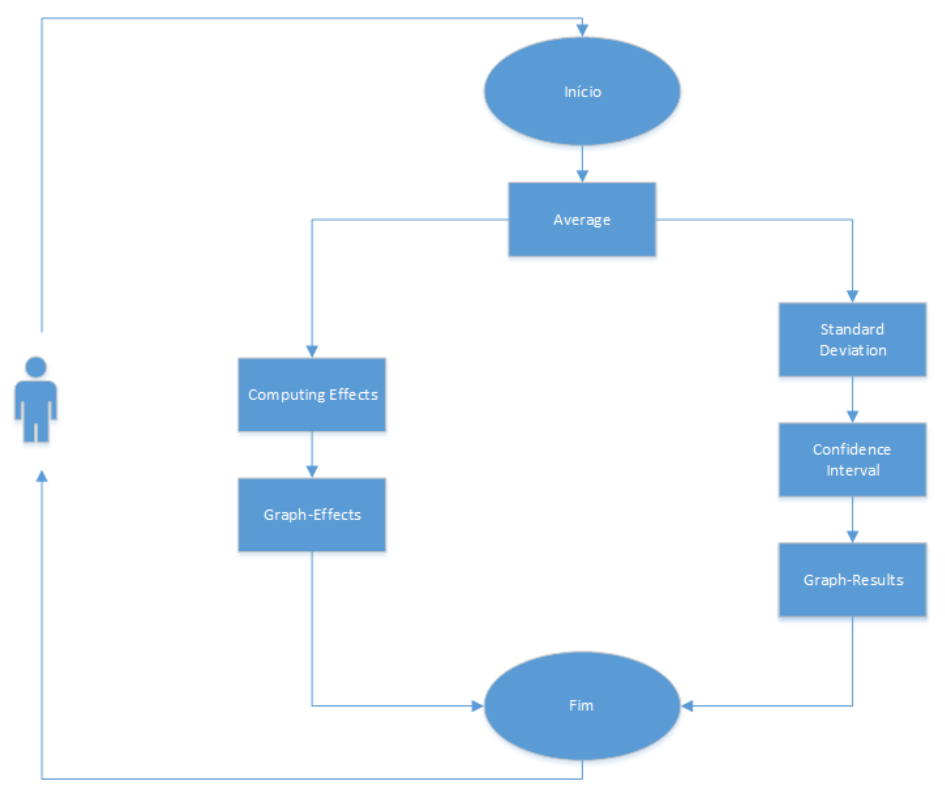

Figura 5.19: Fluxo 3

confiança, e o Web service Graph-Results para gerar o gráfico que apresenta os valores das médias com barras de erros representando o intervalo de confiança.

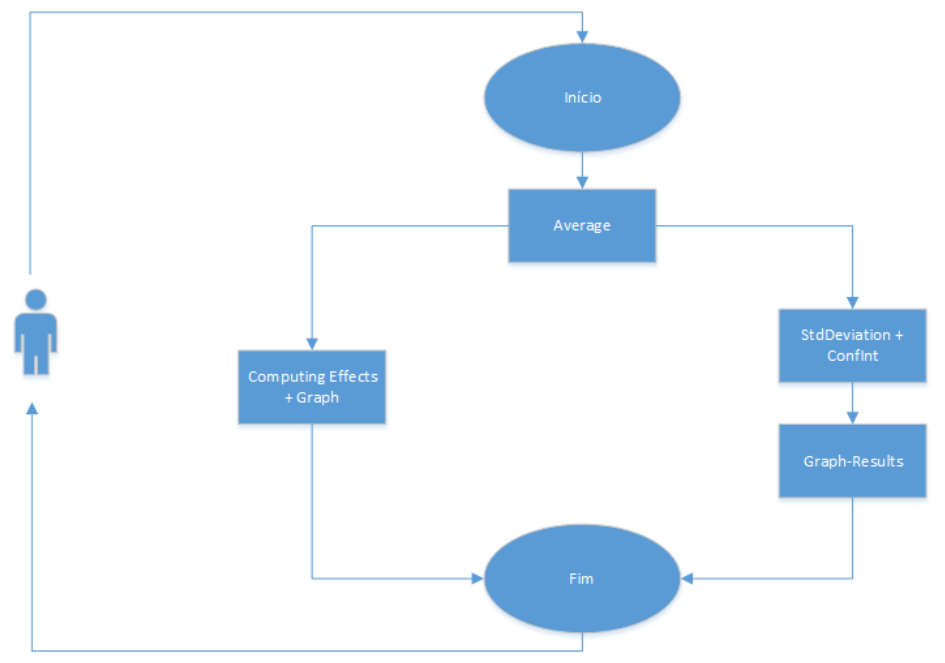

Figura 5.20: Fluxo 4

\subsubsection{Experimento 3}

No experimento 3, o objetivo foi avaliar o comportamento da execução dos Web services compostos, assim como no experimento 1, em um cenário onde todos os Web services acessados fossem da mesma classe, a Gold. Na tabela 5.10 são apresentados os fatores e níveis para o experimento 3.

Na tabela 5.5 estão especificados os contratos SLA que a execução deve obedecer. Apesar de no cenário 1 todos os Web services serem executados paralelamente, o contrato de tempo de 
Tabela 5.10: Planejamento Experimento 3

\begin{tabular}{|c|c|c|}
\hline Fator & Nível 1 & Nível 2 \\
\hline Algoritmo de Composição Automática & Fluxo 3 & Fluxo 4 \\
\hline Carga & Rajadas a cada 9s & Rajadas a cada 3s \\
\hline
\end{tabular}

resposta é estabelecido 2 segundos a mais que o tempo de resposta do Web service com maior tempo de resposta devido ao tempo que o sistema necessita para montar a chamada e fazê-la ao Web service. Se não acrescentar esse tempo seria impossível cumprir o contrato SLA em qualquer condição que o sistema se encontre.

Tabela 5.11: SLAs definidos

\begin{tabular}{|c|c|c|}
\hline SLA & Fluxo 3 & Fluxo 4 \\
\hline Tempo de Resposta & $11700 \mathrm{~ms}$ & $95000 \mathrm{~ms}$ \\
\hline Custo & $\mathrm{R} \$ 466$ & $\mathrm{R} \$ 505$ \\
\hline Reputação & 3 Estrelas & 3 Estrelas \\
\hline
\end{tabular}

$\mathrm{Na}$ figura 5.21 são apresentados os gráficos referentes aos resultados dos fluxos 3 e 4 onde foram disparadas em rajadas a cada 9 segundos. Para os atributos de QoS custo e reputação, gráficos (b) e (c) respectivamente, assim como no experimento 1, não é preciso calcular média ou intervalo de confiança, já que estes atributos não estão associados a execução e repetição da execução do experimento, e sim das escolhas dos Web services a serem executados feitas pelo algoritmo apresentado na seção 5.2.1. Analisando-se os resultados é possível afirmar que em termos de reputação ambos os fluxos conseguiram atingir o objetivo que era de conseguir a melhor reputação possível. Em termos de custo é possível perceber que o fluxo 4 obteve valores consideravelmente mais baixos que o fluxo 3 .

Em termos de tempo de resposta, ao contrário do cenário 1, no cenário 2 a sobrecarga não aconteceu da mesma forma que no cenário 1 . No cenário 2, rajadas a cada 3 segundos, não gerou uma sobrecarga tão impactante no sistema, isso ocorreu devido ao fato dos fluxos do cenários 2 acessarem menos Web services e também devido ao fato de existir uma certa sequencialidade na execução dos Web services, fazendo assim que a sobrecarga no Broker que é o responsável por gerenciar a seleção e execução do Web service concreto seja menor. Para a situação de carga apresentada no gráfico (a) da figura 5.21, onde 50 clientes disparam execuções, distribuídas em rajadas que seguem curva exponencial, sendo que cada rajada é disparada a cada 3 segundos. $\mathrm{O}$ fluxo 3 obteve um desempenho pouco pior que o do fluxo 4. Apesar disso, nenhum dos dois fluxos ultrapassou os SLAs estabelecidos para eles.

Na figura 5.22 são apresentados os resultados para o experimento 3, no entanto, os clientes dispararam as requisições em rajadas a cada 3 segundos, sobrecarregando mais o sistema. Como os valores obtidos para os atributos de QoS custo e reputação não são afetados pelo comportamento da execução, e os clientes eram todos da mesma classe novamente, a "Gold", os resultados se repetiram, como é possível observar nos gráficos (b) e (c) da figura 5.6. 


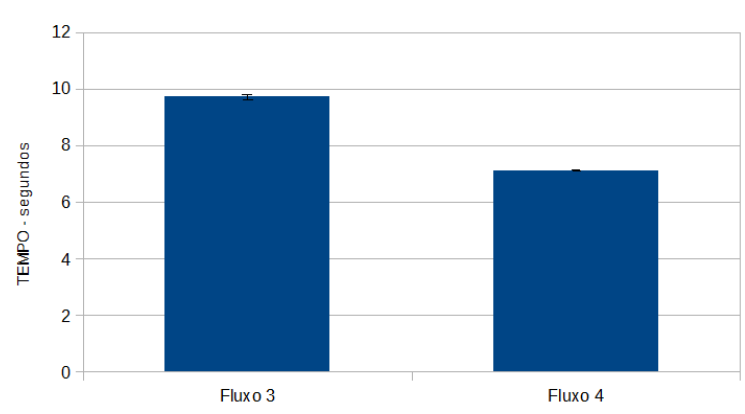

(a) Tempo de resposta

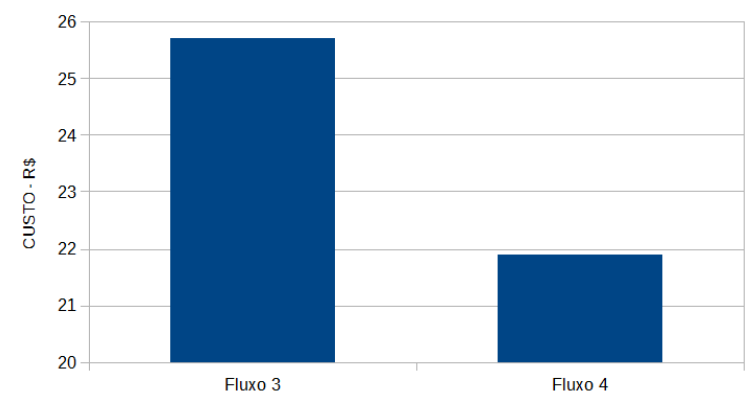

(b) Custo

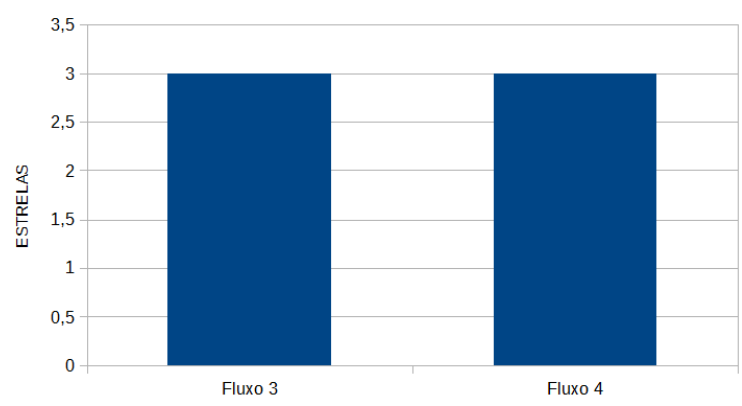

(c) Reputação

Figura 5.21: Fluxo 3 x Fluxo 4- rajadas a cada 9000ms

No gráfico (a) da figura 5.6, apesar de ter sido submetido uma carga um pouco maior no sistema, assim como no experimento 1 , no experimento 3 essa carga não foi suficiente para sobrecarregar o sistema, os 2 fluxos conseguiram respeitar os acordos SLAs. Com a carga um pouco maior é possível também observar que o fluxo 3 sobrecarregou, proporcionalmente, muito mais que o fluxo 4.

Comparando o experimento 3 com o experimento 1, fica claro a maneira que o tipo do fluxo composto impacta nos resultados de tempo de resposta, a medida em que a sobrecarga imposta no sistema varia.

Na figura 5.23 são apresentados os fatores que mais influenciaram no experimento. Assim como no experimento 1, os atributos de QoS custo e reputação, são fixos, ou seja não variam de acordo com a execução, não faz sentido fazer este tipo de cálculo para tais fatores, já que sempre resultaria em $100 \%$ para o algoritmo e $0 \%$ para a carga. Por este motivo, na figura 5.7 é apresentada a influência dos fatores apenas para o tempo de resposta.

Pela análise do gráfico apresentado na figura 5.23, fica bastante claro que para o experimento 3 , a sobrecarga imposta no sistema afetou pouco nos resultados, diferente do apresentado no experimento 1 .

Na figura 5.24 são apresentados os resultados para tempo de resposta médio, com intervalo de confiança, para cada Web service acessado pelos fluxos 3 e 4. 


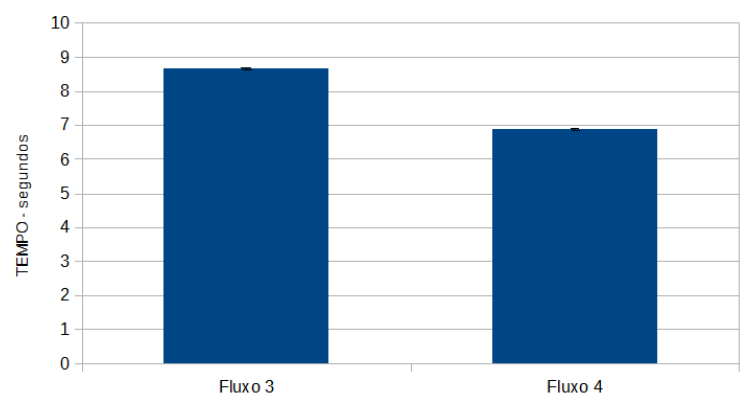

(a) Tempo de resposta

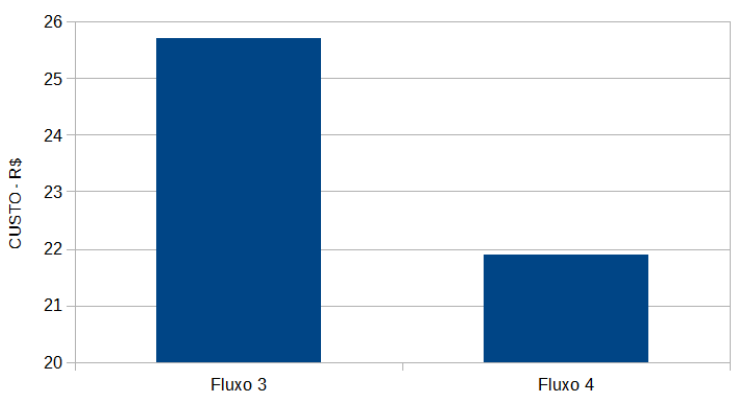

(b) Custo

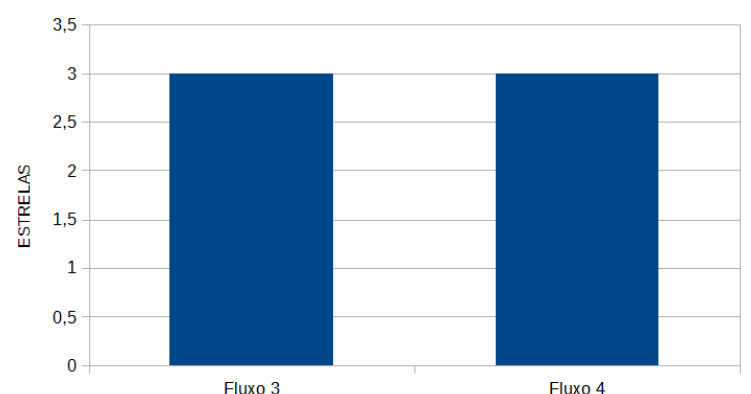

(c) Reputação

Figura 5.22: Fluxo 3 x Fluxo 4 - rajadas a cada 3000ms

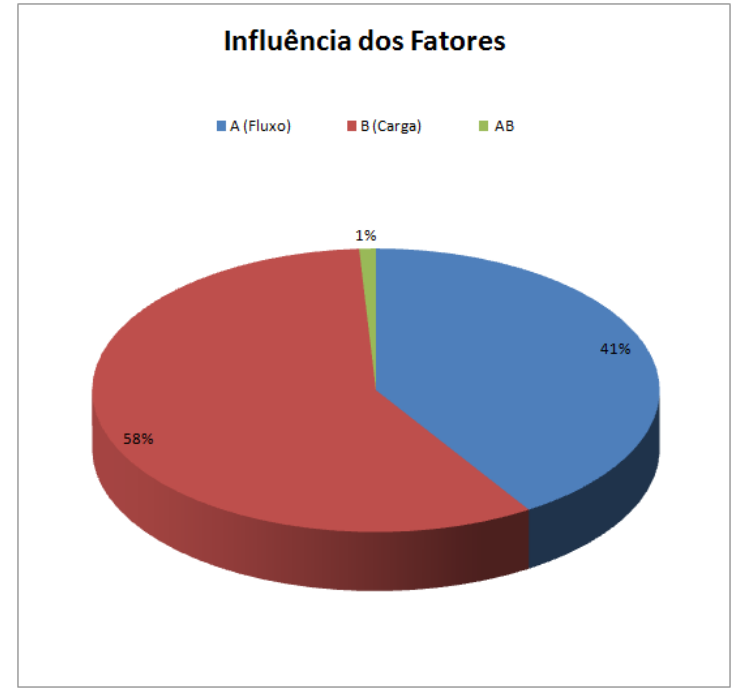

Figura 5.23: Fluxo 3 x Fluxo 4 - Influência dos Fatores

Na figura 5.25 são apresentados o custo para utilização de cada Web service individualmente. Como o custo é o mesmo independentemente da carga submetida ao sistema, não é necessário apresentar o custo para cada situação de carga.

Na figura 5.26 são apresentados a reputação de cada Web service individualmente. Para a reputação, assim como para o custo, o resultado obtido é independentemente da carga submetida ao sistema, não é necessário apresentar o custo para cada situação de carga. 


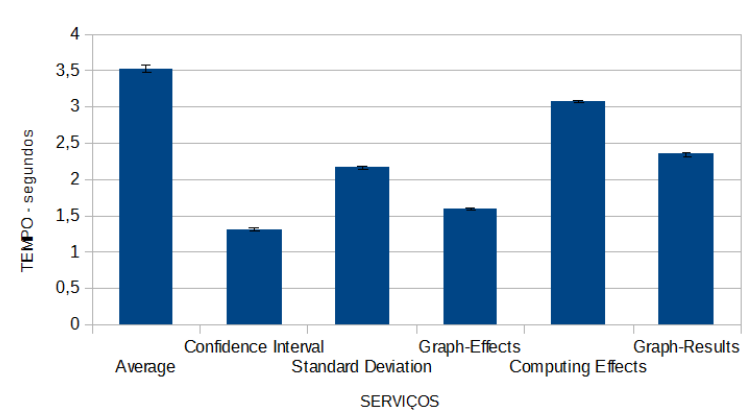

(a) Tempo de resposta - Fluxo 3 - rajadas a cada $3 \mathrm{~s}$

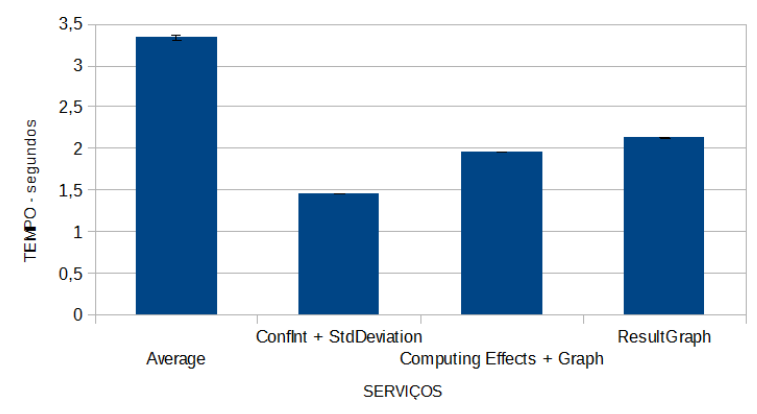

(c) Tempo de resposta - Fluxo 4 - rajadas a cada $3 \mathrm{~s}$

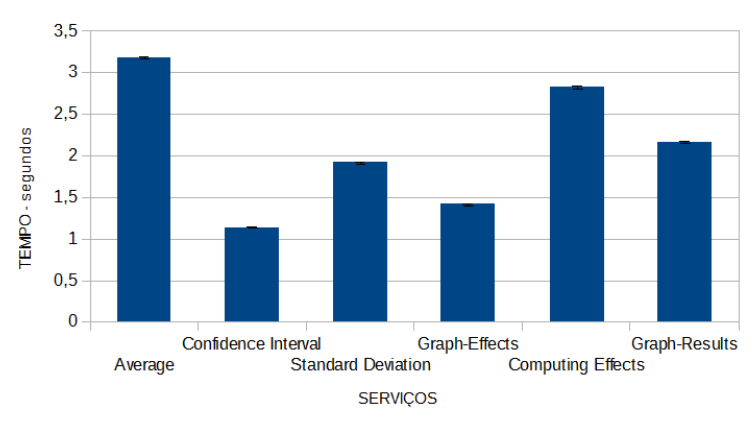

(b) Tempo de resposta - Fluxo 3 - rajadas a cada 9s

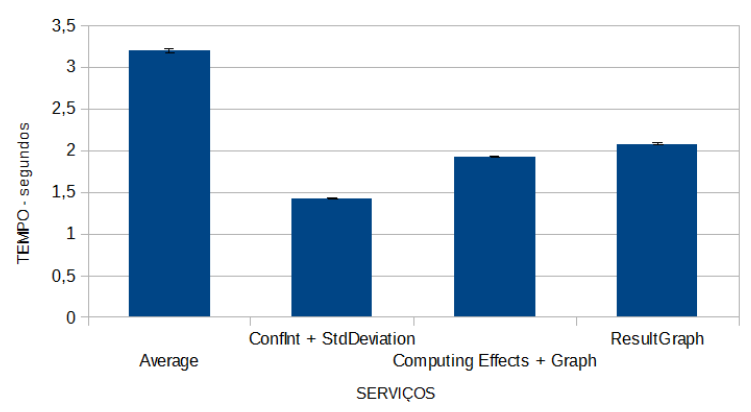

(d) Tempo de resposta - Fluxo 4 - rajadas a cada 9s

Figura 5.24: Tempo de resposta por Web service

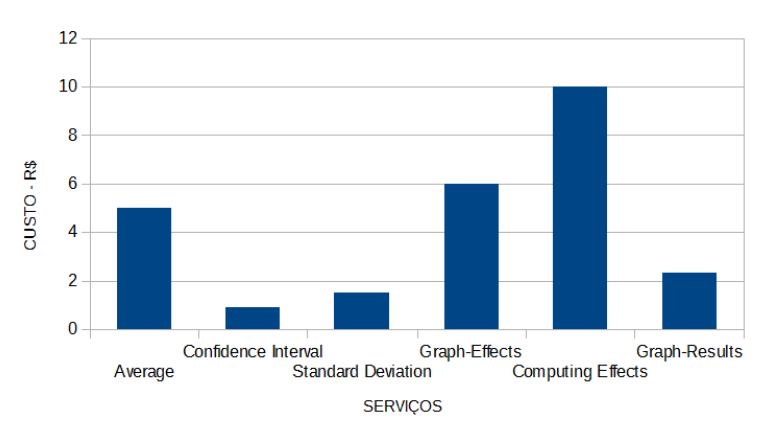

(a) Custo - Fluxo 3

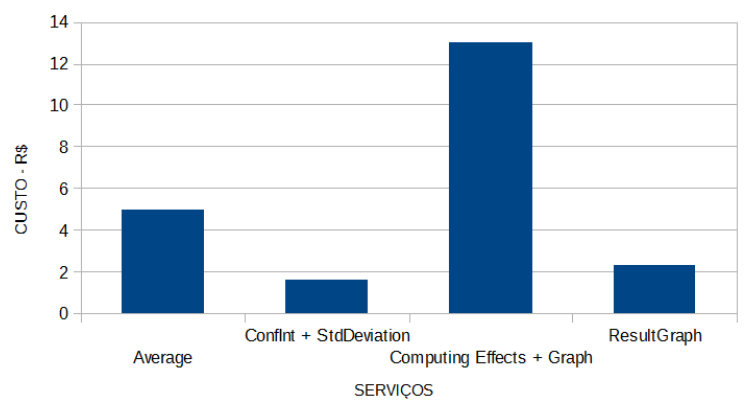

(b) Custo - Fluxo 4

Figura 5.25: Custo por Web service

\subsection{Considerações Finais}

Neste capítulo foi apresentado o ambiente no qual o AWSCS foi implementado e testado. Para os testes foram propostos 2 cenários, um primeiro cenário onde todos os Web services eram acessados de maneira paralela e em um segundo cenário onde havia Web services que dependiam da execução de outro para ser executado.

No cenário 1, os experimentos foram divididos em 2. No primeiro experimento todos os Web services acessados eram da classe Gold. Neste experimento foi possível observar que o fluxo 2 


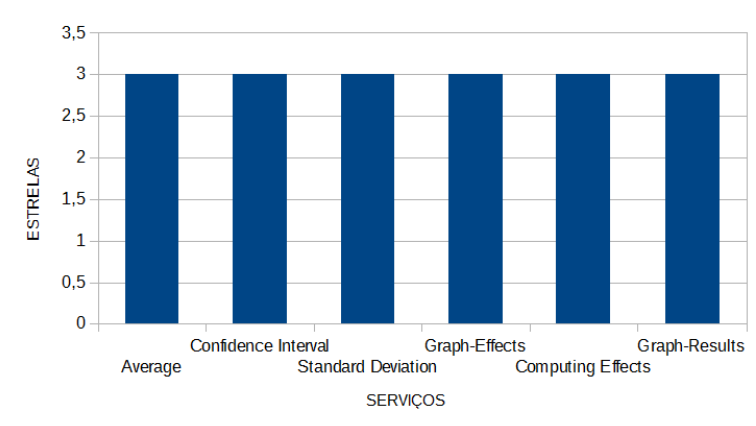

(a) Reputacao - Fluxo 3

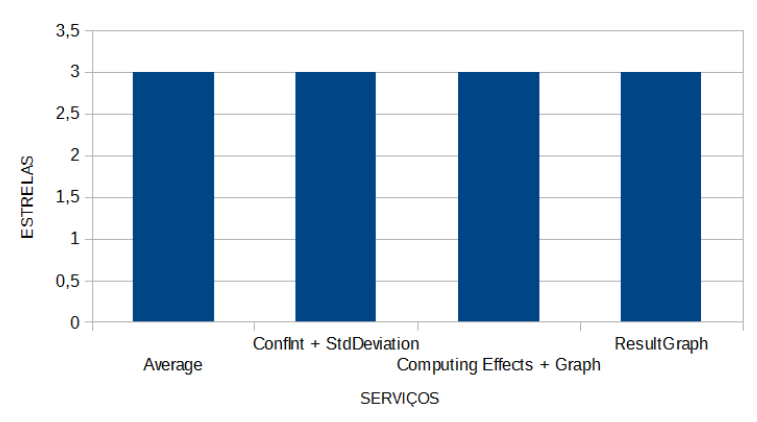

(b) Reputacao - Fluxo 4

Figura 5.26: Reputação por Web service

conseguiu melhor tempo de resposta com os 2 tipos de sobrecarga imposta ao sistema, no entanto a um custo maior.

No experimento 2 já foi possível perceber que clientes com requisitos de QoS, para maioria dos Web services acessados Silver e Bronze, em baixa sobrecarga o fluxo 1 obteve melhor desempenho para o tempo de resposta que o fluxo 2. Mas em situação de alta sobrecarga no sistema foi possível observar a inversão deste resultado, onde o fluxo 2 obteve melhor desempenho para estes mesmos clientes em relação ao fluxo 1.

No experimento 3, em relação ao tempo de resposta e custo, o fluxo 4 obteve melhor desempenho que o fluxo 3, em relação a reputação, ambos empataram.

Com os experimentos apresentados neste capítulo foi possível observar o quanto é imprevisível o comportamento da execução dos Web services compostos quando utilizados em situações de carga diversas. Isso mostra a importância de avaliar o comportamento da execução dos Web services compostos para se decidir qual algoritmo de composição irá gerar os fluxos que melhor se ajustam à situação que é esperada no sistema.

Com isso o objetivo principal desta tese de doutorado foi atingido que é exatamente propor um sistema onde seja possível fazer avaliação de composição de Web services, baseado em atributos de QoS que dependem da execução para serem medidos.

No próximo capítulo serão discutidas as conclusões obtidas com esta tese de doutorado, as contribuições para área que foram obtidas e também os trabalhos que devem ser feitos em continuação ao apresentado nesta tese. 



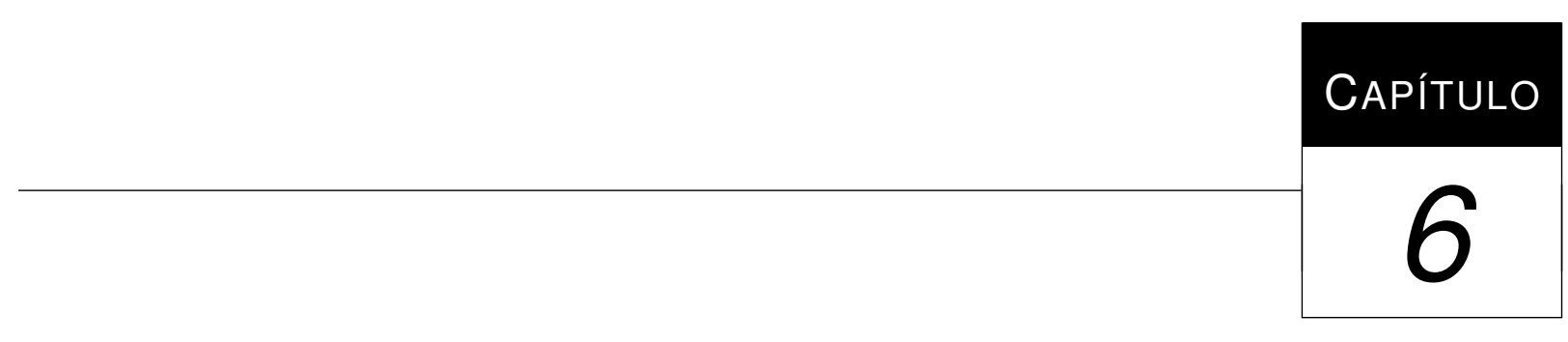

\section{Conclusões}

\subsection{Considerações Iniciais}

SOA é uma arquitetura que torna possível a interoperabilidade entre aplicações desenvolvidas em tecnologias diferentes e, em adição, permite que essas aplicações possam interagir com outras aplicações de uma forma direta. A composição de Web services é uma técnica promissora, que visa atingir um dos principais objetivos da SOA, que é possibilitar a comunicação entre Web services. O desenvolvimento de Web services compostos é muitas vezes uma tarefa complexa para os desenvolvedores, já que a procura por Web services os quais possam ser partes do Web service composto não é trivial.

Com o objetivo de resolver este problema, o uso de Web services semânticos foi proposto. Com os Web services semânticos é possível encontrar os Web services e suas relações com outros Web services por meio dos chamados links semânticos. Devido a essas características dos Web services semânticos é possível conseguir a composição automática de Web services.

Juntamente com a possibilidade de composição automática de Web services surgiram também várias propostas de como conseguir composição automática, como foi apresentado na seção 3.6.1. Com tantas propostas, notou-se a falta de um ambiente onde fosse possível implementar essas abordagens para composição automática e avaliá-las, tanto isoladamente, quanto comparadas com outras abordagens. Para isso foi proposto o sistema AWSCS, apresentado no capítulo 4. 


\subsection{Contribuições}

Esta tese de doutorado propõe que é possível avaliar a composição de Web services considerando atributos de QoS, tanto estáticos quanto os que alteram em tempo de execução.

A avaliação dos atributos de QoS estáticos é simples de ser modelada analiticamente, já que os valores serão os mesmos independente da execução. Para atributos de QoS que alteram em tempo de execução, de acordo com a carga ou até mesmo problemas na rede ou de disponibilidade do provedor, é muito difícil fazer essa avaliação por meio de modelos analíticos ou simulação, já que esses problemas são imprevisíveis e difíceis de quantificar o impacto deles na execução.

Portanto, o objetivo principal desta tese é a proposta de um sistema onde é possível avaliar abordagens para composição automática de Web services baseado em atributos de QoS que dependem da execução para serem medidos e também os atributos estáticos.

Para atingir este objetivo foi proposto um sistema chamado AWSCS, onde é possível implementar abordagens completas para composição automática de Web services, desde o algoritmo para o planejamento automático do fluxo, até a execução das implementações dos Web services atômicos.

Com os experimentos apresentados no capítulo 5 desta tese, foi possível demostrar como é imprevisível o comportamento da execução de Web services compostos. Para isso foram utilizados cenários onde a carga, o tipo de composição e tipo de cliente variavam. Nos experimentos apresentados, foram encontradas situações que a alta sobrecarga no sistema fazia com que determinado fluxo tinha desempenho melhor que o concorrente, mas que em situações de baixa sobrecarga no sistema este cenário se invertia. Além de situações onde o desempenho permanecia melhor para determinado fluxo tanto em condições de baixa sobrecarga, como de alta sobrecarga. Com isso foi possível perceber a importância da execução dos fluxos para quantificar qual fluxo pode ser a melhor alternativa de acordo com a situação mais provável de utilização da composição, quando em produção.

Como principais contribuições desta tese de doutorado podem-se destacar:

- Um protótipo de um sistema para execução de composição automática de Web services, o AWSCS. Este protótipo deve ser compartilhado com a comunidade como uma ferramenta de código aberto, para que qualquer pesquisador possa fazer uso dela. Como, para esta tese foi desenvolvido um protótipo funcional, com ele qualquer abordagem para composição de Web services pode ser avaliada em termos de execução.

- Estudo do comportamento da execução de Web services compostos. 3 experimentos foram executados para a demonstração do funcionamento do AWSCS. Com a execução destes experimentos foi possível quantificar os resultados do tempo de resposta dos Web services, em diferentes situações de execução. Demonstrando como cada fator utilizado nos experimentos pode impactar na execução dos experimentos. 
- Estudo de como a carga reflete na execução total de um Web service composto, considerando modos diferentes de se atingir um mesmo objetivo com implementações alternativas de Web services. Foram apresentados situações onde um fluxo tinha desempenho melhor em situação de baixa sobrecarga, mas quando a sobrecarga era alta essa situação se invertia. Este estudo mostrou como é imprevisível o comportamento da execução dos Web services compostos nas variadas situações na qual o sistema pode se encontrar.

- Estudo de caso de possíveis resultados para composição automática de Web services. Apesar de terem sido utilizados fluxos empíricos para teste, os experimentos demonstraram a importância de execução da composição dos Web services para decisão de qual fluxo utilizar. Podendo assim colocar em um ambiente experimental possíveis abordagens para composição automática e avaliar qual se adapta melhor as necessidades do problema.

- Implementação de um ambiente completo para comparação de algoritmos para composição automática de Web services. Junto aos pesquisadores do LaSDPC, foi construído um ambiente completo para implementação dos algoritmos, onde máquinas foram disponibilizadas para ter função exclusiva de provedores de Web services, registro de Web services, Broker para execução dos Web services e também para disponibilização do protótipo AWSCS.

\subsection{Dificuldades relacionadas ao projeto}

Durante o desenvolvimento do doutorado várias adaptações do projeto inicial foram necessárias. No modelo inicial do projeto, a ideia era utilizar a linguagem BPEL para escrita das descrições dos fluxos, mas devido a natureza complexa e robusta da linguagem, foi necessária a utilização de um mecanismo diferente para gerenciamento da execução dos Web services, uma vez que com a utilização de BPEL é necessário se fazer passos como definição de Web services concretos que devem ser utilizados pela composição, fazer um empacotamento de todas essas informações, publicação do Web service composto em um engine para composição, para então poder fazer acesso ao Web service composto. Todos esses passos tornariam altamente ineficiente a composição automática, o que motivou a proposta de um mecanismo mais simples e eficiente para gerenciamento e execução da composição.

A abordagem escolhida para atingir o objetivo desta tese, que é a prototipação, traz muitas dificuldades inerentes a ela. Uma delas é a configuração dos clusters utilizados nos experimentos, o gerenciamento de várias máquinas é uma tarefa um tanto complexa, já que muitas vezes problemas em cabos de redes, drivers inadequados utilizados para controle das interfaces de rede, configurações de kernel de sistema operacional, limitando números de sockets que poderiam ser criados e utilização máxima da memória principal por processo, por exemplo, são problemas difíceis de serem detectados, principalmente pelo grande número de máquinas que foram utilizadas nos experimentos. 
Outra dificuldade que deve ser destacada foi a dificuldade de se conseguir algoritmos para a composição automática de Web services. O plano inicial para o desenvolvimento desta tese de doutorado era a implementação e avaliação dessas abordagens, implementadas em um protótipo. Como não se encontrou algoritmos para composição automática de Web services para download, a primeira alternativa foi a tentativa de proposta de uma abordagem para composição automática, essa sem sucesso, principalmente pelo quesito tempo, já que muitas dessas abordagens são resultados de anos de pesquisas. Por isso foi decidido fazer a simulação desses algoritmos por meio da criação de fluxos hipotéticos com funcionalidade equivalente, mas utilizando implementações de Web services distintas.

\subsection{Trabalho Futuros}

O desenvolvimento do sistema AWSCS exigiu o estudo de diversas tecnologias para que fosse possível a implementação de um protótipo funcional. Todo o processo desde a proposta, até a obtenção de um protótipo funcional foi um processo bastante complexo o qual o aluno só obteve sucesso, porque seu orientador, professores e colegas do laboratório LaSDPC, sempre estiveram prontos para colaborar. O protótipo apresentado nesta tese é uma versão funcional do AWSCS, no entanto ainda existe muito trabalho a ser feito para evolução do AWSCS para que seja uma ferramenta ainda mais amigável de ser utilizada e também torne possível uma avaliação mais detalhada das composições de Web services nela testada.

Muitas etapas que faziam parte do projeto inicial desta tese de doutorado, mas devido a limitação de tempo e outras atividades que fizeram parte do processo de doutoramento não puderam ser concretizadas, essas tarefas poderão ser realizadas em trabalhos futuros. Entre as melhorias propostas para trabalhos futuros destacam-se:

- Implementação de algoritmos para composição automática de Web services. Com isso se terá um ambiente completo para composição automática de Web services, desde o planejamento do fluxo de composição, até a execução do fluxo. Com isso será possível realizar testes completos da composição automática de Web services.

- Criação de um repositório de Web services semânticos. Existe um projeto chamado OWLSTC, nesse projeto uma coleção de definições semânticas está disponível para testes, no entanto, as implementações dos Web services não existem. Por isso existe a necessidade da criação de um repositório onde, além das definições semânticas, existam as implementações dos Web services para teste. O OWLS-TC está disponível para download em:

http://projects.semwebcentral.org/projects/owls-tc/.

- Utilizar o sistema de tolerância a falha proposto na dissertação de mestrado (Oliveira, 2013). Este sistema já foi testado no broker da WSArch, mas por limitações de tempo não foi pos- 
sível utilizá-lo nesta tese de doutorado. Com este sistema integrado ao Broker será possível avaliar o impacto da falha ao acesso a Web services na execução do Web service composto.

- Implementar políticas de segurança no sistema e avaliar os impactos dessas políticas em Web services compostos. O desenvolvimento do sistema AWSCS não contemplou nenhum aspecto de segurança na primeira versão de seu protótipo. Isso é um aspecto muito importante para ser considerado, já que Web services muitas vezes são executados, utilizando como infraestrutura, a Internet.

Nesta seção foram apresentados alguns dos trabalhos futuros que deverão ser desenvolvidos nos próximos anos, mas além dessas propostas, várias outras deverão surgir para que o sistema AWSCS evolua. Os resultados provenientes destes trabalhos futuros deverão ser divulgados por meio de conferências e revistas de qualidades, específicos da área. 

Ainkisalo, T.; PAAso, T. Latencies of service invocation and processing of the rest and soap web service interfaces. In: Services (SERVICES), 2012 IEEE Eighth World Congress on, 2012, p. 100-107.

Berners-Lee, T.; Hendler, J.; Lassila, O. The semantic web. [On-line].

Disponível em: http://www.sciam.com/article.cfm?articleID= 00048144-10D2-1C70-84A980 9EC588EF21

BIH, J. Service oriented architecture (soa) a new paradigm to implement dynamic e-business solutions. ubiquity, v. 2006, n. August, p. 4, 2006.

Bray, T.; Padli, J.; Sperberg-McQueen, C. M.; Maler, E.; Yergeau, F. Extensible markup language (xml). [On-line $]$.

Disponível em: http: //www.w3.org/TR/1998/REC-xml-19980210

Cardellini, V.; Casalicchio, E.; Grassi, V.; Lo Presti, F. Flow-based service selection forweb service composition supporting multiple qos classes. In: Web Services, 2007. ICWS 2007. IEEE International Conference on, 2007, p. 743-750.

Chandrasekaran, S.; Miller, J. A.; Silver, G. S.; Arpinar, B.; Sheth, A. P. Performance analysis and simulation of composite web services. Electronic Markets, v. 13, n. 2, p. 120-132, 2003.

Chen, X.; Zheng, Z.; LyU, M. Qos-aware web service recommendation via collaborative filtering. In: Bouguettaya, A.; Sheng, Q. Z.; Daniel, F., eds. Web Services Foundations, Springer New York, p. 563-588, 2014.

Disponível em: http://dx.doi.org/10.1007/978-1-4614-7518-7_22

COMER, D. Internetworking with tcp/ip: Principles, protocols, and architecture. Upper Saddle River, NJ, USA: Prentice-Hall, Inc., 1988. 
DijKstra, E. A note on two problems in connexion with graphs. Numerische Mathematik, v. 1, n. 1, p. 269-271, 1959.

Disponível em: http://dx.doi.org/10.1007/BF01386390

Dustdar, S.; Schreiner, W. A survey on web services composition. Int. J. Web Grid Serv., v. 1, n. 1, p. 1-30, 2005.

ERRADi, A.; MAheshwARI, P. A broker-based approach for improving web services reliability. In: Web Services, 2005. ICWS 2005. Proceedings. 2005 IEEE International Conference on, 2005, p. 355-362 vol.1.

ESTRELla, J. C. Wsarch: Uma arquitetura para a provisão de web services com qualidade de serviço. Tese de Doutoramento, Universidade de São Paulo, 2010.

FANG, X.; ZhANG, J.; YIN, Z. A study on the dynamic web service composition based on stochastic petri net. In: Web Information Systems and Mining (WISM), 2010 International Conference on, 2010, p. 113-117.

FARKas, P.; Charaf, H. Web services planning concepts. Journal of WSCG, v. 11, n. 1, p. 23-35, 2003.

Ferris, C.; FArrell, J. What are web services? Communications of the ACM, v. 46, n. 6, p. 31, 2003.

Gouscos, D.; Kalikakis, M.; Georgiadis, P. An approach to modeling web service qos and provision price. In: Web Information Systems Engineering Workshops, 2003. Proceedings. Fourth International Conference on, IEEE, 2003, p. 121-130.

GrønMo, R.; JAEGER, M. C. Model-driven methodology for building qos-optimised web service compositions. In: Distributed Applications and Interoperable Systems, Springer, 2005, p. $68-82$.

GuO, N.; GAO, T.; ZHANG, B. A trusted quality of web services management framework based on six dimensional qows model and end-to-end monitoring. In: Challenges for Next Generation Network Operations and Service Management, Springer, p. 437-440, 2008.

Hatzi, O.; Vrakas, D.; Nikolaidou, M.; Bassiliades, N.; Anagnostopoulos, D.; VLAHAVAS, I. An integrated approach to automated semantic web service composition through planning. Services Computing, IEEE Transactions on, v. 5, n. 3, p. 319-332, 2012.

He, Y.; ZhaO, L.; Wu, Z.; Li, F. Modeling web services composition with transaction extension for performance evaluation. In: Asia-Pacific Services Computing Conference, 2008. APSCC 'O8. IEEE, 2008, p. 476-481. 
Hebeler, J.; Fisher, M.; Blace, R.; Perez-Lopez, A. Semantic web programming. John Wiley \& Sons, 2011.

JAEGER, M. C.; LADNER, H. Improving the qos of ws compositions based on redundant services. In: Next Generation Web Services Practices, 2005. NWeSP 2005. International Conference on, IEEE, 2005, p. 6-pp.

JAIN, R. The art of computer systems performance analysis: Techniques for experimental design, measurement, simulation, and modeling. Wiley, 1991.

JING, S.; YU-YUE, D. Performance analysis of web service composition based on stochastic well-formed workflow. In: Networked Computing (INC), 2010 6th International Conference on, 2010, p. 1-5.

Jordan, D.; Evdemon, J.; Alves, A.; Arkin, A.; Askary, S.; Barreto, C.; Bloch, B.; Curbera, F.; Ford, M.; Goland, Y.; ET AL. Web services business process execution language version 2.0. OASIS Standard, v. 11, 2007.

JUAN, S.; HAO, W. Performance analysis for web service composition based on queueing petri net. In: Software Engineering and Service Science (ICSESS), 2012 IEEE 3rd International Conference on, 2012, p. 501-504.

KAlEPU, S.; KRISHnASWAMY, S.; LOKE, S. W. Verity: A qos metric for selecting web services and providers. In: Proceedings of the Fourth International Conference on Web Information Systems Engineering Workshops, WISEW'03, Washington, DC, USA: IEEE Computer Society, 2003, p. 131-139 (WISEW'03, ).

Disponível em: http://dl.acm.org/citation.cfm?id=1880332.1880353

Kavantzas, N.; Burdett, D.; Ritzinger, G.; Fletcher, T.; Lafon, Y.; Barreto, C. Web services choreography description language version 1.0. W3C candidate recommendation, v. 9, 2005.

Kreger, H. Fulfilling the web services promise. Communications of the ACM, v. 46, n. 6, p. 29-ff, 2003.

Kreger, H.; Brunssen, V.; Sawyer, R.; Arsanjani, A.; High, R. The ibm advantage for soa reference architecture standards. [On-line].

Disponível em: http://www.ibm.com/developerworks/library/ ws-soa-ref-arch/ws-soa-ref-arch-pdf.pdf

Leavitt, N. Are web services finally ready to deliver? Computer, v. 37, n. 11, p. 14-18, 2004.

Lecue, F.; Mehandjiev, N. Seeking quality of web service composition in a semantic dimension. Knowledge and Data Engineering, IEEE Transactions on, v. 23, n. 6, p. 942-959, 2011. 
Lin-FEnG, S.; Yong, Q. A novel end-user oriented service composition model based on quotient space theory. In: Service Sciences (ICSS), 2010 International Conference on, IEEE, 2010, p. 180-184.

LU, J.; YU, Y.; RoY, D.; SAHA, D. Web service composition: A reality check. In: Web Information Systems Engineering-WISE 2007, Springer, p. 523-532, 2007.

Martin, D.; Burstein, M.; Hobbs, J.; Lassila, O.; McDermott, D.; McIlraith, S.; Narayanan, S.; PaOlucci, M.; Parsia, B.; Payne, T.; ET Al. Owl-s: Semantic markup for web services. W3C member submission, v. 22, p. 2007-04, 2004.

McGuinness, D. L.; VAn Harmelen, F.; ET AL. Owl web ontology language overview. W3C recommendation, v. 10, n. 2004-03, p. 10, 2004.

Moodie, M.; Mittal, K. Pro apache tomcat 6. Springer, 2007.

NAKAMURA, L. H. Utilização de web semântica para seleção de informações de web services no registro uddi uma abordagem com qualidade de serviço. Dissertação de Mestrado, ICMC USP, 2012.

Nguyen, X. T.; KowalczyK, R.; Phan, M. T. Modelling and solving qos composition problem using fuzzy discsp. In: Web Services, 2006. ICWS'06. International Conference on, IEEE, 2006, p. 55-62.

Noy, N. F.; MCGuinness, D. L.; ET AL. Ontology development 101: A guide to creating your first ontology. 2001.

Nunes, L. H.; Nakamura, L. H.; Kuehne, B. T.; Oliveira, E. M.; Libardi, R. M. O.; Adami, L. J.; Estrella, J. C.; Reiff-MarganieC, S. Peesos: A web tool for planning and execution of experiments in service oriented systems. In: Web Services, 2014. ICWS 201ibm20124. IEEE International Conference on, 2014.

OliVEIRA, E. M. Implementação de mecanismos tolerantes a falhas em uma arquitetura soa com qos. Dissertação de Mestrado, ICMC - USP, 2013.

Paoli, F.; Lulli, G.; Maurino, A. Design of quality-based composite web services, v. 4294 de Lecture Notes in Computer Science. Springer Berlin Heidelberg, 153-164 p., 2006.

Paolucci, M.; Kawamura, T.; Payne, T. R.; Sycara, K. Semantic matching of web services capabilities. In: The Semantic Web-ISWC 2002, Springer, p. 333-347, 2002.

PAPAZOGlou, M. P. Service-oriented computing: Concepts, characteristics and directions. In: Web Information Systems Engineering, 2003. WISE 2003. Proceedings of the Fourth International Conference on, IEEE, 2003, p. 3-12. 
Perera, S.; Herath, C.; Ekanayake, J.; Chinthaka, E.; Ranabahu, A.; Jayasinghe, D.; Weerawarana, S.; Daniels, G. Axis2, middleware for next generation web services. In: Web Services, 2006. ICWS '06. International Conference on, 2006, p. 833-840.

Pop, C. B.; Chifu, V. R.; Salomie, I.; Dinsoreanu, M. Immune-inspired method for selecting the optimal solution in web service composition. In: Resource Discovery, Springer, p. $1-17,2010$.

PraZeres, C. V. S. Serviços web semânticos: da modelagem à composição. Tese de Doutoramento, ICMC - USP, 2009.

RAO, J.; SU, X. A survey of automated web service composition methods. In: Semantic Web Services and Web Process Composition, Springer, p. 43-54, 2005.

Reinke, C.; Hoeller, N.; Neumann, J.; Groppe, S.; Linnemann, V.; Lipphardt, M. Integrating standardized transaction protocols in service-oriented wireless sensor networks. In: Proceedings of the 2009 ACM symposium on Applied Computing, ACM, 2009, p. 2202-2203.

Senna, C. R.; Bittencourt, L. F.; Madeira, E. R. Uma infra-estrutura para execução dinâmica de serviços em grades computacionais. 27ํ Simpósio Brasileiro de Redes de Computadores e Sistemas Distribuídos, p. 453-466, 2009.

Sheth, A.; Cardoso, J.; Miller, J.; Kochut, K.; Kang, M. Qos for service-oriented middleware. In: Proceedings of the Conference on Systemics, Cybernetics and Informatics, 2002, p. 130-141.

StAm, K.; O’ReE, A. Apache juddi guide. [On-line], access date: 24 sept. 2014.

Disponível em: http://juddi.apache.org/docs/3.x/userguide/html/ index.html

TAher, L.; BAShA, R.; El KhatiB, H. Establishing association between qos properties in service oriented architecture. In: Next Generation Web Services Practices, 2005. NWeSP 2005. International Conference on, IEEE, 2005, p. 6-pp.

TAN, W.; ZHOU, M. Business and scientific workflows: A web service-oriented approach, v. 5. John Wiley \& Sons, 2013.

Thomas, J. P.; Thomas, M.; Ghinea, G. Modeling of web services flow. In: E-Commerce, 2003. CEC 2003. IEEE International Conference on, IEEE, 2003, p. 391-398.

Tosic, V.; Pagurek, B.; Esfandiari, B.; Patel, K. Management of compositions of eand m-business web services with multiple classes of service. In: Network Operations and Management Symposium, 2002. NOMS 2002. 2002 IEEE/IFIP, IEEE, 2002, p. 935-937. 
Wang, P.; ChaO, K.-M.; Lo, C.-C.; HuAnG, C.-L.; LI, Y. A fuzzy model for selection of qos-aware web services. In: e-Business Engineering, 2006. ICEBE'O6. IEEE International Conference on, IEEE, 2006, p. 585-593.

Weerawarana, S.; Curbera, F.; Leymann, F.; Storey, T.; Ferguson, D. F. Web services platform architecture: Soap, wsdl, ws-policy, ws-addressing, ws-bpel, ws-reliable messaging and more. Upper Saddle River, NJ, USA: Prentice Hall PTR, 2005.

Wei, D.; Wang, T.; Wang, J.; Bernstein, A. Sawsdl-imatcher: A customizable and effective semantic web service matchmaker. Web Semantics: Science, Services and Agents on the World Wide Web, v. 9, n. 4, p. 402 - 417, \{JWS \} special issue on Semantic Search, 2011.

Disponível em: http://www.sciencedirect.com/science/article/pii/ S1570826811000722

Woodside, M.; Menasce, D. A. Guest editors' introduction: Application-level qos. Internet Computing, IEEE, v. 10, n. 3, p. 13-15, 2006.

YANG, Y.; ZhenG, W.; LiU, S.; LI, X. A hybrid matchmaking algorithm for semantic web service. In: Computer and Information Technology (CIT), 2012 IEEE 12th International Conference on, IEEE, 2012, p. 147-151.

Yu, H. Q.; ReIfF-Marganiec, S. A backwards composition context based service selection approach for service composition. In: Services Computing, 2009. SCC'09. IEEE International Conference on, IEEE, 2009, p. 419-426.

Yu, Q.; Bouguettaya, A. Computing service skyline from uncertain qows. IEEE T. Services Computing, v. 3, n. 1, p. 16-29, 2010.

ZHANG, L.-J. Cloud computing: Architecture, business value, and innovation opportunities. In: IEEE ICWS/SERVICES-I 2009 TUTORIALS, 2009, p. xxxvii-xli.

Zhou, J.; NiEmela, E. Toward semantic qos aware web services: Issues, related studies and experience. In: Web Intelligence, 2006. WI 2006. IEEE/WIC/ACM International Conference on, IEEE, 2006, p. 553-557. 